\title{
Investigating Social Perceptions Associated with Water Quality in Morgantown, West Virginia
}

Jonas G. Leveque

Follow this and additional works at: https://researchrepository.wvu.edu/etd

\section{Recommended Citation}

Leveque, Jonas G., "Investigating Social Perceptions Associated with Water Quality in Morgantown, West Virginia" (2017). Graduate Theses, Dissertations, and Problem Reports. 7327.

https://researchrepository.wvu.edu/etd/7327

This Dissertation is protected by copyright and/or related rights. It has been brought to you by the The Research Repository @ WVU with permission from the rights-holder(s). You are free to use this Dissertation in any way that is permitted by the copyright and related rights legislation that applies to your use. For other uses you must obtain permission from the rights-holder(s) directly, unless additional rights are indicated by a Creative Commons license in the record and/ or on the work itself. This Dissertation has been accepted for inclusion in WVU Graduate Theses, Dissertations, and Problem Reports collection by an authorized administrator of The Research Repository @ WVU.

For more information, please contact researchrepository@mail.wvu.edu. 


\title{
Investigating Social Perceptions Associated with Water Quality in Morgantown, West Virginia.
}

\author{
Jonas G. Levêque \\ Dissertation submitted \\ to the Davis College of Agriculture, Natural Resources and Design \\ at West Virginia University \\ in partial fulfillment of the requirements for the degree of \\ Doctor of Philosophy \\ in \\ Forest Resource Science \\ Committee: \\ Robert C. Burns, Ph.D., Chair \\ Dave Smaldone, Ph.D. \\ Steven W. Selin, Ph.D. \\ Jinyang Deng, Ph.D. \\ Jasmine Moreira, Ph.D.
}

Division of Forestry and Natural Resources

Recreation, Parks and Tourism Resources Program

Morgantown, West Virginia

2017

Keywords: Water Quality, Perceptions, Risks,

SEM, Bottled Water, Filter, Proximity

Copyright 2017 Jonas Levêque 
ProQuest Number: 10606874

All rights reserved

INFORMATION TO ALL USERS

The quality of this reproduction is dependent upon the quality of the copy submitted.

In the unlikely event that the author did not send a complete manuscript and there are missing pages, these will be noted. Also, if material had to be removed, a note will indicate the deletion.

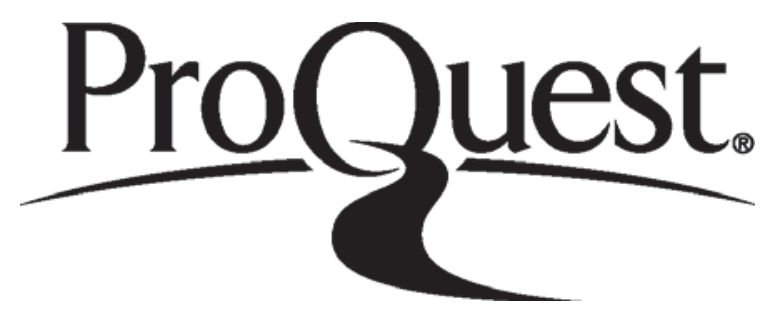

ProQuest 10606874

Published by ProQuest LLC (2017). Copyright of the Dissertation is held by the Author.

All rights reserved.

This work is protected against unauthorized copying under Title 17, United States Code Microform Edition (C) ProQuest LLC.

ProQuest LLC.

789 East Eisenhower Parkway

P.O. Box 1346

Ann Arbor, Ml $48106-1346$ 


\begin{abstract}
This dissertation investigates public perceptions of water quality in Morgantown, West Virginia. In recent years, water has become an increasingly critical issue in terms of quantity worldwide, and also in terms of quality. In developed countries such as the United States, water quality is often taken for granted by the general public. Nonetheless, recent water crises in Flint, Michigan and Charleston, West Virginia, are examples showing there are environmental risks associated with human activities. This dissertation explores the context of West Virginia, with coal mining that is decreasing and non-conventional oil and gas drilling that is increasing in the Appalachia region. The main focus of this dissertation is the understanding of tap water quality perceptions and drinking behaviors. The dissertation is divided in five chapters: introduction of the dissertation, context of West Virginia and risk perceptions, modeling drinking behaviors, model building with Structural Equation Modeling (SEM), and proximity analysis. Utilizing an online survey and a mailing survey, we contacted 5492 residents in Morgantown and surrounding areas in Monongalia County to ask them to take part in a research survey about water quality. With a total effective response rate of $11.3 \%, 603$ persons completed the survey $(88 \%$ residing within Morgantown). The main results of the dissertation are: (1) there exist potential risks of chemical spills in West Virginia, due to the impacts of human activities; (2) most residents are not aware of the quality of their water and do not have strong feelings about their water; (3) bottled water consumption is linked to lower education, lower environmental concern but to higher risks perceptions from drinking from the tap, as well as lower perceptions of organoleptic perceptions from the water (taste, odor, color); (4) using a water filter is mainly linked to higher incomes, low organoleptic perceptions and younger populations; (5) SEM was a useful technique to depict relationships between the different water quality perceptions; (6) SEM found evidence that the
\end{abstract}


construct "Perceived Water Quality" has multicollinearity issues; (7) Proximity to horizontal wells affect water quality perceptions, but the effect size is rather small. The main implications of these results and this dissertation are the lack of communications from industries and governments to the public. There is a gap between what consumers should know and understand about their water quality. Better information from scientists and local decision-makers should be available to the general public in order to make the right choices for water management and environmental protection. Last but not least, this dissertation argues that education is an important issue for West Virginia water quality and the Appalachia Region in general. 


\section{Acknowledgments}

Completion of this dissertation was possible to many persons and resources that are mentioned here.

First, I would like to give my sincere gratitude to Dr. Robert C. Burns, committee Chair, for helping me reaching new levels in research through excellent leadership and mentoring. Robert was instrumental in providing me with all tools necessary to achieve success. Thank you for trusting in me and pushing me to do more and better. I would also like to recognize my other committee members Dr. Smaldone, Dr. Deng, Dr. Selin and Dr. Moreira for their support and advice throughout my dissertation work and also during classes, conferences and other activities. All of them made my stay possible at West Virginia University. I would particularly thank "Dr. Dave" for relaxation tips and chocolate Thursdays.

I would like to express my appreciativeness to the U.S. National Science FoundationExperimental Program to Stimulate Competitive Research (through WV-HEPC-Division of Science and Research) under the Award Number 145852 and the National Institute of Food and Agriculture (NIFA) for the funding of this study. I would also like to thank the numerous persons that I met through the Appalachian Freshwater Initiative, for their input and motivation to learn more and share more information and knowledge.

Lastly, I cannot thank enough my family in France for supporting me being overseas throughout this journey and to believe in me through the ups and downs. Merci beaucoup d'avoir cru en moi. I would also like to thank my fiancée, Elisabeth, for being at my side along this path and to have helped me with my English. Thank you for the Kee family for being here for Elisabeth and I. I would also like to thank my best friend Merlijn Hoftijzer, as well as other friends and the Percival Hall friends and faculty who supported me. 


\section{Table of Contents}

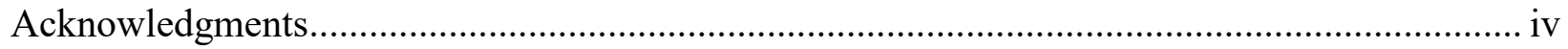

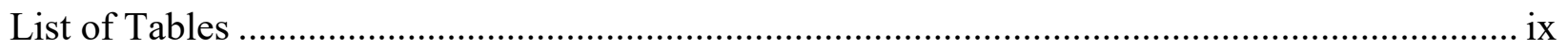

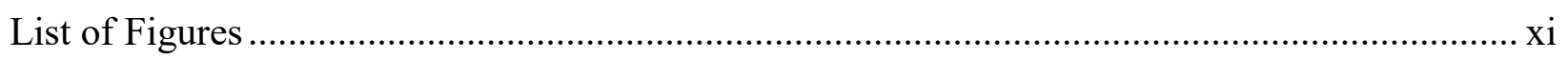

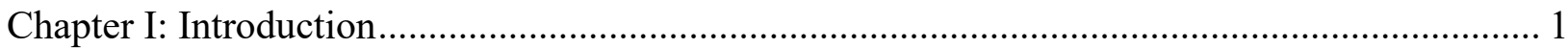

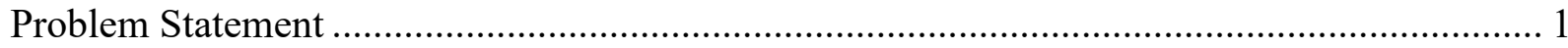

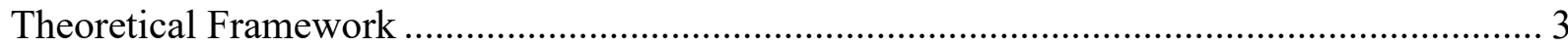

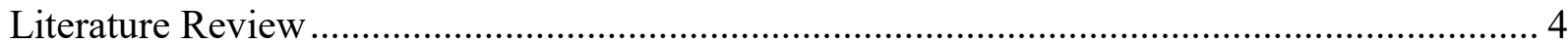

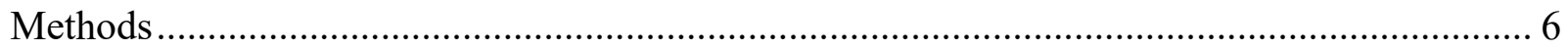

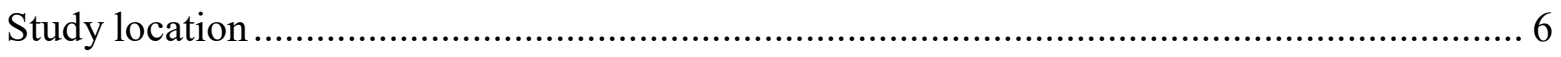

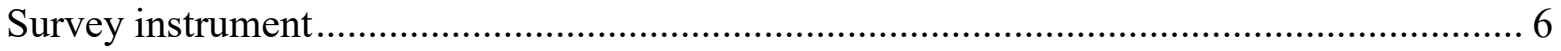

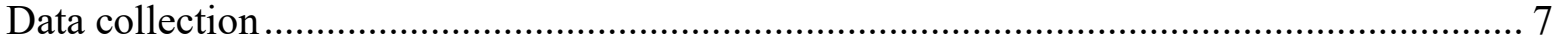

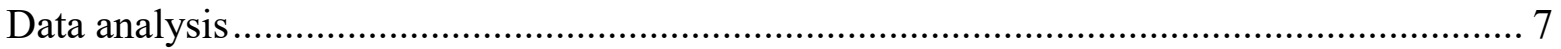

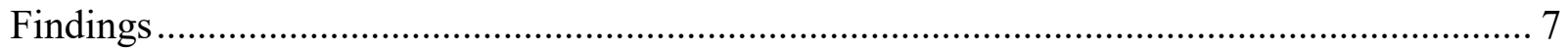

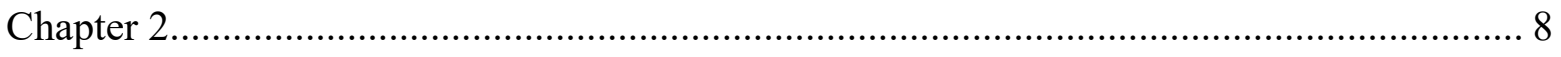

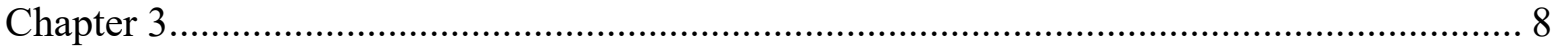

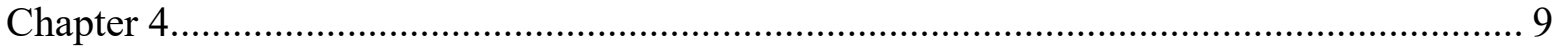

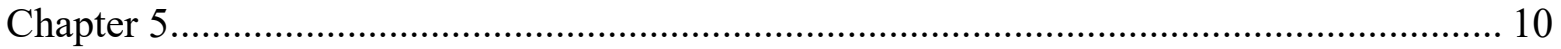

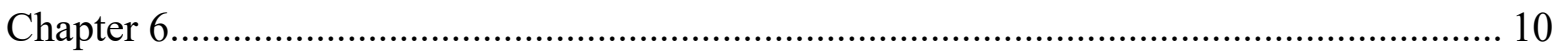

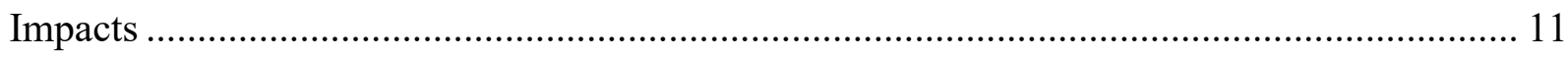

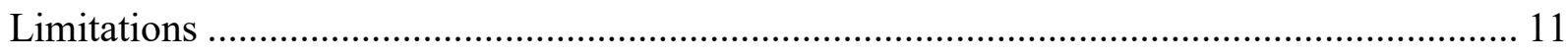

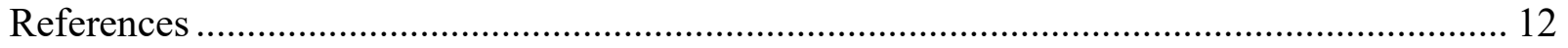

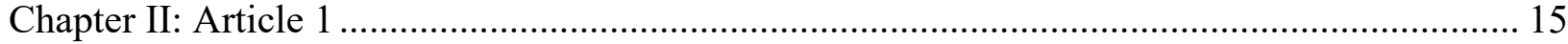

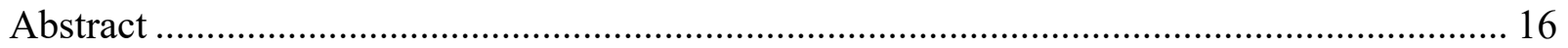

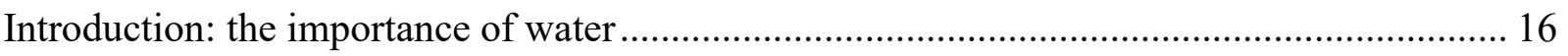

Industrial Development in West Virginia........................................................... 18

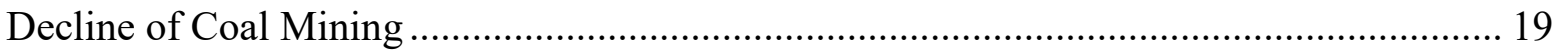

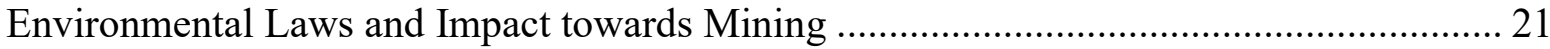

Coal and Gas Mining and Potential Water Pollution Risks............................................. 24

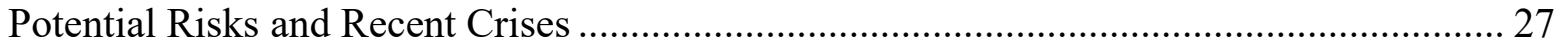

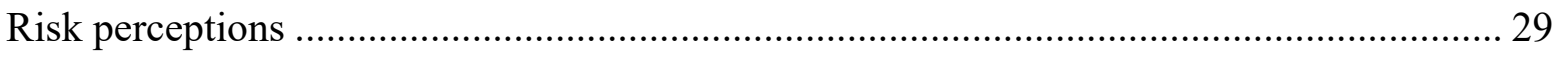

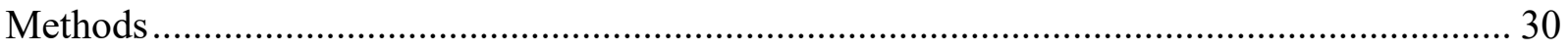

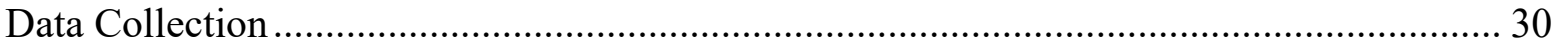




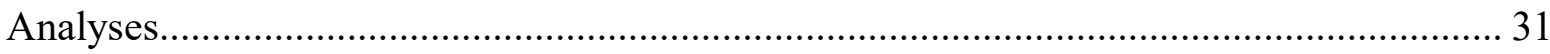

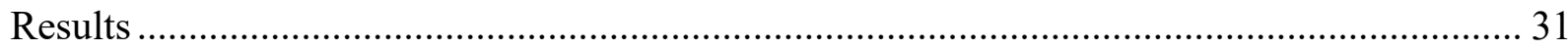

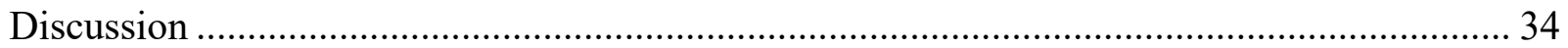

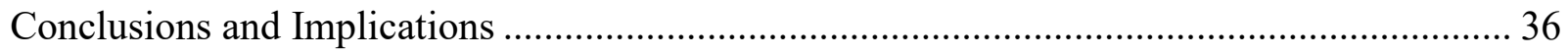

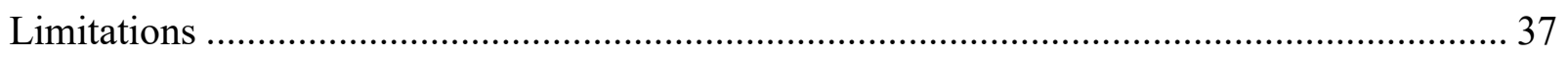

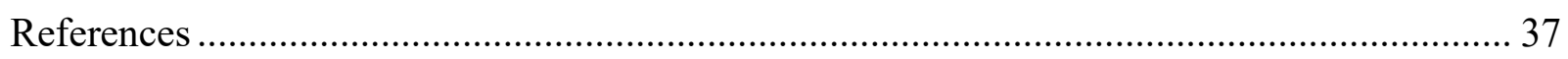

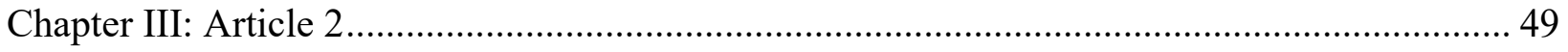

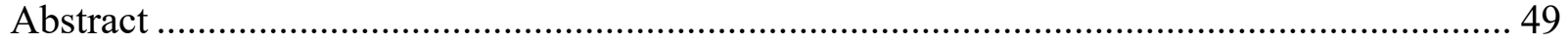

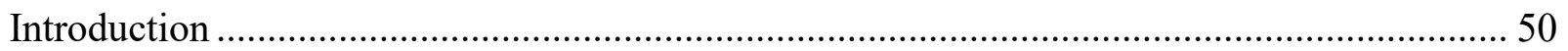

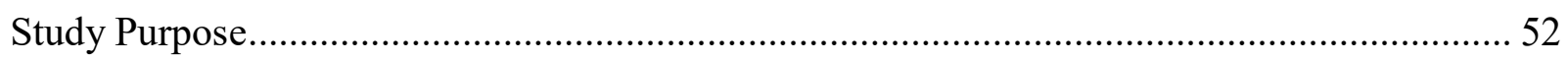

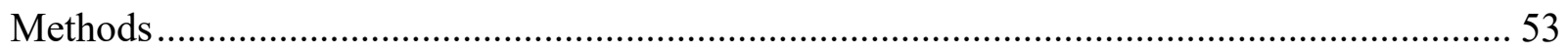

Study Area

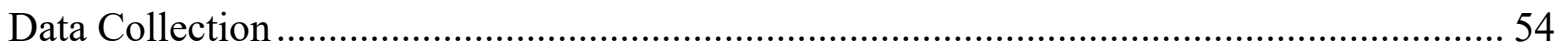

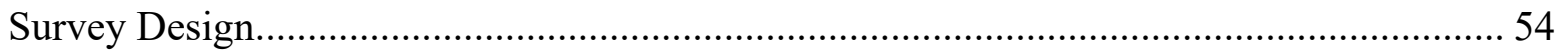

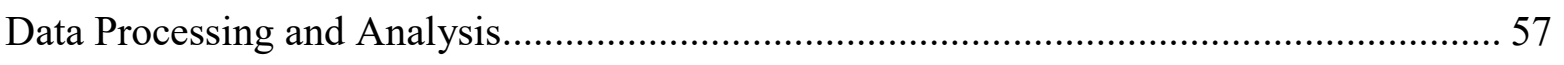

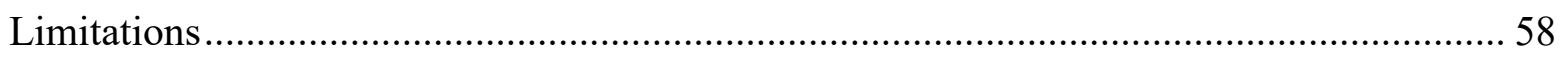

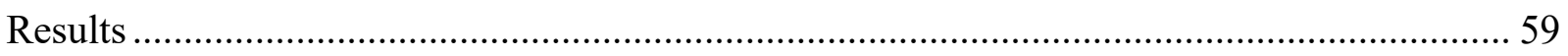

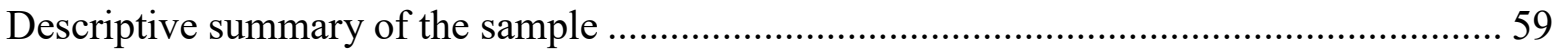

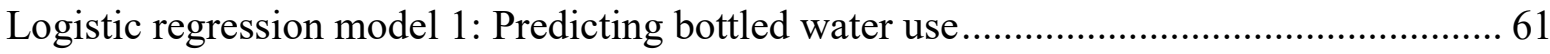

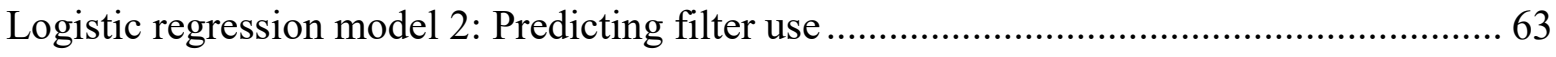

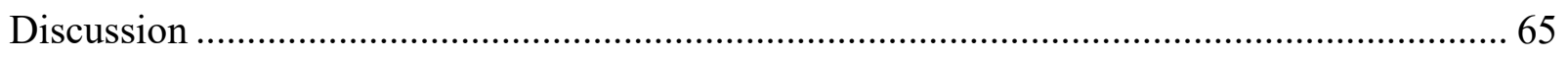

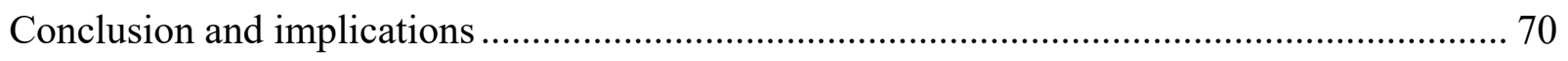

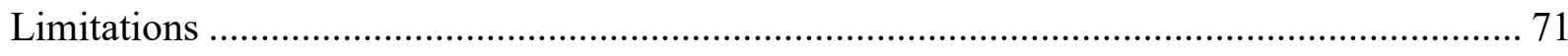

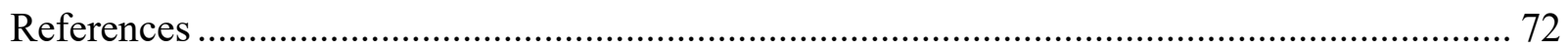

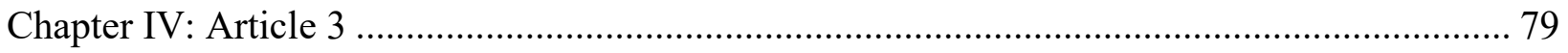

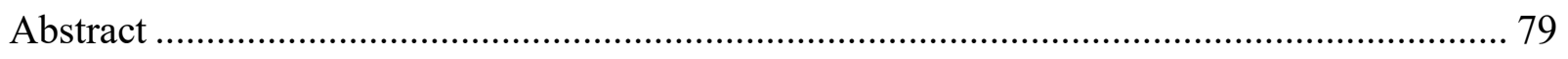

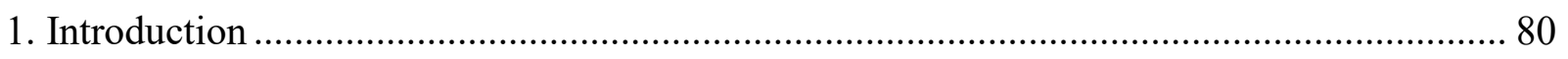

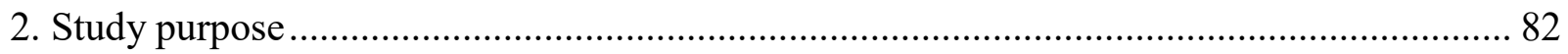

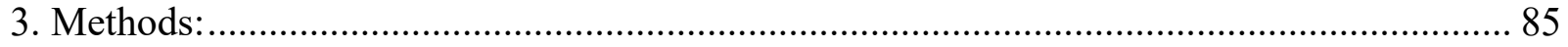

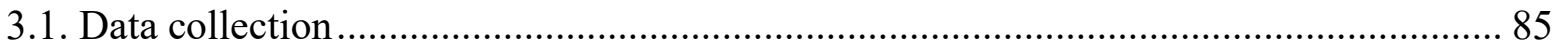

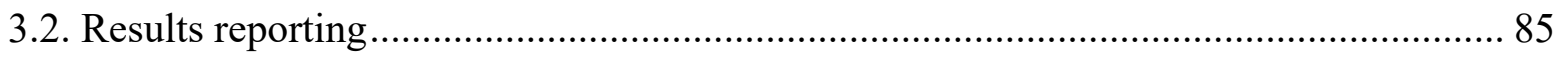

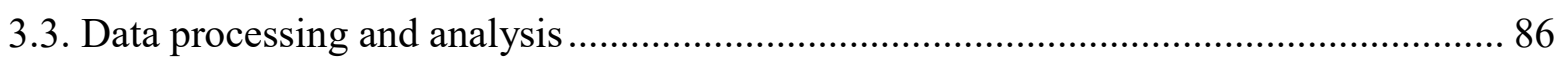




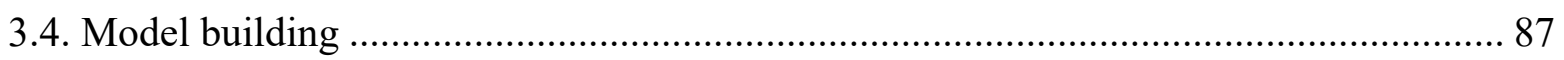

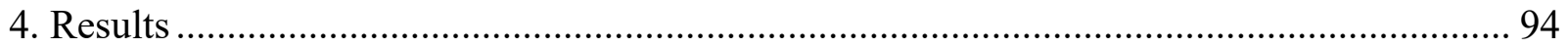

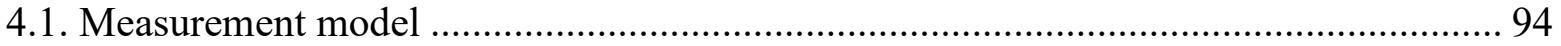

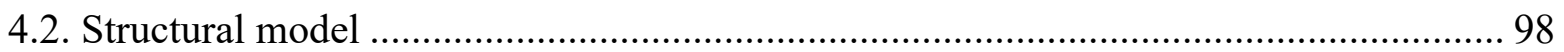

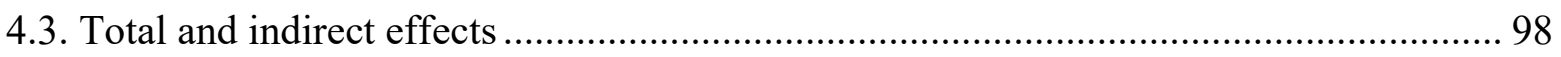

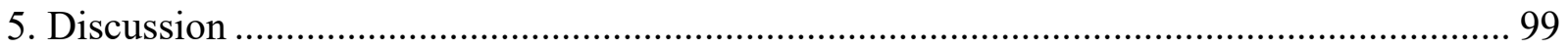

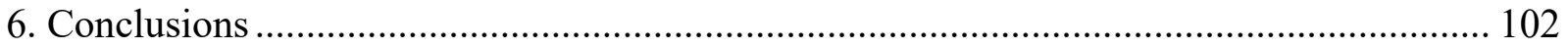

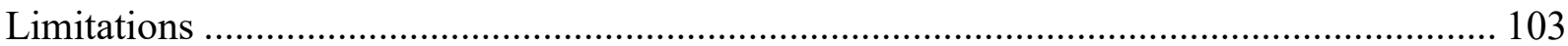

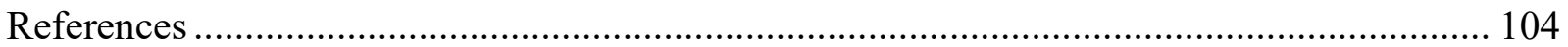

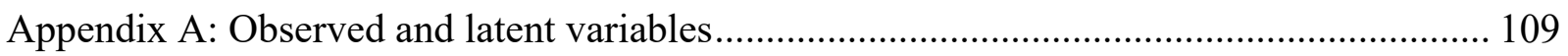

Appendix B: Correlations, means and standard deviations of observed variables $(n=603) .112$

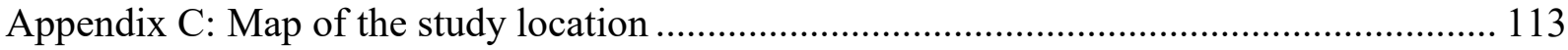

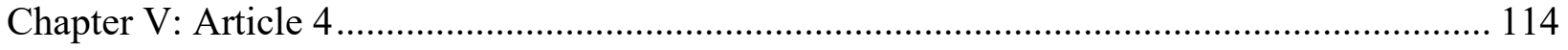

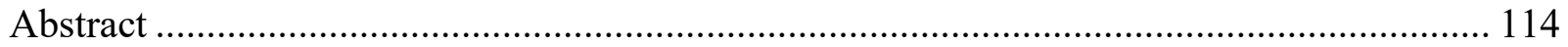

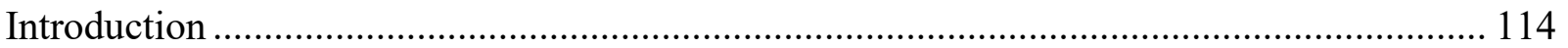

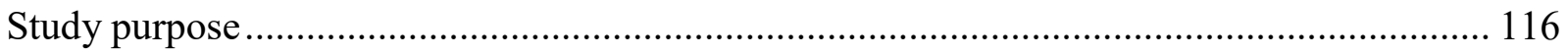

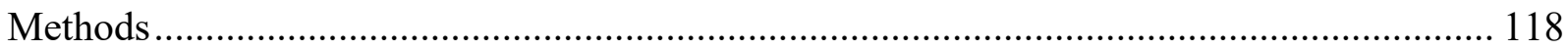

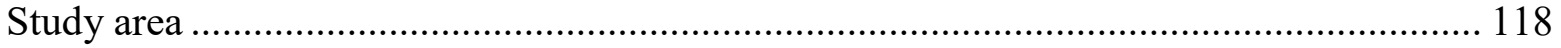

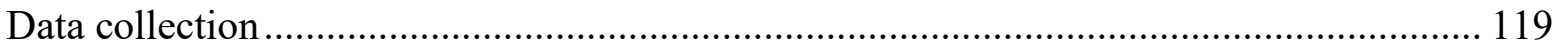

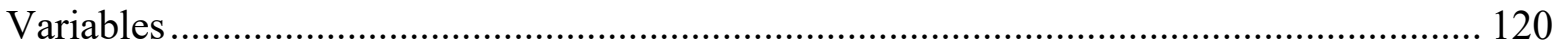

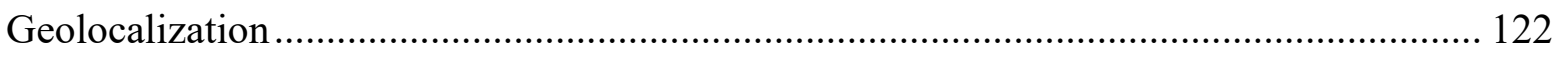

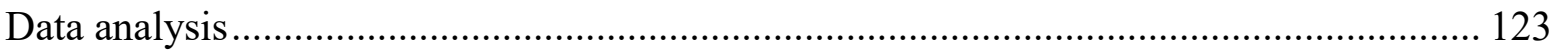

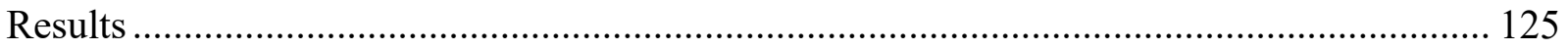

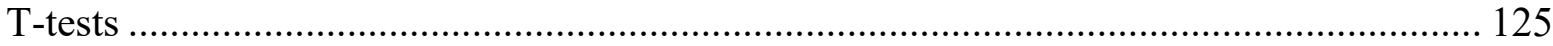

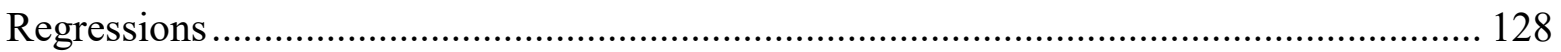

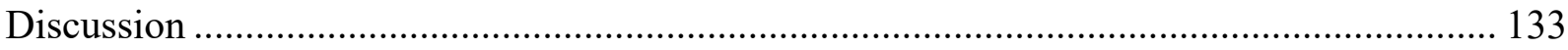

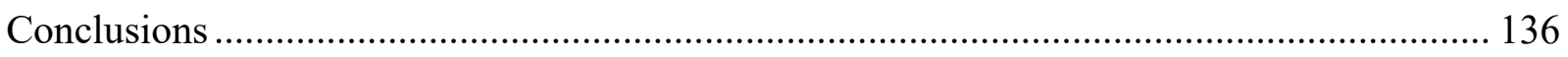

Limitations and future studies .................................................................................... 136

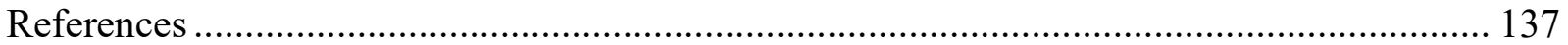

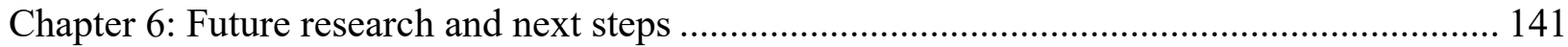

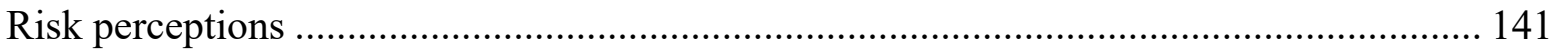

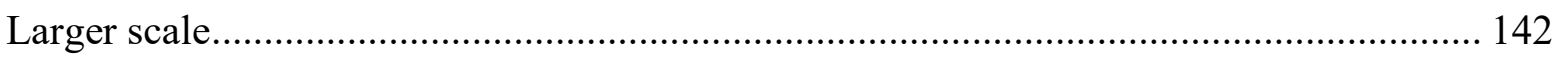




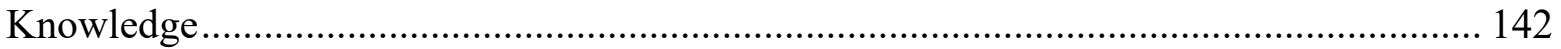

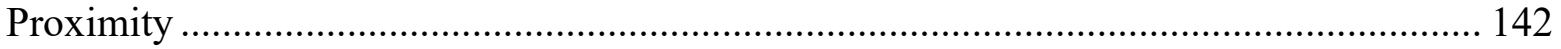




\section{List of Tables}

Chapter II: Article 1

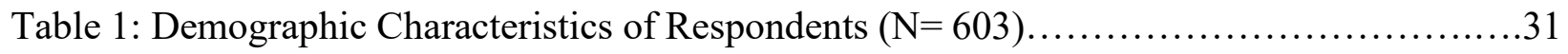

Table 2: Items and Responses for Constructs......................................... 32

Table 3: Perceived Health Risks Regression Table..............................................34

Chapter III: Article 2

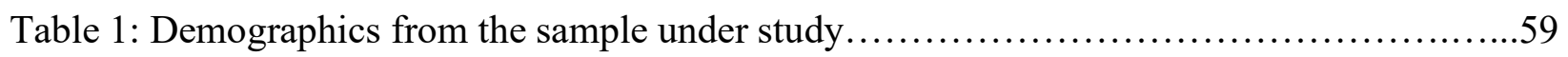

Table 2: Summary of Logistic Regression Analysis Predicting Drinking Bottled Water $(\mathrm{N}=$

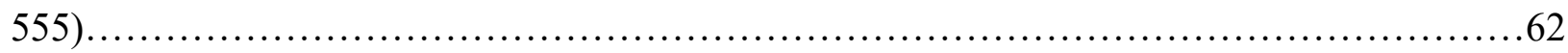

Table 3: Summary of Logistic Regression Analysis Predicting Using a Filter $(\mathrm{N}=546) \ldots \ldots \ldots . .64$ Chapter IV: Article 3

Table 1: Corrected measurement errors and error variances for single-item indicators (model with $\mathrm{n}=603)$ .89

Table 2: Construct Reliability (CR), Average Variance Extracted (AVE) and squared correlations

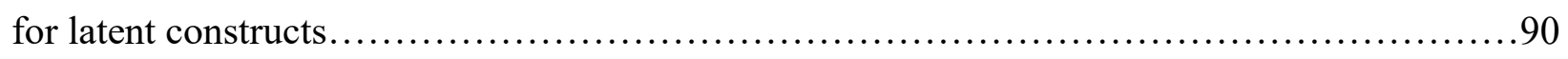

Table 3: Construct Reliability (CR), Average Variance Extracted (AVE) and squared correlations

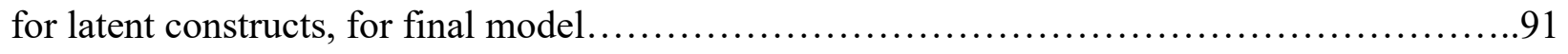

Table 4: Model with and without restrictions on two-factor loadings.......................99

Table 5: CFA parameter estimates, and latent standardized correlations.......................95

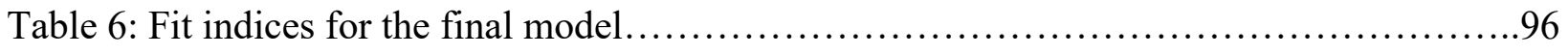

Table 7: Standardized total effects and (total) indirect effects of KSI and ETA on ETA..........99

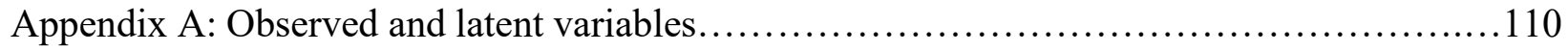

Appendix B: Correlations, means and standard deviations of observed variables $(\mathrm{n}=603) \ldots \ldots 111$ 
Chapter V: Article 4

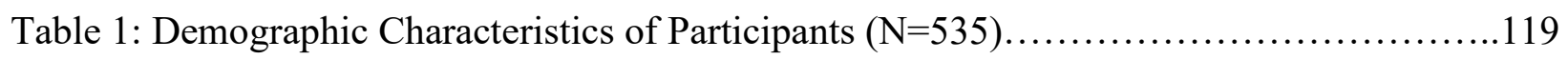

Table 2: Descriptive statistics of the nearest distances per category of feature................123

Table 3: Water Quality Perceptions based on proximity to Active Horizontal Wells...........124

Table 4: Differences for organoleptic perceptions at 3000 meters and 2 miles................126

Table 5: Differences in organoleptic perceptions for $750 \mathrm{~m}$, the median and $1000 \mathrm{~m} \ldots \ldots \ldots \ldots . . .127$

Table 6: Regression analysis summary for proximity variables predicting organoleptic perceptions,

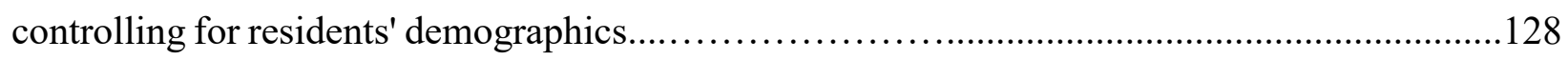
Table 7: Regression analysis summary for proximity variables predicting perceived surface water quality, controlling for residents' demographics...................................129 Table 8: Regression analysis summary for proximity variables predicting perceived health risks, controlling for residents' demographics......................................... 130 Table 9: Regression analysis summary for proximity variables predicting environmental concern, controlling for residents' demographics. 
Chapter I: Introduction

\section{List of Figures}

Figure 1: Detailed Relationships between water quality perceptions. In Doria et al. (2009).........5

Chapter IV: Article 3

Figure 1: Full Structural Model. Latent constructs are shown in ellipses. Observed variables are shown in rectangles. $d$ represents the disturbances from the endogenous latent constructs

Figure 2: Path model and loadings. ${ }^{*} \mathrm{p}<.05,{ }^{* *} \mathrm{p}<.01,{ }^{* * *} \mathrm{p}<.001$. Grey small arrows represent

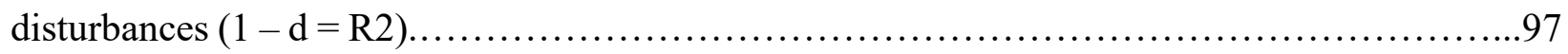

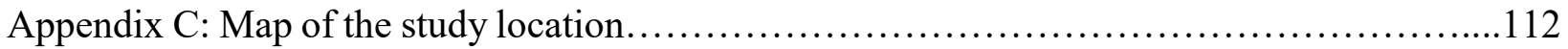

Chapter V: Article 4

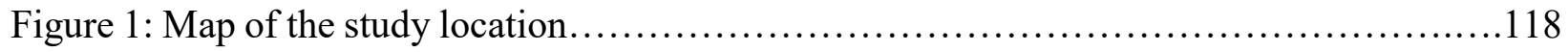

Figure 2: Locations of the different features and residents' locations.........................122 


\section{Chapter I: Introduction}

The dissertation is divided in five chapters. The first part of this chapter highlights the significance of water quality in the U.S. through the problem statement and the theoretical framework. The second part of the chapter describes the methodology as well as a succinct summary of each chapter.

\section{Problem Statement}

Throughout the world, water crises are emerging as human demands for water increase (World Bank, 2016). According to the International Energy Association (2012) and the U.S. Geological Survey (2016), worldwide freshwater resources represent less than 3\% of the world water resources, with up to $70 \%$ being not readily accessible. From the resources that are available, $70 \%$ are used for agriculture. With climate change and human population increases, these resources are more at risk and careful management should be practiced (World Health Organization, 2015).

In West Virginia, coal mining has been decreasing over the past few decades, while unconventional oil and gas drilling has been gradually increasing. Evidence from the literature shows that freshwater resources are at risk from all of these activities. While aging coal mines and infrastructures can result in Acid Mine Drainage, increasing the risk of pollution, unconventional oil and gas drilling uses massive amounts of water resources, increasing the risk of pollution, aboveground and underground (the literature being split on the realistic possibility of underground contamination) (Engelder et al. 2014; Harkness et al., 2017; Osborn et al. 2011). Although water is needed for many uses, including personal consumption and recreational purposes, there have only been a few studies that aimed at understanding the public perceptions 
of water quality in the Appalachia region. A chemical spill on the Elk River, in January 2014, near West Virginia's state capitol (Charleston) created worldwide negative publicity about West Virginia, highlighting the fact that even Western countries are still facing large-scale water pollution concerns (Whelton et al., 2015). This water crisis, as well as the Flint (MI) contamination, occurring just two years after Charleston's (WV) crisis, demonstrated a lack of trust and transparence into certain water systems in the U.S. (Roy, 2017). Bottled water consumption is rising in the U.S. and worldwide, resulting in concern over inefficiency and pollution (International Bottled Water Association, 2013; Van Der Linden, 2015). The International Bottle Water Association (2013) states that it takes 1.39 gallons of water to produce one gallon of bottled water. This estimation does not take into account the environmental costs associated with transportation, storage and recycling (Saylor et al., 2011, Van Der Linden, 2015). Studies have also shown that there is a misinformation about bottled water: it is generally less controlled than tap water and deemed less safe than tap water (Zivin et al., 2011). As a result, water pollution events have increased concerns over water quality and increased doubts about the actual safety of tap water quality (Guadayol et al., 2016). Thus, the main goal of this dissertation was to understand how water quality is perceived by Morgantown residents, as well as obtaining information about their behaviors in terms of water consumption, and linking these with environmental factors. Risk perceptions were especially of interest within this dissertational work. The implications of the results are used to determine whether there are needs for water quality communication in West Virginia. More specifically, results of this dissertation are important because they lay the understanding of communication needs in West Virginia relating to risk management in the context of water quality and natural resources in general. Results of this study particularly enhance the 
comprehension of strategies that scientists and local decision-makers should use to communicate with the larger general public. Our results can also be used to decrease the amount of bottled water consumed and improve the environment, by educating specific groups of people (e.g. $8^{\text {th }}$ grade students...).

\section{Theoretical Framework}

Overall, this dissertation is based on risk perceptions to understand water quality perceptions and water drinking behaviors in Morgantown. The literature explicitly states that there are a multitude of theories related to risk perceptions that conflict with each other (Ferrer and Klein, 2015; Sjöberg, 2000). More specifically, we aimed at investigating the role of diverse factors that affect health risk perceptions associated with drinking from the tap. According to Ferrer and Klein (2015, p.86), "risk perceptions are threat-specific, rather than reflecting a general sense of optimism or pessimism". According to Sjöberg (2000), theories and model related to risk perceptions are incomplete. More specifically, this author affirms that the psychometric paradigm and the cultural theory are not explaining enough variance in the perceptions of risks (Sjöberg, 2000). The former theory uses cognitive stimuli to predict risks, suggesting that all risks are depending on someone's sensitivity to risks (Sjöberg, 2000). The latter is the theory used by Syme and Williams in their Australian sample (1993). According to Sjöberg (2000), the cultural theory is not valid because it focuses on values and lifestyles, which were weakly correlated to risk perceptions in several studies. Sjöberg (2000) proposes another approach, with the use of attitudes to predict risks, and especially highlights that Structural Equation Modeling models confirm the directionality of attitudes and values in forming risk beliefs. As such, when constructing items, the correct messages should be conveyed to reflect attitudes and beliefs. Dosman et al. (2001) add demographic variables and explain how these are good predictors of 
risk perceptions. Therefore, we followed Sjöberg's recommendations and used literature that refers to such a method (e.g. Doria et al., 2009). Using the works of Dosman et al. (2001) and Ferrer and Klein (2015), we tried to understand how risk perceptions affect behaviors. As such, we did not try to test objective knowledge of the respondents but their feelings to a particular threat (Ferrer and Klein, 2015).

\section{Literature Review}

As four articles were written within this dissertation, the literature is only succinctly presented here and more studies are presented under each article. Chapter 2 introduces the context of how the extractive industries in West Virginia affect water quality. Since water quality is a rather broad topic, several disciplines have studied water quality perceptions with a large focus on health-related studies (for a review, see Doria, 2010). An important perspective of the literature is the perception of risks, and how risk can affect behaviors. The works of Doria et al. (2005, 2009) and Syme and Williams (1993) are especially of importance in regards to the understanding of the relationships between factors that affect perceptions (see figure 1). The measure of perceived water quality was used to depict the satisfaction with tap water (Doria et al., 2009). The use of Structural Equation Modeling was especially of interest as a statistical technique that enables us to look at relationships simultaneously instead of different independent 
multiple regressions (Kline, 2015). This is described more extensively within Chapter 4.

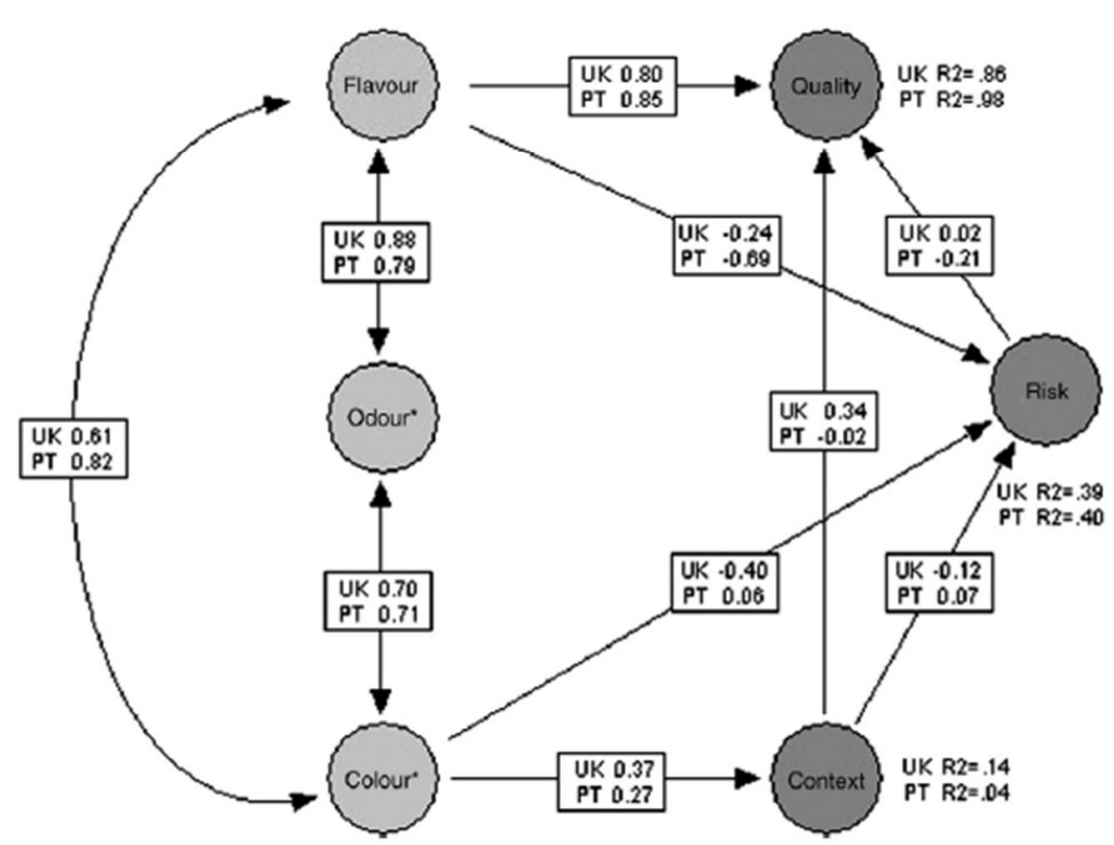

Fig 1. SEM standardised solutions and $R^{2}$ of latent variables of model $(\mathrm{A})$. Disturbances UK: quality $=.378 ;$ risk $=.780 ;$ context $=.929$. Disturbances PT: quality $=.074 ;$ risk $=.771$ context $=.980$.

Figure 1: Detailed relationships between water quality perceptions. In Doria et al. (2009).

Risk perceptions are especially important when examining studies that seek to characterize the factors that influence bottled water consumption (Hu et al., 2011). Many studies have focused on this behavior to understand why people chose to drink bottled water, regardless of increased plastic pollution and global water crises. Because only a few studies have examined water filter use, we extended this behavior in this dissertation to the use of filtered water. Chapter 3 describes how perceptions explain bottled water use and filter use. A measure of perceived surface water quality (rivers, streams and lakes) was also used to understand how these variables were related to behavior (Hu et al., 2011). Some other water literature looked at social capital and how world views could affect perceptions (Syme and Williams, 1993). Even though we did not look at these items, we used the link with environmental concern in order to depict some of the relationships with water quality perceptions. Specifically, we used the work of Dutcher et al. 
(2007) to understand people's environmental concern and how this influenced water quality perceptions. To quantify this, Chapter 5 focuses on the role of proximity in affecting water quality perceptions and environmental concern. Specifically, we looked at wells, mines and rivers.

In order to investigate these perceptions, the following section describes the methods that we used.

\section{Methods}

\section{Study location}

The targeted study area was Morgantown and the surrounding areas within Monongalia County, in northcentral West Virginia. Located in the heart of the Appalachia region, the study location was selected for its geography (proximity to a river, coal and gas extraction) as well as its population (approximately 77,500 habitants older than 18 years old), as Morgantown is one of the largest cities in West Virginia (City of Morgantown, 2017; U.S. Census Bureau, 2016).

\section{Survey instrument}

The survey instrument was designed by using the findings of theoretical literature focusing on water quality perceptions (Doria et al., 2005; 2009; Hu et al., 2011; Syme and Williams, 1993). The survey included 27 questions, and took approximately 10 to 15 minutes to complete. For constructs and items, we chose to follow the literature with 5-pt Likert scales throughout the survey. For consistency purposes, we used 1: "strongly disagree," 5: "strongly agree" everywhere in the survey. For the water quality perceptions of the rivers, lakes and streams, we used 1: "very poor"; 2: "poor"; 3: "fair"; 4: "good"; 5: "excellent". The specific items and scales are described in the different chapters. 


\section{Data collection}

The data were collected following two methods. The first consisted of emailing a link to the survey to randomly selected residents from Monongalia County. Using a third-party contractor, 5492 residents were randomly selected. For design purposes, we needed at least 386 persons to answer the survey. A first invitation was emailed to the selected residents, followed by four reminders, as suggested by Dillman et al. (2014).

The second method was mailing a printed questionnaire to 186 randomly residents that were selected from another database in Monongalia County. A first postcard was sent to them, followed by paper versions of the questionnaire (Dillman et al., 2014). The data were collected from the beginning of November 2015 to the end of January 2016.

\section{Data analysis}

Data were analyzed using IBM Statistical Package for Social Sciences (SPSS) v. 24, ArcMap and LISREL. With these different software, we used general frequencies, t-tests, chi-squares, multiple linear regressions, logistic regressions as well as Structural Equation Modeling. ArcMap was used to measure distances in terms of mapping. Specific procedures and hypotheses are discussed in each chapter.

\section{Findings}

With a combined response rate of $11.3 \%, 603$ residents completed the survey. Even if this may represent a low response rate it is rather typical of web surveys (Sax et al., 2003). A nonresponse bias was run using Israel (2011), comparing early respondents with late respondents. There were no significant differences for individual items or within demographics. Regarding the representativeness of the sample, the U.S. Census Bureau (2016) demographics data comparison 
indicated that more women (56\%) answered the survey than Morgantown's population (48\%), and that respondents earned a higher income than the general population. These results are typical of survey research, and indicate trustworthiness in the external validity of our results (Dillman et al., 2014). In this sense, we can affirm that our sample represents Morgantown's population. We also checked for biases in regards to the two different data collection methods, and found relatively small differences (a higher income, more educated and older population for the mail-back survey generally higher perceptions of the water quality), which disappeared at the construct level.

This rest of this section summarizes the findings per chapter.

\section{Chapter 2}

Focusing on the general context of water crises in the U.S., as well as the history of coal, timber, and other extraction efforts in West Virginia, this chapter investigates the potential environmental impacts on water from coal mining and oil and gas drilling in West Virginia and the Appalachia through the literature. The purpose of the chapter was to introduce the water crisis in West Virginia and the possible risks that can occur. A last part of this chapter compares the water crisis to risks perceptions. Findings show that most respondents are uncertain of their tap water quality or do not hold strong opinions about their tap water quality. Our findings show that risks perceptions are associated with organoleptic perceptions (taste, odor and color) as well as the perceptions of the chemical spill likelihood in Monongalia County. Implications of these results are the need for more information about risks and water management.

\section{Chapter 3}


This chapter describes the factors that explain drinking behaviors regarding bottled water and filtered tap water. About one-third of the respondents drink primarily from bottled water. The factors that explained this behavior are risk perceptions, education, organoleptic perceptions and environmental concern. Specifically, the odds of drinking bottled water significantly decrease as education, organoleptic perceptions, and environmental concern scores increase. In contrast, as the score of perceived health risks increases the odds of drinking bottled water significantly increase. Regarding filter use, about half of respondents used a filter when drinking water from the tap. The factors that predict this behavior were age, organoleptic perceptions and income. The odds of using a filter significantly decrease as age and organoleptic perceptions scores increase. In addition, as the score of income increases, the odds of using a filter significantly increase. These results show that education is necessary to decrease bottled water use, and that more communication about the risks of using tap water is needed. Filter use is very dissimilar from bottle use, as income, age and organoleptic perceptions affect its use. In this case, it would be important to marketers and filter producers to promote filters to a specific audience. Perceived water quality was dismissed from the analyses as it was suspected to be multicollinear with risk perceptions and organoleptic perceptions.

\section{Chapter 4}

This chapter examines the relationships between the variables, using a rather recent statistical technique: Structural Equation Modeling (SEM). The aim of this chapter was to design and test a model to fit the data. Details of the extensive procedures are presented in the chapter. Our model provided good fit indices. Specifically, $50 \%$ of the variance in health risk perceptions and $43 \%$ of the variance in organoleptic perceptions are explained by the model. Constructs such as environmental concern, area satisfaction and perceived surface water quality are important 
factors in explaining these variances. Perceived water quality was found to have multicollinearity issues (as suspected in Chapter 3). We were able to demonstrate this effect by using SEM. Implications of these results are that perceived water quality should not be used as a stand-alone construct. This contradicts previous research on water quality (i.e., Doria et al. 2005, 2009). These results also reinforced the need for more and better information towards tap water quality in West Virginia.

\section{Chapter 5}

This chapter was different from the previous ones as it introduced proximity. As such, ArcMap was used to process the data and create the variables of interest. Of interest to us was to create proximity to: active horizontal oil and gas wells, active conventional wells, abandoned wells, active mines, abandoned mines and rivers. We aimed at understanding whether proximity would affect water quality perceptions. Our results showed that there are differences for horizontal wells within a limit of six kilometers from a home. Specifically, residents who live closer to horizontal wells were likely to perceive that water quality was worse than residents who live further away. The other proximity variables also show some differences, but these are smaller in effect size as explained in the chapter. Horizontal wells show the most interesting results when used to predict water quality perceptions, as proximity indicated more perceived risks and lower perceptions of the water quality in general. Nevertheless, all of the results have small effect sizes, indicating that there is an effect of proximity on water quality perceptions, but that this effect is rather small. Implications from these results include the need for more information and communication about horizontal drilling as well as more research for risk perceptions.

\section{Chapter 6}


This chapter addresses the future steps and research that need to be pursued in order to understand risk perceptions related to water quality in West Virginia. For instance, next steps include, but are not limited to, (1) repetition of this study at a larger scale, and different counties with a more rural population in West Virginia, (2) inclusion of other factors into the model (e.g. trust, previous experiences), (3) focus-group studies to explore qualitative aspects of water quality in West Virginia.

\section{Impacts}

The results of this dissertation show that there needs to be more communications about risk perceptions and water quality in Morgantown, WV. In place like West Virginia, residents need to be aware of the potential risks affecting them and need to understand what they mean. This will help the residents form an opinion in regards to their water quality which will in turn affect their decision-making when elected representatives who will make decisions about risk management and water quality monitoring. The Elk River spill in Charleston (WV) is an example where mismanagement and lack of regulations led to a disaster. Our data supports the fact that most people do not have an opinion about their water quality. Additionally, when looking at the results of predicting bottled water use, there needs to be an awareness strategy to decrease the use of bottled water. As such, there needs to be information on water quality monitoring differences available to the residents.

\section{Limitations}

This study was part of a larger study of water quality in the Appalachia region and as such several limitations occurred. First, the database of email addresses was purchased through a 
third-party contractor. In that regard, we had no control over the random selection of the sample. Originally targeting Monongalia County, most addresses received were contained within Morgantown ( $88 \%$ of respondents lived in Morgantown).

Second, other factors could have been used in the survey instrument to understand risk perceptions: factors such as trust in specific actors such as the local government, state agencies like the U.S. EPA as well as the role of media and media exposure to a particular incidence: for example, the Elk River spill. Because of space and time constraints, several items were not included in the final version of the survey. Other limitations are discussed under each research chapter.

\section{References}

City of Morgantown (2017). The City of Morgantown, WV. Retrieved June 1, 2017 (http://www.morgantownwv.gov).

Dillman D. A., Smyth J. D. \& Christian L. M. (2014). Internet, phone, mail, and mixed-mode surveys: The tailored design method. John Wiley \& Sons.

Doria M. F. (2010). Factors influencing public perception of drinking water quality. Water Policy, 12(1), 1-19.

Doria M. F., Pidgeon N. \& Hunter P. R. (2009). Perceptions of drinking water quality and risk and its effect on behaviour: A Cross-National Study. Science of the Total Environment, 407(21), $5455-5464$.

Doria, M. F., Pidgeon, N., Hunter, P. R. (2005). Perception of tap water risks and quality: a structural equation model approach. Water Science and Technology, 52(8), 143-149. 
Dosman, D. M., Adamowicz, W. L., \& Hrudey, S. E. (2001). Socioeconomic determinants of health-and food safety-related risk perceptions. Risk analysis, 21(2), 307-318.

Dutcher D. D., Finley J. C., Luloff A. E. \& Johnson, J. B. (2007). Connectivity with nature as a measure of environmental values. Environment and behavior, 39(4), 474-493.

Engelder, T., Cathles, L. M., \& Bryndzia, L. T. (2014). The fate of residual treatment water in gas shale. Journal of Unconventional Oil and Gas Resources, 7, 33-48.

Ferrer, R. A., \& Klein, W. M. (2015). Risk perceptions and health behavior. Current opinion in psychology, 5, 85-89.

Guadayol M., Cortina M., Guadayol J. M. \& Caixach J. (2016). Determination of dimethyl selenide and dimethyl sulphide compounds causing off-flavours in bottled mineral waters. Water Research, 92, 149-155.

Harkness, J. S., Darrah, T. H., Warner, N. R., Whyte, C. J., Moore, M. T., Millot, R., Kloppmannd, W., Jacksone, R. B., \& Vengosh, A. (2017). The Geochemistry of Naturally Occurring Methane and Saline Groundwater in an Area of Unconventional Shale Gas Development. Geochimica et Cosmochimica Acta, 208, 302-334.

Hu Z., Morton L. W. \& Mahler R. L. (2011). Bottled water: United States consumers and their perceptions of water quality. International Journal of Environmental Research and Public Health, 8(2), 565-578.

International Bottle Water Association (2013). Water use benchmarking study. Antea Group, IBWA. Retrieved from http://www.bottledwater.org/files/IBWA\%20Water\%20Use\%20Benchmarking\%20Report\%20- 
\%20Exec\%20Summary\%20FINAL\%20102113.pdf\#overlay-context=reports-studies. (Accessed 20 April 2016).

International Energy Association. (2012). "Water for Energy: Is Energy Becoming a Thirstier Resource?" Paris, France: OECD/IEA.

Kline, R. B. (2015). Principles and Practice of Structural Equation Modeling, fourth ed. Guilford Publications.

Osborn, S. G., Vengosh, A., Warner, N. R., \& Jackson, R. B. (2011). Methane contamination of drinking water accompanying gas-well drilling and hydraulic fracturing. Proceedings of the National Academy of Sciences, 108(20), 8172-8176.

Roy, S. (2017). The Hand-in-Hand Spread of Mistrust and Misinformation in Flint. American Scientist, 105(1), 22.

Saylor A., Prokopy L. S. \& Amberg S. (2011). What's wrong with the tap? Examining perceptions of tap water and bottled water at Purdue University. Environmental Management, 48(3), 588-601.

Sjöberg, L. (2000). Factors in risk perception. Risk analysis, 20(1), 1-12.

Syme G. J. \& Williams K. D. (1993). The psychology of drinking water quality: An exploratory study. Water Resources Research, 29(12), 4003-4010.

U.S. Census Bureau (2016) 2010-2014 American community survey 5-Year Estimates. Retrieved from http://factfinder.census.gov/faces/nav/jsf/pages/community_facts.xhtml\#. (Accessed 22 May 2016). 
U.S. Geological Survey. (2016). “The World's Water.” Retrieved April 3, 2016

(http://water.usgs.gov/edu/earthwherewater.html).

Van Der Linden S. (2015). Exploring beliefs about bottled water and intentions to reduce consumption the dual-effect of social norm activation and persuasive information. Environment and Behavior, 47(5), 526-550.

Whelton, A. J., McMillan, L., Connell, M., Kelley, K. M., Gill, J. P., White, K. D., Gupta, R.,

Dey, R. \& Novy, C. (2015). Residential tap water contamination following the Freedom Industries chemical spill: Perceptions, water quality, and health impacts. Environmental Science \& Technology, 49(2), 813-823.

World Bank. (2016). The critical face of climate change - Water. Washington D.C.:

International Bank for Reconstruction and Development/the World Bank.

World Health Organization. (2015). “Drinking-water, Fact sheet N³91.” Retrieved February 10, 2016 (http://www.who.int/mediacentre/factsheets/fs391/en/).

Zivin J. G. \& Neidell M. (2013). Environment, health, and human capital. Journal of Economic Literature, 51(3), 689-730.

\section{Chapter II: Article 1}

Understanding Water Quality in West Virginia, USA: A Unique Challenge

Jonas G. Levêque

Robert C. Burns

(Article submitted to the Journal of Rural Social Sciences, under review since June 2016) 


\begin{abstract}
This study reports on an investigation focusing on water quality in the Appalachian Region, and specifically West Virginia. Because of competition, market considerations, along with recent, stronger environmental regulations, coal mining has been decreasing in West Virginia. In a context of transition from coal towards gas exploration, a public survey was conducted in Morgantown (WV) in order to understand residents' perceptions of their tap water quality. Results show that residents indicate having little information about their tap water quality and, as such are less likely to drink water from the tap when they believe there are health risks associated with tap water consumption. This paper suggests the right type and delivery method of education is needed to better address the perceptions of risks associated with drinking water and also the perceptions of risks associated with extraction of natural resources such as natural gas or coal.
\end{abstract}

Keywords: Water Quality, Extractive Resources, Environmental Risks, Resident Perceptions.

Footnote 1: Acknowledgments to US National Science Foundation-Experimental Program to Stimulate Competitive Research (through WV-HEPC-Division of Science and Research) and the National Institute of Food and Agriculture (NIFA) for the funding of this study.

\title{
Introduction: the importance of water
}

Water is a basic need, and its access is vital to agriculture and life. As the world population increases, water management is becoming more and more critical (World Bank 2016). The United Nations first held the World Water Day in 1993, in order to improve visibility of efforts on water security (UN-Water 2016). A decade later, they created a special agency: the UN- 
Water, as an "inter-agency coordination mechanism for all freshwater related issues, including sanitation" (UN-Water 2016, section about UN-Water, para 1). In 2010, the United Nations recognized access to water and sanitation as a Human Right (World Health Organization (WHO) 2015). Although water is becoming more critical, there are many issues that aggravate the scarcity of water. According to the WHO (2015, section Challenges, para 1) "climate change, increasing water scarcity, population growth, demographic changes and urbanization already pose challenges for water supply systems. By 2025, half of the world's population will be living in water-stressed areas."

Directly related to climate change, a rise of atmospheric temperatures also means higher water temperatures and drastically decreased freshwater quality (Boehlert, Strzepek, Chapra, Fant, Gebretsadik, Lickley, Swanson, McCluskey, Neumann and Martinich 2015). With higher water temperatures, the content of dissolved oxygen in the water decreases, resulting in less oxygen for bacteria to consume organic matter, thus changing the whole water ecosystem (Boehlert et al. 2015; WHO 2015). In addition, as noted by the Organization for Economic Co-operation and Development, the use of new technologies with unknown impacts on ecosystems and human health such as nanotechnologies presents another risk for water quality (OECD 2016).

In their 2012 report, The International Energy Association (IEA 2012) predicted that the energy sector, representing $15 \%$ of the world's water use, will increase water use to $85 \%$ by the year 2030. The same report also showed that rivers and streams are becoming warmer as a result of water being used for various types of energy generation. The water is used as a coolant, and discharged back into the rivers at a higher temperature (IEA 2012). The world's freshwater resources represent only $2.5 \%$ of the world water resources, with $70 \%$ of it being stored in glaciers and the north and south poles (IEA 2012, U.S. Geological Survey 2016). The majority of 
the world's freshwater (70\%) is being used for agriculture (IEA 2012). In 2016, The World Bank suggested in its report that climate change will drastically affect the distribution of water as we know it, deepening the stress on this resource. The year 2015 was the warmest year ever recorded, exemplifying the fact that 14 of the 15 warmest years since the year 1880 fell between 2001 and 2016 (NASA 2016). Climate change poses a threat to watersheds worldwide. For example, the second largest lake in Bolivia (Poopó Lake) completely dried up in January 2016 (The New York Times 2016). A US centered example is the state of California which is at risk for droughts, potentially causing problems for agriculture and for the local populations (Cheng, Hoerling, AghaKouchak, Livneh, Quan, and Eischeid 2016; Diffenbaugh, Swain, and Touma 2015).

All of these factors suggest that humanity will face challenges of water management in terms of distribution, use and quality. The purpose of this paper is to demonstrate the need for better water management in the Appalachian Region, specifically in West Virginia. Considering the history of coal mining and the recent development of non-conventional gas extraction, this paper reviews the literature to describe the potential environmental risks. This paper argues that there is a need for more research on water quality together with incorporation of social aspects.

\section{Industrial Development in West Virginia}

According to the US Forest Service, the state of West Virginia is the third most forested state in the US with $78 \%$ of its land covered by forests (West Virginia Division of Forestry 2010). Laid out over the Appalachian Mountains, West Virginia has been of major importance for the development of the United States especially regarding energy supplies such as coal and oil (Bowen, Manzi, Meinert and Witt 2012). However, with aging mines and the increased 
development of natural gas extraction and associated techniques utilizing water, West Virginia is facing a transitional period that produces legitimate concerns over water quality.

West Virginia's industrial development started with the regional steel industry's exploitation of coal during the American Industrial Revolution (Gittell 1989; Rice and Brown 1993). West Virginia has also had the ability to provide coal to many other locations thanks to its significant fluvial system that created an important canal for distribution (Kelly 1997). Notably, the Monongahela river, located within the Northern part of the State, "had fifteen locks and dams that gave it a navigable depth of nine feet between Pittsburgh and Morgantown and of seven feet from Morgantown to Fairmont" (Rice and Brown 1993:183). In the meantime, the development of the railroad and the development of the United States in general made a huge contribution to the coal market expansion in West Virginia (Lewis 1998). The rapid development of West Virginia was also possible because of the influx of human capital and the important inputs of out-of-state capitals that flowed into West Virginia's industries (Lewis 1998; Rice and Brown 1993). The effects of the Industrial Revolution on West Virginia's development were spectacular as the production of coal boomed during WWI. Production continued on increasing until the Great Depression, reaching 139,297,146 tons annually for the region of West Virginia in 1929, representing a model of industrial capitalism (Lewis 1998; Rice and Brown 1993). However, since the end of the $20^{\text {th }}$ century, coal mining has slowly decreased its influence on the energy markets (Betz, Partridge, Farren and Lobao 2015; Bell and York 2012; Höök and Aleklett 2009).

\section{Decline of Coal Mining}

When referring to the US coal mining decline that took place during the second part of the $20^{\text {th }}$ Century, one is referring to an employment decline within the coal mining industry (Bell and 
York 2012). Interestingly, the increase in unemployment that occurred following World War II resulted from a structural change led by innovation in extractive techniques and through the development of heavy mechanization (Betz et al., 2015; Bell and York 2012; Höök and Aleklett 2009). As Bell and York (2012) explain, even though production rates drastically increased during this period - due to an increased demand - coal mining employment severely decreased. In fact, fewer highly-skilled employees were found to have higher productivity than the original number of employees, decreasing marginal costs and increasing profitability. The literature on coal mining industries and finite natural resources extraction in general developed the idea of "boom and bust cycles" to describe the production cycles related to market prices and environmental policies. This ultimately affected the socio-economic landscape of certain communities (Betz et al. 2015; Black, McKinnish and Sanders 2005). In their study on four Appalachian States (Kentucky, Ohio, Pennsylvania and West Virginia), Black et al. (2005) showed that a boom in the 1970s was followed by a bust in the 1980s. Their study focused on intensive coal production counties. For instance, Black et al. (2005) explained that the boom of the 1970s was a result of the oil embargo in the Middle East, causing the demand for coal to increase as a substitution to oil, and consequently, led coal prices to increase to a peak between 1978 and 1982 (Black et al. 2005). Additionally, the 1970s saw several changes in legislation with environmental policies (next section) and health and security policies, including both the Coal Act of 1969 and the Mine Act of 1977 (U.S. Department of Labor 2016). As a consequence of all these events, a boom occurred and participated in the job creation that was seen in the coal industry of the 1970s (Betz et al. 2015; Black et al. 2005). Inversely, the following decade saw a return to lower oil prices, restructuring the coal market and, by extension, the employment market (Black et al. 2005). Nonetheless, production increased over that period and even though 
the industry declined in terms of profits, earnings per worker did not significantly change during the 1980s due to the fact that coal miners became more skilled with advances in technology (Höök and Aleklett 2009; Black et al. 2005). Despite similar earnings per worker, Black et al. (2005) calculated that negative employment spillovers during the bust period of the 1980s outweighed the positive employment spillovers that occurred during the boom period of the 1970s.

Following the trend of the 1980s, the period of the 1990s saw a similar increase. Over this decade, Partridge, Betz and Lobao (2013) found the presence of a significant positive correlation between poverty and coal mining in the Appalachian region, supporting existing literature on what is called the "natural resource curse" (for a review, see Betz et al. 2015; Partridge et al. 2013).

The period of the 2000s to the year 2010 represented a stagnation and later a decrease of coal production not only for the State of West Virginia but for the whole United States. This change was largely due to the expansion of China and India as leaders in coal production (EIA 2016).

\section{Environmental Laws and Impact towards Mining}

The context of the coal decline in the US involves environmental regulations regarding public health, nature degradation, and major world decisions. With growing environmental concerns about the quality of public air towards the end of the 1960s, the U.S. Congress passed the Air Quality Act in 1967 to control air contaminants by geographical region (Aborn and Axelrod 1968). The Act's implementation was recognized as a failure as most states did not implement the act, and the regionalization of the act made it difficult to coordinate specific actions across the diverse geographical regions and states (EPA 2015a). 
After this failure, the year 1970 marked a turn in US society: the first Earth Day was celebrated, demonstrating a public awareness of the environment (EPA 2015a). That same year, President Nixon signed into law the EPA's Clean Air Act, representing one of the first major changes in US federal environmental law (EPA 2015a). The plan aimed to reduce air pollutants that were emitted by stationary sources, such as coal plants. As a result of this plan, the EPA created the National Ambient Air Quality Standards (NAAQS) which were enforced in every State (EPA 2015a). In 1977, the Clean Air Act was amended because the set goals were not met within the original deadlines (EPA 2015a). That same year, the Surface Mining Control and Reclamation Act was implemented to create the Office of Surface Mining Reclamation and Enforcement (OSMRE) under the Department of the Interior with the goal to protect the land and streams that have been affected by coal mining (OSMRE 2015; US Code 2014). Specifically, this Office is responsible for enforcing the protection of the land and ensuring that provisions are made by the companies in order to restore the land as it was before the mining exploitation (US Code 2014). According to the US Code (2014), for each ton of coal mined (and depending on the types of mining methods) a specific fee is due to the OSMRE fund for restoration.

At the same time, the Federal Water Pollution Control Act of 1948 was revised into the Clean Water Act of 1972 (CWA) and amended in 1977 (EPA 2015b). The CWA was especially important in regards to spills: "The CWA prohibits the discharge of oil or hazardous substances to waters of the U.S. or their adjoining shorelines in quantities that may be harmful to the public health or welfare or the environment" (EPA 2015b, section Oil Spills, and Spills Prevention, para1). To ensure the compliance of these regulations, the EPA uses inspectors to examine installations based on their risk level which can be defined by the age of the installation, the proximity to a sensitive area or the type of contaminant that is used (EPA 2015b). 
The 1970s was a critical period that enabled the creation of laws to protect the environment, affecting coal production in the Appalachian Region (Höök and Aleklett 2009). Bell and York (2012) wrote that coal mining employers fought these environmental laws for the most part by persuading their employees that these regulations were destroying the coal industry. Gould, Pellow and Schnaiberg (2004) also affirmed that, in the context of the environment, the populations that are the most at risk are the ones that resist legislation change for environmental protection.

In the 1990s, the Clean Air Act was revised with major changes, providing amendments aimed at improving atmospheric air quality and particularly preventing acid rains caused by sulfur present in gas emissions (EPA 2015a). These amendments specifically aimed at reducing the use of coal power plants that released a significant amount of sulfur (EPA 2015a). This Act had a strong effect on West Virginia because it increased the demand for clean coal, which favored coal produced in the Western part of the US over the Appalachian coal that contains more sulfur in certain regions (EIA 2016; EPA 2015a; Betz et al. 2015; Höök and Aleklett 2009).

In more recent years (2010 - present) coal production significantly dropped for all of the US coal-producing regions, with a 15\% decrease in the Appalachian Region for the year 2015-2016 (EIA 2016). The EIA points out the fact that the demand for coal has decreased because of a switch toward natural gas which emits less mercury than coal does. This change supports new regulations to be implemented in 2016: the Mercury and Air Toxics Standards referred to as MATS (EPA 2015a). Moreover, on an international scale, China and India have increased coal production, resulting in lower U.S. coal exports. Additionally, the Organization of the Petroleum Exporting Countries (OPEC) has maintained a low price strategy on oil, affecting the profitability of gas and coal (EIA 2016). Höök and Aleklett (2009) predicted an increase in 
recoverable coal reserves in the Appalachian region that would potentially peak in 2030, but environmental policies aimed at reducing anthropogenic climate change and conserving nature may decrease these predictions (Höök and Aleklett 2009). McIlmoil and Hansen (2010), suggested forecasts that would indicate a drastic decrease on the coal production in West Virginia. These authors advise West Virginia's state to diversify its economy in preparation for the coal decline (McIlmoil and Hansen 2010).

\section{Coal and Gas Mining and Potential Water Pollution Risks}

Understanding West Virginia's regional context suggests that the state faces issues that may be different from other states when investigating water quality. More precisely, other watersheds in the US are more concerned with agricultural techniques and policies that are affecting their water quality (Moore, Parker and Weaver 2008). The transition that the state of West Virginia faces with this decrease in coal mining creates critical management issues regarding the hazardous waste that this industry produced and produces (Underwood, Kruse and Bowman 2014). The use of polluting chemicals in high concentration for coal mining creates concerns in terms of waste disposal. For instance, many studies have been conducted in order to reduce the risk of acid mine drainage (AMD) and the pollution of streams and rivers (Mitsch and Wise 1998). Specifically, water infiltration in old mines can lead to AMD. In 2000, Sams III and Beer (2000:16) wrote in their water quality assessment study that: "the environmental effects from 200 years of coal mining have resulted in 2,390 stream miles in the Allegheny and Monongahela River Basin that have been affected by acid mine drainage to the point of not being able to support fish communities." This statement expresses some of the unique concerns regarding water quality in West Virginia. 
In parallel, the use of mountain top mining, a technique that consists of mining a mountain with the use of explosives and removing the leftover materials into valley fills, is predicted to increase (Townsend, Helmers, Kingdon, McNeil, Beurs and Eshleman 2009). According to a recent study, mountain top mining decreased the Central Appalachian Region's height by $40 \%$ on average, a stunning finding (Ross, McGlynn and Bernhardt 2016). Not only did these authors suggest that this method is diminishing the height of mountains, but also that the created "valley fills" have direct impacts on the $\mathrm{pH}$ of the streams and thus on water quality (Ross et al. 2016). Bernhardt, Lutz, King, Fay, Carter, Helton, Campagna and Amos (2012) explain that higher conductivity levels decrease the water quality and hence the number of macroinvertebrates and fish in streams. Several studies found that areas affected by surface mining or valley fills had decreased stream water quality compared with areas not impacted by mining (Bernhardt et al., 2012; Griffith, Norton, Alexander, Pollard and LeDuc 2012). Furthermore, Bernhardt et al. (2012) found that mining and valley fills were affecting streams in areas well beyond the boundaries of the mining permit limits. These authors suggest that impacts of mining can be noticed at the watershed level (Bernhardt et al. 2012). Additionally, Pond, Passmore, Pointon, Felbinger, Walker, Krock, Fulton and Nash (2014) found no differences between old and more recent mining sites on the diminished water quality of streams affected by coal mining. These authors point out the fact that streams located on reclaimed sites (sites that have been restored to the original state of the land before mining) do not have a higher water quality than streams located on currently mined sites, implying that areas affected by coal mining are impacted long after mining activities have stopped (Pond et al. 2014). Palmer, Bernhardt, Schlesinger, Eshleman, Foufoula-Georgiou, Hendryx, Lemly, Likens, Loucks, Power, White and Wilcock (2010) wrote that mountain top removing affects human health through exposure to streams and 
air by exposure to the chemicals contained in them. McAuley and Kozar (2006) found that ground water quality was significantly decreased in mined areas in contrast to unmined areas. Bernhardt et al. (2012) suggest that the larger the area is mined, the deeper the impacts on water quality. Griffith et al. (2012) add that the reclaimed sites have a different soil structure than the original sites, directly affecting evapotranspiration and microclimates in the local area. In contrast, Zégre, Maxwell and Lamont (2013) did not find significant differences in streamflow over time at the regional scale, comparing areas that were mined and areas that did not extract coal.

Today, extraction industries are diversifying their activities with the development of hydraulic fracturing and the recent exploitation of the Marcellus and Utica Shales that extend from Alabama through New York (Coleman, Milici, Cook, Charpentier, Kirschbaum, Klett, Pollastro and Schenk 2011). Together with technological improvements and larger demand, nonconventional natural gas extraction has become a new opportunity for energy companies, and its development has widely expanded across the country (Kargbo, Wilhelm and Campbell, 2010; Higginbotham, Pellillo, Gurley-Calvez and Witt 2010). These gas shale formations represent some of the largest gas shale fields in the world (Brasier, Filteau, McLaughlin, Jacquet, Stedman, Kelsey and Goetz 2011). Their profitability is estimated to be massive, and would enhance the economies of the local populations that were impacted by the decline of the steel industry in the region (Kahn 1999). In addition, gas emissions are said to be cleaner than the ones emitted from coal (EIA 2016).

However, like coal mining, natural gas extraction is also known to be associated with water pollution risks that are notably caused by the chemicals used in the extraction process (Howarth, Ingraffea and Engelder 2011; Torres, Yadav and Khan 2016). In the case of natural gas 
extraction, these environmental risks have the potential to have a particularly dire effect on water quality, considering the hydraulic fracturing fluids used in the fracturing process are toxic and would be problematic in the case of a spill (Elsner and Hoelzer 2016; Kargbo et al. 2010). The fluids used for hydraulic fracturing are composed of water mixed with chemical agents that are used to alter the geological formation containing the gas (Vidic, Brantley, Vandenbossche, Yoxtheimer and Abad 2013). However, some of the chemicals used are not regulated under the US Safe Drinking Water Act, and the disclosure of their use is not compulsory (Maule, Makey, Benson, Burrows and Scammell 2013; Osborn, Vengosh, Warner and Jackson 2011; Torres et al. 2016; Vidic et al. 2013). The storage of contaminated water with radioactive elements (from underground elements) and these chemicals pose potential risks if leaks occur (Vidic et al. 2013; Osborn et al. 2011).

\section{Potential Risks and Recent Crises}

This shift within the region along with the increased extraction methods utilizing water (natural gas extraction) causes concerns about the disposal of waste and about the risk of spills. For instance, the following recent crises in the management of water are examples where risk prevention has failed. Environmental risks are the foundation for environmental disasters. Bell and York (2010:124) describe one of these disasters that occurred in 2000 in Kentucky: an "impoundment collapsed, spilling 250 million gallons of coal waste (20 times greater than the Exxon Valdez oil spill), polluting more than 70 miles of West Virginia and Kentucky waterways, killing wildlife, and razing habitat. Homes were destroyed by the thick, black sludge.”

More recently, many water-related incidents have occurred in the US. In early January 2014, Charleston (WV) made the case for West Virginia when a chemical spill occurred as a result of a 
leak from a coal processing solvent tank (Whelton, McMillan, Connell, Kelley, Gill, White, Gupta, Dey and Novy 2015). The Elk River, which runs directly through Charleston, was contaminated by more than 10,000 gallons of solvent that impacted 300,000 inhabitants for more than three months (Whelton et al. 2015). West Virginia waters are the source of different major rivers, including the Ohio and the Potomac Rivers. West Virginia waters and these critical rivers host many outdoor activities such as fishing and swimming (WV Division of Tourism 2012; WV Rivers Coalition 2016; Bureau of Business \& Economic Research 2015). Moreover, West Virginia is the source of world renowned rivers, including the Gauley River, known as one of the World's best rivers for whitewater boating (WV Division of Tourism 2012; 2016; WV Rivers Coalition 2016). Water resources play a key role in West Virginia tourism: in 2010, the tourism sector generated $\$ 4.27$ billion into West Virginia's economy (WV Division of Tourism 2012). Considering that outdoor activities are important in West Virginia, it is reasonable to think that the image of this chemical spill in Charleston weakened the tourism sector. As such, the economic impacts of a spill are often difficult to estimate. From a medical point of view, Dwight, Fernandez, Baker, Semenza, and Olson (2005) found that illness from water pollution affects the economy. In general, urbanization and industrialization increase the runoff of pollutants into water systems (Dwight et al. 2005; Bay, Greenstein, Lau, Stenstrom and Kelley 1996).

In 2015, several other human-influenced water catastrophes took place. In August 2015, as the EPA was investigating a gold mine leakage, workers created a breach that spilled 3 million gallons of toxic water into the Animas River, a tributary of the Colorado River System (Turkewitz 2015). More recently, the city of Flint (MI), experienced lead contamination of its drinking water in Fall 2015. The majority of the water pipes of the city were made of lead, and the city changed the source of its water supply for financial reasons to the Flint River with 
devastating results. Flint's inhabitants were exposed to a lethal risk because the new water source flowing through their lead pipes was highly corrosive due to industrial waste (Ingraham 2016). Chemical disasters from mining also happen on a global scale, as was seen in the state of Minas Gerais (Brazil) on November 8, 2015. The failure of a dam spilled mining wastewater, killing 23 people and contaminating residents' water and living areas for hundreds of kilometers according to the IBAMA (2015).

One of the main issues with contamination is the potential that it may last in the environment and accumulate, impacting both nature and the livelihood of populations (Pond et al. 2014). These recent crises are reminders that environmental risks exist and can affect communities. These risks have consequences on population's perceptions of water and ultimately on their behavior.

\section{Risk perceptions}

Risk perceptions are complex and are at the corner of different theories trying to explain these perceptions (Ferrer and Klein, 2015; Sjöberg, 2000). Ferrer and Klein (2015) explicitly affirm that risk perceptions must refer to a specific threat and not to a broad sense of risks. In our study, we specifically look at health risks relating to tap water quality such as illness and getting sick from drinking tap water. Our study focuses on the attitude-belief process, described by Söjberg (2000) instead of theories such as the psychometric paradigm or the cultural theory (for a discussion, see Sjöberg, 2000).

Purpose of the study

In order to understand risk perceptions, we are exploring the link between the likelihood of a chemical spill, the attitudes towards tap water quality (taste, odor and color) with health risk perceptions associated with drinking from the tap. We seek to understand how a belief, health 
risk perceptions, are related to attitudes from water quality in Morgantown (WV), confirming or refuting Sjöberg's (2000) theory. Some other factors are not included in this manuscript as we assessed other links with different analyses in three other manuscripts.

\section{Methods}

\section{Data Collection}

A household survey was developed and implemented by the authors, and data collection took place from November 2015 through January 2016. A random sample of 5492 residents from Morgantown (WV) and nearby suburban areas were selected to participate in an online and mailback survey (using Dillman, Smyth and Christian 2014) regarding their water quality perceptions. A total of 603 residents responded (184 mail-back surveys and 385 online surveys), resulting a combined response rate of $11.29 \%$.

The survey instrument included questions relating to organoleptic perceptions (taste, odor, color), perceived health risk associated with drinking water from the tap and other items such as the perceived likelihood of a chemical spill in the Morgantown area, based on Doria, Pidgeon and Hunter (2009) and Syme and Williams (1993). The items were measured using a 5-pt Likert scale with a level of agreement, (1) being strongly disagree and (5) strongly agree (see Table 2). Two scales were created: the perceived health risks scale, combining 4 items, and the organoleptic scale, combining 3 items (Vaske 2008). Two items were reverse-coded for the perceived health risk scale. Respondents with a higher score on the perceived health risk scale think there are less health risks associated with drinking tap water. Numerous other factors were also measured but not presented within the scope of this paper. 
Analyses

First, this paper presents the socio-demographics associated with the sample for the purpose of understanding potential bias in the sampling method. Following this, a descriptive analysis of the items of interest is shown (Table 2). Finally, the perceived health risks scale is regressed on the perceived chemical spill risk and organoleptic perceptions (taste, odor and color).

\section{Results}

Table 1: Demographic Characteristics of Respondents $(\mathrm{N}=603)$

\begin{tabular}{lcc}
\hline Characteristic & $n$ & $\%$ \\
\hline Gender & 326 & 56 \\
Female & 258 & 44 \\
Male & & \\
Age $(\mathrm{N}=584, \mathrm{M}=51.74, \mathrm{SD}=13.09)$ & & \\
Education & 4 & $<1$ \\
Some High School & 49 & 8 \\
High School Graduate & 96 & 16 \\
Some College & 50 & 8 \\
Two-year College & 166 & 28 \\
Four-year College & 223 & 38 \\
Graduate or Professional degree & & \\
Household Income & 27 & 5 \\
$<\$ 25,000$ & 98 & 19 \\
$\$ 25,000-\$ 49,999$ & 102 & 19 \\
$\$ 50,000-\$ 74,999$ & 86 & 16 \\
$\$ 75,000-\$ 99,999$ & 125 & 24 \\
$\$ 100,000-\$ 149,999$ & 89 & 17 \\
$>\$ 150,000$ & & \\
& &
\end{tabular}


Race

American Indian/ Alaska Native $\quad 4 \quad<1$

$\begin{array}{lll}\text { Asian } & 14 & 2\end{array}$

Black/ African-American $\quad 12 \quad 2$

Native Hawaiian/ Pacific Islander $\quad 1 \quad<1$

$\begin{array}{lll}\text { White } & 540 & 95\end{array}$

Ethnicity

Hispanic $\quad 6 \quad 1$

$\begin{array}{lrr}\text { Non-Hispanic } & 568 & 99\end{array}$

Note. Total of percentages are not 100 for every characteristic because of rounding.

Regarding the socio-demographic items, a comparison with US census data (U.S. Census Bureau 2016), shows the sample is representative of the population: the mean age, the education and the race/ethnicity correspond to the characteristics of Morgantown's population. The data show that the population is highly educated, reflecting the fact that the city of Morgantown is home to a major land grant university. Two points of discrepancy are the household income and the sex. The sample under study includes a higher proportion of people earning $\$ 100,000$ or more per year $(40.6 \%)$ than the actual population (13.6\%). People who have a higher income are perhaps more likely to have access to the internet and to answer the survey than people who earn less (U.S. Census Bureau 2016). Regarding sex, females are more represented in the sample population (55\%) than in the actual population (48\%). This result reflects current literature where women tend to answer surveys in higher proportions than men (Dillman et al. 2014).

Table 2 defines the items that were used to compose the scales for the following analyses.

Table 2: Items and Responses for constructs

\begin{tabular}{|c|c|c|c|c|c|}
\hline \multirow[t]{2}{*}{ Item } & Strongly & Disagree & Neutral & Agree & Strongly \\
\hline & Disagree & & & & Agree \\
\hline
\end{tabular}




\begin{tabular}{|c|c|c|c|c|c|}
\hline $\begin{array}{l}\text { There are health risks } \\
\text { associated with drinking tap } \\
\text { water in my home }(\mathrm{N}=595 \text {, } \\
\mathrm{M}=2.50)\end{array}$ & $17.3 \%$ & $35.3 \%$ & $31.1 \%$ & $12.6 \%$ & $3.7 \%$ \\
\hline $\begin{array}{l}\text { There are so many chemicals } \\
\text { and additives in my home tap } \\
\text { water that it must be unhealthy } \\
(\mathrm{N}=599, \mathrm{M}=2.71)\end{array}$ & $15.5 \%$ & $27.2 \%$ & $33.7 \%$ & $17.4 \%$ & $6.2 \%$ \\
\hline $\begin{array}{l}\text { I don't believe there is any } \\
\text { possibility of becoming ill from } \\
\text { drinking water straight from the } \\
\text { tap }(\mathrm{N}=601, \mathrm{M}=3.16)\end{array}$ & $8.8 \%$ & $25.5 \%$ & $19.6 \%$ & $32.8 \%$ & $13.3 \%$ \\
\hline $\begin{array}{l}\text { My home tap water will not } \\
\text { harm anybody }(\mathrm{N}=601 \text {, } \\
\mathrm{M}=3.48)\end{array}$ & $4.3 \%$ & $14.8 \%$ & $25.6 \%$ & $38.6 \%$ & $16.6 \%$ \\
\hline \multicolumn{6}{|c|}{ Perceived Health Risk Scale (Cronbach's $\alpha=.840$ ) } \\
\hline $\begin{array}{l}\text { I am happy with the taste } \\
(\mathrm{N}=596, \mathrm{M}=3.28)\end{array}$ & $12.7 \%$ & $19.2 \%$ & $17.4 \%$ & $38 \%$ & $12.7 \%$ \\
\hline $\begin{array}{l}\text { I am happy with the color } \\
(\mathrm{N}=596, \mathrm{M}=3.28)\end{array}$ & $3.8 \%$ & $7.2 \%$ & $17.4 \%$ & $55.2 \%$ & $16.4 \%$ \\
\hline $\begin{array}{l}\text { I am happy with the odor } \\
(\mathrm{N}=596, \mathrm{M}=3.28)\end{array}$ & $6.4 \%$ & $10.9 \%$ & $20 \%$ & $47.2 \%$ & $15.5 \%$ \\
\hline \multicolumn{6}{|c|}{ Organoleptic Scale (Cronbach's $\alpha=.882$ ) } \\
\hline $\begin{array}{l}\text { I think that a chemical spill is } \\
\text { highly likely to happen in the near } \\
\text { future in Mon County ( } N=596 \text {, } \\
M=3.03 \text { ) }\end{array}$ & $7.6 \%$ & $16.3 \%$ & $50 \%$ & $17.8 \%$ & $8.4 \%$ \\
\hline
\end{tabular}

One of the major, if not simplistic, findings of the analysis is that a majority of respondents feel somewhat neutral about the threat of poor water quality. Respondents were neutral in their 
perceptions of risks and organoleptic perceptions of the tap water quality and the risk of a chemical spill. Table 2 shows that a slight majority of respondents (ranging $42.7 \%$ to $55.2 \%$ ) felt that there are no health risks associated with drinking tap water. The number of respondents being neutral in this regard was relatively high as well.

In order to assess the link between the different constructs, a linear regression was used to investigate whether the perceived health risks could be predicted from the likelihood of a chemical spill and the organoleptic perceptions (Table 3). Assumptions of linear regression were tested and validated. Results show that $47 \%$ of the variance in perceived health risks can be significantly imputed to the variance of the organoleptic scale and the perceived risk of a chemical spill $\left(\mathrm{F}(2,590)=259.610, \mathrm{p}<.001 ; \mathrm{R}^{2}=.466\right)$. The more respondents were happy with the taste, odor and color of their water, the less they would perceive health risks associated with drinking from the tap $(\mathrm{t}=-18.769, \mathrm{p}<.001, \mathrm{CI}(95 \%)=[-.595 ;-.482])$. Additionally, the more respondents felt a chemical spill was likely in the Morgantown area, the more they would perceive health risks associated with drinking from the tap $(\mathrm{t}=7.276, \mathrm{p}<.001, \mathrm{CI}(95 \%)=[.152$; $.265])$.

Table 3: Perceived Health Risks Regression Table.

\begin{tabular}{lccc}
\hline & $B$ & $S E B$ & $\beta$ \\
\hline $\begin{array}{l}\text { Organoleptic } \\
\text { Perceptions }\end{array}$ & -0.54 & 0.03 & $-0.59^{* * *}$ \\
$\begin{array}{l}\text { Chemical Spill } \\
\text { Likelihood }\end{array}$ & 0.21 & 0.03 & $0.23^{* * *}$ \\
\hline
\end{tabular}

Note. ${ }^{*} \mathrm{p}<.05,{ }^{* *} \mathrm{p}<.01,{ }^{* * *} \mathrm{p}<.001$ (two-tailed).

\section{Discussion}


The results presented in the previous section shed light on the fact that respondents of this survey were rather neutral in their responses (Table 2). This finding suggests issues with knowledge on the risks associated with drinking from the tap and from the risk associated with extraction industries present in the area. These results are reflective of past studies (Pahl-Wostl, Gupta and Petry 2008; Theodori, Luloff, Willits and Burnett 2014). Notably, Pahl-Wostl et al. (2008) showed that there is a growing need for social learning about water resources management and sustainability science. Similarly, Sagoff (2013:245) posited that scientists have a role to play in giving the right tools to citizens and policy makers by "not only measur[ing] the likelihood of harm but also to say what is harmed and what the harm is". Theodori et al. (2014) found that people who had more knowledge on hydraulic fracturing techniques were more inclined to support natural gas extraction, demonstrating the need for educational outreach in areas where perceived risks is high. These authors called for the need to have transparent information about the techniques used and across the diverse actors, agencies and researchers (Theodori et al. 2014). In this sense, collaboration efforts between different actors and stakeholders should strive for improving water management.

The results of the linear regression highlight the fact that attitudes towards water quality and the likelihood of a chemical spill significantly explain health risk perceptions associated with drinking tap water. The results are in line with previous literature, confirming Sjöberg's (2000) statement, and show the need for further research in this domain (Doria et al. 2009; Syme and Williams 1993). These results have implications in terms of communication with the public and what information should be provided to the public and in what manner (Maule et al. 2013; Sagoff 2013, Theodori et al. 2014). Water companies should aim at providing the general public with transparent information regarding water quality. Extraction companies should work together 
with federal and state agencies in order to provide appropriate information concerning the levels of potential risks of water contamination.

\section{Conclusions and Implications}

One managerial option that has often been considered for pollution is the monetarization of public goods (Olmstead 2010). In opposition to air quality trading markets, water quality trading markets are more complex because of non-point source pollution: the origin of the pollution cannot be attributed to a unique source (Olmstead 2010). Therefore, water quality trading is rarely successful because water pollution is not uniform, and its spatial distribution is difficult to determine (Olmstead 2010). Policy-makers are facing the choice between trading markets, taxes and permits, all of which have consequences for liability issues (Olmstead 2010). Concerning water pollution from point source pollution, the United States has chosen to use a permit system. In terms of liability, the EPA can act under the Comprehensive Environmental Response, Compensation, and Liability Act (Superfund) (EPA 2016). The role of this fund is "to clean up uncontrolled or abandoned hazardous-waste sites as well as accidents, spills, and other emergency releases of pollutants and contaminants into the environment. Through CERCLA, EPA was given power to seek out those parties responsible for any release and assure their cooperation in the cleanup" (EPA 2016, section 42 U.S.C. $§ 9601$ et seq. (1980), para 1). Regulations and advances in engineering and technology should target the minimization of risks. As such, Zirogiannis, Alcorn, Rupp, Carley and Graham (2016) found that West Virginia had the most comprehensive legislation regulating risks related to unconventional gas wells, and the highest degree of compliance associated with it, in the country. This shows that the increase of natural gas extraction in West Virginia is one of the most monitored in terms of environmental 
impacts. The results of this study are to be contrasted with other literature that highlights the role of patents in the non-public disclosure of the chemicals used in gas extraction processes, slowing regulations towards risk prevention (Maule et al. 2013; Osborn et al. 2011; Torres et al. 2016; Vidic et al. 2013).

In conclusion, this study shows that the public perceptions of water quality are associated with the perceived risks associated with drinking water and with the likelihood of a chemical spill. Nonetheless, a majority of the respondents appear to have no opinion on the issues. For example, the main water provider in Morgantown (Morgantown Utility Board) only has an online version of their water testing. The authors suggest better communication between agencies and private companies to deliver a clear message to the public regarding the safety associated with extraction industries and drinking water from the tap.

\section{Limitations}

This study was part of a larger work on risk perceptions and as such only a few variables were selected to be represented within this particular manuscript. As such, a Structural Equation Modeling approach was used to depict more of these relationships in another article (Levêque and Burns, 2017). Other limitations imply the need for larger-scale studies to have a larger pictures of risk perceptions in West Virginia. Other factors such as media exposure, trust in different agencies or water provider could also explain variance in risk perceptions. Future studies should include these factors.

\section{References}


Aborn Richard A. and Carl E. Axelrod. 1968. "State Air Pollution Control Legislation." Boston College Law Review 9(3):712-756.

Bay, Steven M., Darrin J. Greenstein, Sim-Lin Lau, Stenstrom, Michael K. and Carolyn G. Kelley. 1996. "Toxicity of Dry Weather Flow from the Santa Monica Bay Watershed.” Bulletin of the Southern California Academy of Sciences 95(1):33-45.

Bell, Shannon E. and Richard York. 2010. “Community Economic Identity: The Coal Industry and Ideology Construction in West Virginia." Rural Sociology 75(1):111-143.

Bernhardt, Emily S., Brian D. Lutz, Ryan S. King, John P. Fay, Catherine E. Carter, Ashley M. Helton, David Campagna and John Amos. 2012. "How Many Mountains Can We Mine? Assessing the Regional Degradation of Central Appalachian Rivers by Surface Coal Mining." Environmental Science \& Technology 46(15):8115-8122.

Betz, Michael R., Mark D. Partridge, Michael Farren and Linda Lobao. 2015. "Coal Mining, Economic Development, and the Natural Resources Curse.” Energy Economics 50:105-116.

Black, Dan, Terra McKinnish and Seth Sanders. 2005. "The Economic Impact of the Coal Boom and Bust." The Economic Journal 115(503):449-476.

Boehlert, Brent, Kenneth M. Strzepek, Steven C. Chapra, Charles Fant, Yohannes Gebretsadik, Megan Lickley, Richard Swanson, Alyssa McCluskey, James E. Neumann and Jeremy Martinich. 2015. "Climate Change Impacts and Greenhouse Gas Mitigation Effects on US Water Quality.” Journal of Advances in Modeling Earth Systems 7(3):1326-1338. 
Bowen, Eric, Patrick Manzi, Tess A. Meinert and Tom S. Witt. 2012. "Fossil Energy Opportunities for West Virginia." Bureau of Business and Economic Research, West Virginia University.

Brasier, Kathryn J., Matthew R. Filteau, Diane McLaughlin, Jeffrey Jacquet, Richard C.

Stedman, Timothy W. Kelsey and Stephan J. Goetz. 2011. "Residents' Perceptions of Community and Environmental Impacts from Development of Natural Gas in the Marcellus Shale: A Comparison of Pennsylvania and New York Cases." Journal of Rural Social Sciences 26(1):32-61.

Bureau of Business \& Economic Research. 2015. "West Virginia Economic Outlook, 2015.” West Virginia University College of Business and Economics, West Virginia University.

Cheng, Linyin, Martin Hoerling, Amir AghaKouchak, Ben Livneh, Xiao-Wei Quan and Jon Eischeid. 2016. "How Has Human-Induced Climate Change Affected California Drought Risk?" Journal of Climate 29(1):111-120.

Coleman, James L., Robert C. Milici, Troy A. Cook, Ronald R. Charpentier, Mark Kirschbaum, Timothy R. Klett, Richard M. Pollastro and Christopher J. Schenk. 2011. “Assessment of Undiscovered Oil and Gas Resources of the Devonian Marcellus Shale of the Appalachian Basin Province, 2011." U.S. Geological Survey Fact Sheet 2011-3092. Retrieved October 8, 2015 (pubs.usgs.gov/fs/2011/3092/).

Diffenbaugh, Noah S., Daniel L. Swain and Danielle Touma. 2015. “Anthropogenic Warming Has Increased Drought Risk in California." Proceedings of the National Academy of Sciences 112(13):3931-3936. 
Dillman, Don A., Jolene D. Smyth and Leah Melani Christian. 2014. Internet, phone, mail, and mixed-mode surveys: The tailored design method. John Wiley \& Sons.

Doria, Miguel de França, Nick Pidgeon and Paul R. Hunter. 2009. "Perceptions of Drinking Water Quality and Risk and its Effect on Behaviour: A Cross-National Study." Science of the Total Environment 407(21):5455-5464.

Dwight, Ryan H., Linda M. Fernandez, Dean B. Baker, Jan C. Semenza and Betty Olson. 2005. Estimating the Economic Burden from Illnesses Associated with Recreational Coastal Water Pollution - a Case Study in Orange County, California." Journal of Environmental Management 76(2):95-103.

Elsner, Martin and Kathrin Hoelzer. 2016. "Quantitative Survey and Structural Classification of Hydraulic Fracturing Chemicals Reported in Unconventional Gas Production.” Environmental Science \& Technology 50(7):3290-3314.

Ferrer, R. A., \& Klein, W. M. (2015). Risk perceptions and health behavior. Current opinion in psychology, 5, 85-89.

Gittell, Ross. 1989. "The Role of Community Organization in Economic Development: Lessons from the Monongahela Valley." National Civic Review 78(3):187-196.

Gould, Kenneth A., David N. Pellow and Allan Schnaiberg. 2004. "Interrogating the Treadmill of Production: Everything You Wanted to Know about the Treadmill but Were Afraid to Ask." Organization \& Environment 17(3):296-316.

Griffith, Michael B., Susan B. Norton, Laurie C. Alexander, Amina I. Pollard and Stephen D. LeDuc. 2012. "The Effects of Mountaintop Mines and Valley Fills on the Physicochemical 
Quality of Stream Ecosystems in the Central Appalachians: a Review." Science of the Total Environment 417:1-12.

Levêque, J. G., \& Burns, R. C. (2017). A Structural Equation Modeling approach to water quality perceptions. Journal of Environmental Management, 197, 440-447.

Higginbotham, Amy, Adam Pellillo, Tami Gurley-Calvez and Tom S. Witt. 2010. "The Economic Impact of the Natural Gas Industry and the Marcellus Shale Development in West Virginia in 2009." Bureau of Business and Economic Research West Virginia University.

Höök, Mikael and Kjell Aleklett. 2009. "Historical Trends in American Coal Production and a Possible Future Outlook." International Journal of Coal Geology 78(3):201-216.

Howarth, Robert W., Anthony Ingraffea, A and Terry Engelder. 2011. "Natural Gas: Should Fracking Stop?" Nature 477(7364):271-275.

IBAMA. 2015. Preliminary Report on the Environmental Impacts of Disaster Involving the Fundão Dam in Mariana, Minas Gerais, Brazil. Instituto Brasileiro do Meio Ambiente e dos Recursos Naturais Renováveis - IBAMA. Retrieved June 15, 2016.

(http://www.ibama.gov.br/phocadownload/noticias_ambientais/laudo_tecnico_preliminar.pdf).

Ingraham, Christopher. 2016. “This Is How Toxic Flint's Water Really Is.” The Washington Post, January, 15. Retrieved February 2, 2016

(www.washingtonpost.com/news/wonk/wp/2016/01/15/this-is-how-toxic-flints-water-really-is/).

International Energy Association. 2012. "Water for Energy: Is Energy Becoming a Thirstier Resource?" Paris, France: OECD/IEA.

Kahn, Matthew E. 1999. “The Silver Lining of Rust Belt Manufacturing Decline. Journal of Urban Economics 46(3):360-376. 
Kargbo, David. M., Ron G. Wilhelm and David J. Campbell. 2010. "Natural Gas Plays in the Marcellus Shale: Challenges and Potential Opportunities." Environmental Science \& Technology $44: 5679-5684$.

Kelly, Morgan. 1997. “The Dynamics of Smithian Growth.” The Quarterly Journal of Economics 112(3):939-964.

Lewis, Ronald L. 1998. Transforming the Appalachian countryside: Railroads, Deforestation, and Social Change in West Virginia, 1880-1920. University of North Carolina Press.

Maule, Alexis L., Colleen M. Makey, Eugene B. Benson, Isaac J. Burrows and Madeleine K. Scammell. 2013. "Disclosure of Hydraulic Fracturing Fluid Chemical Additives: Analysis of Regulations." NEW SOLUTIONS: A Journal of Environmental and Occupational Health Policy 23(1):167-187.

McAuley, Steven D. and Mark D. Kozar. 2006. Ground-water Quality in Unmined Areas and near Reclaimed Surface Coal Mines in the Northern and Central Appalachian Coal Regions, Pennsylvania and West Virginia. U.S. Department of the Interior, U.S. Geological Survey Scientific Investigations Report 2006-5059; Denver, CO: Information Services.

McIlmoil Rory and Evan Hansen. 2010. The Decline of Central Appalachian Coal and the Need for Economic Diversification. Thinking Downstream: White Paper \#1. Morgantown, West Virginia: Downstream Strategies.

Mitsch, William J. and Karen M. Wise. 1998. "Water Quality, Fate of Metals, and Predictive Model Validation of a Constructed Wetland Treating Acid Mine Drainage." Water Research 32(6):1888-1900. 
Moore, Richard. H., Jason Shaw Parker and Mark Weaver. 2008. “Agricultural Sustainability, Water Pollution, and Governmental Regulations: Lessons from the Sugar Creek Farmers in Ohio." Culture \& Agriculture 30(1-2), 3-16.

NASA. 2016. "NASA, NOAA Analyses Reveal Record-Shattering Global Warm Temperatures in 2015." Retrieved February 3, 2016 (www.nasa.gov/press-release/nasa-noaa-analyses-revealrecord-shattering-global-warm-temperatures-in-2015)

OECD. 2016. "Nanomaterials in Waste Streams - Current Knowledge on Risks and Impacts." Retrieved February 24, 2016 (www.keepeek.com/Digital-AssetManagement/oecd/environment/nanomaterials-in-waste-streams_9789264249752-en\#page2)

Office of Surface Mining Reclamation and Enforcement, Department of the Interior. 2015. “Laws, Regulations, and Guidance.” Retrieved February 4, 2016 (www.osmre.gov/lrg.shtm)

Olmstead, Sheila M. 2010. "The Economics of Managing Scarce Water Resources.” Review of Environmental Economics and Policy 4(2):179-198.

Osborn, Stephen G., Avner Vengosh, Nathaniel R. Warner, Robert B. Jackson. 2011. "Methane Contamination of Drinking Water Accompanying Gas-Well Drilling and Hydraulic Fracturing." Proceedings of the National Academy of Sciences 108(20):8172-8176.

Pahl-Wostl, Claudia, Joyeeta Gupta and Daniel Petry. 2008. "Governance and the Global Water System: a Theoretical Exploration." Global Governance: A Review of Multilateralism and International Organizations 14(4):419-435.

Palmer, Margaret A., Emily S. Bernhardt, William H. Schlesinger, Keith N. Eshleman, E. Foufoula-Georgiou, Michael S. Hendryx, A. D. Lemly, G. E. Likens, O. L. Loucks, M. E. Power, 
Peter S. White and Peter R. Wilcock. 2010. "Mountaintop Mining Consequences.” Science 327:148-149.

Partridge, Mark D., Michael R. Betz and Linda Lobao, L. 2013. "Natural Resource Curse and Poverty in Appalachian America." American Journal of Agricultural Economics 95(2):449-456.

Pond, Gregory J., Margaret E. Passmore, Nancy D. Pointon, John K. Felbinger, Craig A. Walker, Kelly J. G. Krock, Jennifer B. Fulton and Whitney Nash. 2014. "Long-Term Impacts on Macroinvertebrates Downstream of Reclaimed Mountaintop Mining Valley Fills in Central Appalachia. Environmental management 54(4):919-933.

Rice, Otis K. and Stephen W. Brown. 1993. West Virginia:A History. Lexington, KY: University Press of Kentucky.

Ross, Matthew R., Brian L. McGlynn and Emily S. Bernhardt. 2016. "Deep Impact: Effects of Mountaintop Mining on Surface Topography, Bedrock Structure, and Downstream Waters.” Environmental Science \& Technology 50:2064-2074.

Sagoff, Mark. 2013. “What Does Environmental Protection Protect?” Ethics, Policy \& Environment 16(3):239-257.

Sams III, James I. and Kevin M. Beer. 2000. Effects of Coal-Mine Drainage on Stream Water Quality in the Allegheny and Monongahela River Basins - Sulfate Transport and Trends. WaterResources Investigations Report 99-4208. Lemoyne, PA: U.S. Department of the Interior, U.S. Geological Survey, National Water-Quality Assessment Program.

Sjöberg, L. (2000). Factors in risk perception. Risk analysis, 20(1), 1-12. 
Syme, Geoffrey J. and Katrina D. Williams. 1993. "The Psychology of Drinking Water Quality: An Exploratory Study.” Water Resources Research 29(12):4003-4010.

The New York Times. 2016 “A Lake in Bolivia Evaporates, and with It a Way of Life.” The New York Times January 23. Retrieved February 3, 2016

(http://www.nytimes.com/2016/01/24/world/americas/a-lake-in-bolivia-evaporates-and-with-it-away-of-life.html?_r=0).

Theodori, Gene L., A. E. Luloff, Fern K. Willits and David B. Burnett. 2014. "Hydraulic Fracturing and the Management, Disposal, and Reuse of Frac Flowback Waters: Views from the Public in the Marcellus Shale.” Energy Research \& Social Science 2:66-74.

Torres, Luisa, Om P. Yadav and Eakalak Khan. 2016. “A Review on Risk Assessment Techniques for Hydraulic Fracturing Water and Produced Water Management Implemented in Onshore Unconventional Oil and Gas Production." Science of The Total Environment 539:478493.

Townsend, Philip A., David P. Helmers, Clayton C. Kingdon, Brenden E. McNeil, Kirsten M. de Beurs and Keith N. Eshleman. 2009. "Changes in the Extent of Surface Mining and Reclamation in the Central Appalachians Detected Using a 19762006 Landsat Time Series. Remote Sensing of Environment 113:62-72.

Turkewitz, Julie. 2015 “Environmental Agency Uncorks Its Own Toxic Water Spill at Colorado Mine.” The New York Times, August, 10. Retrieved October 19, 2015

(www.nytimes.com/2015/08/11/us/durango-colorado-mine-spill-environmental-protectionagency.html). 
Underwood, Bruce E., Natalie A. Kruse and Jennifer R. Bowman. 2014. “Long-Term Chemical and Biological Improvement in an Acid Mine Drainage-Impacted Watershed. Environmental Monitoring and Assessment 186(11):7539-7553.

U.S. Census Bureau. 2016. “2010-2014 American Community Survey 5-Year Estimates.” Retrieved April 3, 2016

(http://factfinder.census.gov/faces/nav/jsf/pages/community_facts.xhtml\#)

U.S. Code. 2014. Title 30-Mineral Lands and Mining, Chapter 25-Surface Mining Control and Reclamation. United States Government Publishing Office. Retrieved February 22, 2016 (www.gpo.gov/fdsys/pkg/USCODE-2014-title30/pdf/USCODE-2014-title30-chap25.pdf).

U.S. Department of Labor. 2016. "History of Mine Safety and Health Legislation. Mine Safety and Health Administration - MSHA.” Retrieved February 24, 2016 (arlweb.msha.gov/mshainfo/mshainf2.htm).

U.S. Environmental Protection Agency. 2015a. "Progress Cleaning the Air and Improving People's Health." Retrieved January 1, 2016 (www.epa.gov/clean-air-act-overview/progresscleaning-air-and-improving-peoples-health\#emissions).

U.S. Environmental Protection Agency. 2015b. "Summary of the Clean Water Act." Retrieved June 6, 2015 (www.epa.gov/laws-regulations/summary-clean-water-act).

U.S. Environmental Protection Agency. 2016. "Summary of the Comprehensive Environmental Response, Compensation, and Liability Act (Superfund).” Retrieved March 6, 2016 (https://www.epa.gov/laws-regulations/summary-comprehensive-environmental-responsecompensation-and-liability-act). 
United Nations Water. 2016. "United Nations Inter-Agency Mechanism on all Freshwater Related Issues, Including Sanitation.” Retrieved February 10, 2016 (www.unwater.org/about/en/).

U.S. Energy Information Administration. 2016. "Short-Term Energy Outlook." Retrieved January 30, 2016 (www.eia.gov/forecasts/steo/report/coal.cfm).

U.S. Geological Survey. 2016. “The World's Water.” Retrieved April 3, 2016 (http://water.usgs.gov/edu/earthwherewater.html).

Vaske, Jerry J. 2008. Survey Research and Analysis: Applications in Parks, Recreation and Human Dimensions. State College, PA: Venture Publishing.

Vidic, R. D., S. L. Brantley, J. M. Vandenbossche, D. Yoxtheimer and J. D. Abad. 2013. "Impact of Shale Gas Development on Regional Water Quality.” Science 340(6134):826-836.

West Virginia Division of Forestry. 2010. West Virginia Statewide Forest Resource Assessment, A Comprehensive Analysis of the State's Forests and Related Natural Resources, WVDOF, East Charleston, WV.

West Virginia Division of Tourism. 2012. West Virginia Ten Year Tourism Plan. Submitted by AECOM and Mary Means and Associates.

West Virginia Division of Tourism. 2016. "Whitewater Adventures and Lake Activities." Retrieved February 29, 2016 (http://gotowv.com/adventure-play/whitewater-lake/).

West Virginia Rivers Coalition. 2016. "Protecting Headwaters.” Retrieved January 12, 2016 (http://www.wvrivers.org/). 
Whelton, Andrew J., Lakia McMillan, Matthew Connell, Keven M. Kelley, Jeffrey P. Gill, Kevin D. White, Rahul Gupta, Rajarshi Dey and Caroline Novy. 2015. "Residential Tap Water Contamination Following the Freedom Industries Chemical Spill: Perceptions, Water Quality, and Health Impacts." Environmental Science \& Technology 49(2):813-823.

World Bank. 2016. The Critical Face of Climate Change-Water. International Bank for Reconstruction and Development/the World Bank: Washington, D.C.

World Health Organization. 2015. "Drinking-water, Fact sheet N³91." Retrieved February 10, 2016 (http://www.who.int/mediacentre/factsheets/fs391/en/).

Zégre, Nicolas P., Aaron Maxwell and Sam Lamont. 2013. Characterizing Streamflow Response of a Mountaintop-Mined Watershed to Changing Land Use.” Applied Geography 39:5-15.

Zirogiannis, Nikolaos, Jessica Alcorn, John Rupp, Sanya Carley John D. Graham. 2016. "State Regulation of Unconventional Gas Development in the US: An Empirical Evaluation.” Energy Research \& Social Science 11:142-154. 


\title{
Chapter III: Article 2
}

Predicting Water Filter and Bottled Water Use in Appalachia:

A Community-scale Case Study

Jonas G. Levêque

Robert C. Burns

(Paper published in the International Journal of Water and Health, IWA Publishing, in Summer 2017 Issue: Volume 15(3), June)

\begin{abstract}
A questionnaire survey was conducted in order to assess residents' perceptions of water quality for drinking and recreational purposes in a mid-sized city in northcentral West Virginia. Two logistic regression analyses were conducted in order to investigate the factors that influence bottle use and filter use. Results show that $37 \%$ of respondents primarily use bottled water and that $58 \%$ use a household filter when drinking from the tap. Respondents with lower levels of environmental concern, education levels, and lower organoleptic perceptions were most likely to perceive health risks from tap water consumption, and were most likely to use bottled water. Income, age and organoleptic perceptions were predictors of water filter use among respondents. Clean water for recreational purposes was not found to be significant with either of these models. Our results demonstrate that bottle use and filter use are explained differently. We argue that more education and better communication about local tap water quality would decrease the use of bottled water. We demonstrate that household filters could be used as an alternative to bottled water.
\end{abstract}

Keywords: bottled water, communication, filters, perceptions, water quality. 


\section{Introduction}

Water is one of the most elementary resources on earth, and its access is crucial for life. In a context of population increase and global climate change, water management and water quality are becoming more and more critical (World Bank 2016). In parallel, bottled water consumption globally has increased significantly over the past two decades (Doria 2010; Hu et al. 2011; Varga 2011; Guadayol et al. 2016). Recent literature has identified different factors that explain variations in tap water quality perceptions, in some cases resulting in the search for alternatives and the use of bottled water (Doria 2006; Doria et al. 2009; Zivin et al. 2011). When comparing tap water in Texas with one brand of bottle water, Raj (2005) found that the tap water was safer because of the presence of anti-bacteriological agents not found in the bottled water. More recent literature also indicates that tap water is more strictly controlled than bottled water in the U.S. (Hu et al. 2011; Zivin et al. 2011). In this regard, Raj explained that tap water is regulated by the U.S. Environmental Protection Agency while bottled water is controlled by the U.S. Food and Drug Administration. However, many studies have found that bottled water is perceived by the general public as having better quality, fewer health risks and better taste than tap water (Anadu \& Harding 2000; Raj 2005; Hu et al. 2011; Zivin et al. 2011).

The 2014 Elk River spill, in West Virginia, represents an example where the population was placed in a position of risk from tap water consumption (Whelton et al. 2015). In addition, Zivin et al. (2011) wrote that alternatives to tap water consumption increased when water-related incidents occurred in the US, having direct consequences on the economy through the use of bottled water and filters. Hu et al. (2011) added that risk perceptions can go both ways and that incidents related to certain brands of bottled water have impacts on the consumption of these 
products. In fact, the literature points to the fact that water quality perceptions are affected by organoleptic perceptions (i.e. taste, odor and color) and health risk perceptions (Doria 2006). These two latter factors are related, as the literature shows that health risk perceptions are significantly associated with organoleptic perceptions (Turgeon et al. 2004; Doria 2006; Hu et al. 2011; Proulx et al. 2012). In addition, Hu et al. (2011) found that perceptions regarding both surface water quality (i.e. streams, rivers and lakes) and groundwater water quality in the immediate geographic area of respondents' homes significantly impacted the perceptions of the tap water quality. Socio-economic factors were found to be significant in multiple studies when related to the use of bottled water (Doria 2006; O'Donnell \& Rice 2012; Akpinar \& Gul 2014). For example, Akpinar \& Gul (2014) found that lower income would predict the absence of bottle use in Turkey. Still other studies (Abrahams et al. 2000; O’Donnell \& Rice 2012) found that non-white populations were more likely to use bottled water in the US. Added to these factors, Espinosa-García et al. (2014) explained that a high level of bottled water use in Mexico was also due to misinformation and marketing of bottled water companies. These different results suggest important differences between countries and regions. According to the International Bottle Water Association (2013), it takes 1.39 liters of water to make 1 liter of bottled water in the US. Still other literature suggests the environmental cost (i.e. fabrication, transport, pollution) associated with bottled water consumption is significantly high (Hu et al. 2011; Saylor et al. 2011; Van Der Linden 2015). Thus, in a context of reduced freshwater availability at a global scale, combined with global climate change, people who are more concerned about the environment favor less using bottled water (Saylor et al. 2011; Merkel et al. 2012; Van Der Linden 2015). Besides, environmental risks associated with human activities such as mining and gas drilling can increase risk perceptions linked with drinking tap water (Merkel et al. 2012). In the case of the 
Appalachia Region, human activities have played a major role in that environmental risk, historically as a result of coal mining, and now with the expansion of natural gas extraction (Sams III \& Beer 2000; Higginbotham et al. 2010; Underwood et al. 2014). Therefore, concern about the environment seems to be relevant in defining bottled water use in the US.

\section{Study Purpose}

Though bottled water use has been widely studied, the frameworks utilized by researchers vary considerably, with focuses ranging from health to economics (Doria 2010). In contrast, filter use has received less attention in the literature. For example, Dupont et al. (2010) focused on health risks related to filter use, while Abrahams et al. (2000) used an economics approach. Our study aims to understand residents' perceptions of tap water quality, and to understand the factors that predict bottled water and filter use in a mid-sized city in northcentral West Virginia. We propose to analyze filter use and to contrast it with bottle use, utilizing a non-economical approach, similar to Doria et al. (2009) and Hu et al. (2011). Using Doria et al.' s variables, we replicated items related to perceived water quality, perceived health risks and organoleptic perceptions. Building on $\mathrm{Hu}$ et al., we explore how clean water and its link to recreation, environmental concern and satisfaction with living in the area predict the uses of bottled water and filters. As recreation is important in West Virginia, it seemed reasonable to test the presence or absence of relationship between recreation and tap water quality (West Virginia Division of Tourism 2012). Tested in various studies, environmental concern seemed to be of interest in studying tap water quality, especially regarding the context of West Virginia and its recent chemical spill (Merkel et al. 2012; Saylor et al. 2011; Whelton et al. 2015). Satisfaction with living in the area was based 
on Syme and Williams (1993), as they found that Australian residents who had a positive perception of water quality were significantly more satisfied with the area where they lived.

More precisely, we defined the following hypotheses:

H1: Higher perceived health risks, lower perceived water quality, lower organoleptic perceptions of the tap water and lower satisfaction with living in the area were hypothesized to increase the likelihood of bottle and filter use.

H2: Respondents who indicated higher importance for clean water for recreation and who perceived local streams, rivers and lakes as having a poor water quality were hypothesized to be more likely to use bottled water and filters.

H3: A higher level of environmental concern was hypothesized to decrease the use of bottled water and to increase the use of filters.

H4: Based on several studies, we hypothesized that women, younger generations, higher incomes and lower education were more likely to use bottles and filters. Higher incomes were especially thought to have better opportunity to purchase alternatives to drinking tap water (Sjöberg, 2000).

\section{Methods}

Study Area

The city of Morgantown (WV) and its suburban area was chosen in order to conduct the survey. This area represents about 90,000 residents (total population). Morgantown Utility Board is responsible for pumping the water from the Monongahela River, treating and distributing the tap 
water in the surveyed area. In that respect, Morgantown can be considered to have a medium density housing.

\section{Data Collection}

A questionnaire survey was designed by our expertise at West Virginia University, under the Appalachian Freshwater Initiative, funded by the National Science Foundation. A sample of 5,492 residents of Morgantown (WV) and suburban areas were randomly drawn by the thirdparty contractor who provided the database. These residents were asked to take part in an online survey regarding their home tap water quality. The data were collected between November 2015 and January 2016. The targeted residents received a first invitation by e-mail followed by four reminders; 3 days, 13 days, 30 days and 45 days after the first invitation. Using a separate database available from West Virginia University, 184 residents were randomly prompted to participate in a mail back survey (Dillman et al. 2014). These residents received a post card announcing the survey, followed by two mail-back surveys, with one week separating each (Dillman et al. 2014). The mail-back letter included a cover letter, the survey instrument, and a self-addressed stamped envelope. Combining these two methods, 557 respondents answered the online survey while 46 respondents answered the mail back survey. A total of 603 residents completed the survey, reaching a response rate of $11.3 \%$ (after deleting false addresses). The targeted adult population was 77,500 residents (adult population). The sample size reached the necessary 385 responses needed for analyses (Dillman et al. 2014).

\section{Survey Design}


The questionnaire asked residents about the perceived water quality of their home tap water, the associated perceived health risks generated by tap water consumption, the organoleptic perceptions with it, items related to their environmental concern (Syme \& Williams 1993; Dutcher et al. 2007; Doria et al. 2009). The respondents were also asked their perceptions of the surface water quality in local lakes and rivers, the importance of clean water for recreation and their satisfaction with living in the area, similar to previous research (Syme \& Williams 1993; Hu et al. 2011; Smith \& Desvousges 2012). A 5-pt Likert scale was used to measure levels of agreement: (1) strongly disagree, (2) disagree, (3) neutral, (4) agree and (5) strongly agree. Scales were created by combining several items. The Cronbach's $\alpha$ was employed to measure the reliability of the scales, with any value above .70 indicating appropriate consistency of the scales (Vaske 2008).

The following items were used to produce these scales:

- perceived health risks scale (Doria et al. 2009) combining four items, "There are health risks associated with drinking tap water in my home", "I don't believe there is any possibility of becoming ill from drinking water straight from the tap" (reverse coded), "There are so many chemicals and additives in my home tap water that it must be unhealthy", "My home tap water would not harm anybody" (reverse coded) (Cronbach's $\alpha=.840$ );

- perceived water quality scale (Syme \& Williams 1993; Doria et al. 2009) combining two items, "I don't believe the quality of my home tap water is so bad that it needs improvement," "My tap water is usually of high quality" (Cronbach's $\alpha=.810$ ); 
- organoleptic scale (Doria et al. 2009) combining three items, "I am happy with the taste of my tap water," "I am happy with the color of my tap water," "I am happy with the odor of my tap water" (Cronbach's $\alpha=.882$ );

- environmental concern scale (Dutcher et al. 2007) combining five items, "If things continue on their present course, we will soon experience a major ecological catastrophe," "The problems of the environment are not as bad as most people think" (reverse coded), "We are quickly using up the world's natural resources," "People worry too much about human progress harming the environment" (reverse coded), "We are spending too little money on improving and protecting the environment," (Cronbach's $\alpha=.867)$;

- area satisfaction scale (Syme \& Williams 1993) combining two items, "If I had the opportunity, I'd rather live in another area" (reverse coded), "In general, I would be happy living in this area for the next 15 years," (Cronbach's $\alpha=.792)$.

A clean water for recreation scale (Smith \& Desvousges 2012) was based on a 5-pt Likert scale measuring different levels of importance with (1) being not at all important, (2) somewhat not important, (3) neutral, (4) somewhat important and (5) very important. The five items composing the scale were: "Clean water for my own recreation on/in water is...," "Clean water for my potential future recreational use is...," "Preserving clean water for future generations is...," "Satisfaction from knowing that there is clean water is...," "Satisfaction from knowing that others can enjoy clean water for recreation is...," (Cronbach's $\alpha=.828)$.

Respondents were asked to rate the surface water quality in local streams, lakes and rivers (based on Hu et al. 2011) with a 5-pt. Likert scale: (1) very poor, (2) poor, (3) fair, (4) good, and (5) excellent. Respondents were also asked whether they primarily purchase bottled water for their 
drinking purposes by the use of a yes/no question (based on Hu et al. 2011). Using a similar dichotomous choice, respondents were asked to indicate whether they were using a filter when drinking water from the tap. The survey instruments also included items designated to gather demographic data.

\section{Data Processing and Analysis}

The data were analyzed using Statistical Package for the Social Sciences (SPSS) version 24. In order to understand what factors predict the use of bottled water and the use of water filters, two logistic regression models were used. Demographics were included in the models: income, age, gender and level of education were expected to influence the use of bottles or filters according to previous literature. The scales defined in the previous section were created based on Vaske (2008) using the mean of the other items in the scale in order to reduce missing data and create more accurate scales. Perception of the surface water quality and income were missing data ( $n=34$ and $n=76$, respectively). We replaced the missing data with the mean of the variables (Vaske 2008). This technique has the disadvantage of diminishing estimations of $\mathrm{R}^{2}$ but seems a reasonable approach for these two variables (Vaske 2008). The different variables used for the two logistic regressions were as follows: the perceived health risks scale, perceived water quality scale, organoleptic scale, environmental concern scale, area satisfaction scale, perception of surface water quality, clean water for recreation, as well as gender, age, income and education. Since previous studies indicate strong significant prediction of perceived water quality from perceived health risks and organoleptic perceptions (Doria et al. 2009), the assumption of multicollinearity was checked and was not found to be of concern. However, even though multicollinearity was not high among these variables (Variance Inflation Factor below 3), initial 
testing of the logistic regression model that included the perceived water quality scale resulted in a poor fitting model and suppression effects on other variables. This scale was removed for these analyses. More research in the testing of this scale using Structural Equation Modeling showed that multicollinearity occurred between perceived water quality, perceived health risks and organoleptic perceptions (Levêque and Burns, 2017).

\section{Limitations}

Non-response bias was checked by comparing responses from individuals who answered the survey after the first survey invitation with responses from those who answered the survey after the last reminder (Israel 2011). No significant differences were found either in individual items or within the demographics. In addition, a comparison of the data from this study and the U.S. Census Bureau (2016) demographics data was made, showing the respondents in this study were somewhat different from the local population. More women (56\%) answered the survey than the actual population (48\%), and income was higher within this database than seen in the general population. Although the survey was designed using Dillman et al. (2014) to increase the response rate, biases present in the sample are the result of a low response rate that typically affects web surveys (Sax et al. 2003). By using two different data collection methods, we searched for biases and found that mail-back respondents $(n=46)$ were older, reported higher income levels, were more educated, and had generally higher perceptions of water quality than the respondents from the web-survey. However, when controlling for this group during the analyses, the results were similar and indicated the same pattern.

The consequence of these biases is not considered to be of large magnitude for two reasons: (1) we are interested in understanding the relationship between variables, which is less affected by 
non-response bias than univariate variables analyses (Blair \& Zinkhan 2006); and (2) with 45 days between the first respondents and the last respondents, the method used to test non-response bias is said to be reliable (Blair \& Zinkhan 2006; Dillman et al. 2014).

\section{Results}

Descriptive summary of the sample

Table 4: Demographics from the sample under study.

\begin{tabular}{|c|c|c|c|c|}
\hline Demographic & & & & \\
\hline variable & $n$ & $\%$ & $M$ & $S D$ \\
\hline Female & 326 & 56 & & \\
\hline Age & 584 & & 51.74 & 13.91 \\
\hline $18-29$ & 32 & 5 & & \\
\hline $30-39$ & 105 & 18 & & \\
\hline $40-49$ & 116 & 20 & & \\
\hline $50-59$ & 151 & 25 & & \\
\hline $60-69$ & 120 & 20 & & \\
\hline $70-79$ & 50 & 8 & & \\
\hline $80+$ & 9 & 1 & & \\
\hline Household income & 527 & & $\$ 89.051$ & / \\
\hline
\end{tabular}




\begin{tabular}{|c|c|c|}
\hline$\$ 0-\$ 24,999$ & 27 & 5.1 \\
\hline$\$ 25,000-\$ 49,999$ & 98 & 18.6 \\
\hline$\$ 50,000-\$ 74,999$ & 102 & 19.4 \\
\hline$\$ 75,999-\$ 99,999$ & 86 & 14.2 \\
\hline$\$ 100,000-\$ 149,999$ & 125 & 20.7 \\
\hline$\$ 150,000$ or more & 89 & 14.7 \\
\hline Education & & \\
\hline Some high school & 4 & .7 \\
\hline High school graduate & 49 & 8.3 \\
\hline Some college & 96 & 16.3 \\
\hline Two-year college & 50 & 8.5 \\
\hline Four-year college & 166 & 28.2 \\
\hline Graduate or professional degree & 223 & 37.9 \\
\hline
\end{tabular}

Table 1 summarizes the main demographics of the respondents. A total of $37 \%$ of the respondents indicated that they primarily used bottled water for their drinking purposes. Over half of the respondents (58\%) affirmed they used a filter when drinking from the tap. Almost half of the respondents (46\%) affirmed that they agreed or strongly agreed with being happy with the taste, color and odor of their tap water. A majority of respondents (60\%) disagreed or strongly 
disagreed with statements related to risk perceptions associated with drinking water from the tap (mean $=2.64)$, indicating that most respondents thought there were not many health risks involved with drinking from the tap. Respondents felt rather neutral about the environment (mean $=3.44$ ), with $21 \%$ agreeing or strongly agreeing with the proposed statements (high environmental concern) and 9\% disagreeing or strongly disagreeing with the statements (low environmental concern). A majority of respondents (60\%) agreed or strongly agreed with items related to their satisfaction with living in the area. Regarding the perceived surface water quality, respondents felt rather neutral (mean $=3.21$ ) with $43 \%$ evaluating the water quality of lakes, rivers and streams as fair. Most respondents felt strongly about the importance of clean water for recreation $($ mean $=4.70)$, with $57 \%$ of respondents who indicated that the statements were very important to them.

\section{Logistic regression model 1: Predicting bottled water use}

Logistic regression was conducted to assess whether the demographic variables and the water quality perceptions significantly predicted the use of bottled water for drinking purposes. The assumptions of independence of observations and the linearity of independent variables with the $\log$ of the dependent variable were met. The model predicts whether a respondent uses bottled water $\left(\chi^{2}=123.55, d f=10, p<.001\right)$. Table 2 presents the odds ratios that suggest that the odds of drinking bottled water significantly decrease as education, organoleptic perceptions and environmental concern scores increase. Specifically, the odds of drinking bottled water deteriorate by 0.78 per unit increase of education, by 0.46 per unit increase of organoleptic perceptions and by 0.76 per unit increase of environmental concern. In contrast, as the score of perceived health risks increases by one unit, the odds of drinking bottled water significantly 
increase by 1.36. Interestingly, gender, age, income, area satisfaction, perceived surface water quality and clean water for recreation were not significant in modifying the odds of drinking bottled water. The Nagelkerke pseudo $\mathrm{R}^{2}$ indicates a moderate strength of the model in predicting the use of bottled water by respondents (see Table 2). The Hosmer and Lemeshow test of good fit is non-significant, indicating a good model fit $\left(\chi^{2}=5.89, d f=8, p=.659\right)$.

Table 2: Summary of Logistic Regression Analysis Predicting Drinking Bottled Water $(N=555)$

\begin{tabular}{|c|c|c|c|c|c|c|}
\hline & & & & & Wald & \\
\hline Predictor & $B$ & $S E$ & $O R$ & $95 \% C I$ & statistic & $p$ \\
\hline Female & 0.08 & 0.21 & 1.09 & {$[0.72,1.66]$} & 0.17 & .678 \\
\hline Age & -0.01 & 0.01 & 0.99 & {$[0.97,1.00]$} & 3.28 & .070 \\
\hline Income & -0.01 & 0.07 & 0.99 & {$[0.86,1.15]$} & 0.01 & .917 \\
\hline Education & -0.25 & 0.08 & 0.78 & {$[0.67,0.91]$} & 10.16 & .001 \\
\hline $\begin{array}{c}\text { Perceived } \\
\text { health risks }\end{array}$ & 0.31 & 0.15 & 1.36 & {$[1.01,1.85]$} & 3.99 & .046 \\
\hline $\begin{array}{c}\text { Organoleptic } \\
\text { perceptions }\end{array}$ & -0.77 & 0.14 & 0.46 & {$[0.35,0.61]$} & 28.89 & $<.001$ \\
\hline $\begin{array}{r}\text { Environmental } \\
\text { concern }\end{array}$ & -0.27 & 0.13 & 0.76 & {$[0.59,0.98]$} & 4.46 & .035 \\
\hline
\end{tabular}




\begin{tabular}{r|cccccc} 
Area & & & & & \\
Satisfaction & 0.08 & 0.12 & 0.93 & {$[0.73,1.17]$} & 0.40 & .525 \\
Perceived & & & & & & \\
surface water & 0.04 & 0.14 & 1.04 & {$[0.79,1.38]$} & 0.08 & .773 \\
quality & & & & & & \\
Clean water for & 0.49 & 0.25 & 1.64 & {$[0.99,2.69]$} & 3.79 & .051 \\
recreation & & & & & & \\
\hline Pseudo $R^{2}$ & 0.274 & & & & & \\
(Nagelkerke) & & & & & & \\
& & & & & & \\
\end{tabular}

Notel. Drinking bottled water coded as $0=$ does not use bottled water, $1=$ uses bottled water.

$S E=$ standard error for regression coefficient (B). CI = confidence interval for odds ratio (OR).

Logistic regression model 2: Predicting filter use

A second logistic regression was conducted to assess whether the demographic variables and the water quality perceptions predicted the use of a filter when drinking tap water. The assumptions of independence of observations and the linearity of independent variables with the log of the dependent variable were met. The model adequately predicts whether a respondent uses a filter $\left(\chi^{2}=63.56, d f=10, p<.001\right)$. Table 3 presents the odds ratios that suggest that the odds of using a filter significantly decrease as age and organoleptic perceptions scores increase. Specifically, the odds of using a filter deteriorate by 0.99 per year gained and by 0.55 per unit increase of organoleptic perceptions. In contrast, as the score of income increases by one unit, the odds of using a filter significantly increase by 1.38. Gender, education, perceived health 
risks, environmental concern, area satisfaction and clean water for recreation were not significant in modifying the odds of using a filter when drinking tap water. The Nagelkerke pseudo $\mathrm{R}^{2}$ specifies a modest strength of the model in predicting the use of filter by respondents (see Table 3). This model was not as strong as the previous model, even though the Hosmer and Lemeshow test of good fit is non-significant, indicating a good model fit $\left(\chi^{2}=14.99, d f=8, p=.059\right)$.

Table 3: Summary of Logistic Regression Analysis Predicting Using a Filter $(N=546)$

\begin{tabular}{|c|c|c|c|c|c|c|}
\hline & & & & & Wald & \\
\hline Predictor & $B$ & $S E$ & $O R$ & $95 \% C I$ & statistic & $p$ \\
\hline Female & -0.01 & 0.19 & 0.99 & {$[0.67,1.46]$} & 0.02 & .992 \\
\hline Age & -0.01 & 0.01 & 0.99 & {$[0.97,0.99]$} & 4.28 & .039 \\
\hline Income & 0.32 & 0.07 & 1.38 & {$[1.20,1.59]$} & 20.93 & $<.001$ \\
\hline Education & -0.09 & 0.07 & 0.91 & {$[0.79,1.05]$} & 1.64 & .200 \\
\hline $\begin{array}{l}\text { Perceived } \\
\text { health risks }\end{array}$ & -0.16 & 0.15 & 0.85 & {$[0.64,1.13]$} & 1.24 & .265 \\
\hline $\begin{array}{r}\text { Organoleptic } \\
\text { perceptions }\end{array}$ & -0.59 & 0.14 & 0.55 & {$[0.42,0.73]$} & 17.48 & $<.001$ \\
\hline $\begin{array}{r}\text { Environmental } \\
\text { concern }\end{array}$ & 0.02 & 0.12 & 1.02 & {$[0.82,1.29]$} & 0.04 & .834 \\
\hline
\end{tabular}




\begin{tabular}{|c|c|c|c|c|c|c|}
\hline $\begin{array}{r}\text { Area } \\
\text { Satisfaction }\end{array}$ & 0.03 & 0.12 & 1.03 & {$[0.82,1.30]$} & 0.07 & .795 \\
\hline Perceived & & & & & & \\
\hline $\begin{array}{r}\text { surface water } \\
\text { quality }\end{array}$ & -0.26 & 0.13 & 0.77 & {$[0.59,1.00]$} & 3.71 & .054 \\
\hline $\begin{array}{r}\text { Clean water for } \\
\text { recreation }\end{array}$ & -0.04 & 0.21 & 0.96 & {$[0.64,1.45]$} & 0.03 & 0.859 \\
\hline $\begin{array}{c}\text { Pseudo R } \\
\text { (Nagelkerke) }\end{array}$ & 0.148 & & & & & \\
\hline
\end{tabular}

Note 2. Using a filter coded as $0=$ does not use a filter, $1=$ uses a filter. SE $=$ standard error for regression coefficient $(B) . C I=$ confidence interval for odds ratio $(O R)$.

\section{Discussion}

Our first logistic regression model shows that education, environmental concern, organoleptic perceptions and health risk perceptions are predictors of bottled water use. Validating part of our hypothesis (H1), our findings illustrate that organoleptic perceptions represent the most important predictor of bottle use, as indicated by much previous literature (Anadu \& Harding 2000; Saylor et al. 2011; Zivin et al. 2011; Huerta-Saenz et al. 2012). Regarding education and health risk perceptions, the literature is rather divided regarding these results. On one hand, Levallois et al. (1999) found no significant relationship between bottled water use and health risk perceptions. Conversely, Hu et al. (2011) and Abrahams et al. (2000) found a significant relationship with risk perceptions but did not find education to be significant in predicting bottled 
water use. Our results indicate that lower levels of education predict the use of bottled water, which confirms one of the hypotheses present in (H4) and replicates the findings of Dupont et al. (2010) in their sample of Canadian household residents. Together with the fact that health risk perceptions are predicting bottle use (confirming $\mathrm{H} 1$ ), our results highlight the need for education about water quality concerns. By having the right information, citizens can make informed decisions on their drinking behaviors. Nonetheless, Dupont et al. warned that information must be explicit, since less educated people are less likely to find and make the right interpretation of the information given. As mentioned earlier, Espinosa-Garcia et al. (2014) showed that marketing and miscommunication in Mexico led to higher levels of bottled water consumption. Means (2002) also made a link between marketing of bottled water companies who advertise for higher water quality, and higher sales of bottled water in the US. De Giglio et al. (2015, p.63) mentioned that recent marketing strategies of bottled water companies consist in promoting "eco-friendly" bottles to attract people who have higher environmental concern. As hypothesized in (H3), we demonstrated that environmental concern has a significant impact in the use of bottled water, contrasting with $\mathrm{Hu}$ et al. (2011), but similar to other studies (Saylor et al. 2011; Merkel et al. 2012; Van Der Linden 2015). For example, Saylor et al. (2011) proposed the creation of a campaign focusing on the environmental impacts of plastic bottles in order to influence behaviors. Accordingly, it is the role of scientists, public authorities, and ultimately water companies to decide what type of information is provided to the public to influence behaviors (Sagoff 2013). In our study gender was not found to be a significant predictor, similar to Dupont et al.'s study, but contrasting with Hu et al. and Saylor et al. where women were found to drink significantly more bottled water than men. Our analyses revealed that age is not significant in predicting the use of bottled water, in line with Dupont et al. but differing from $\mathrm{Hu}$ 
et al. Satisfaction with living in the area does not predict bottle use, not finding evidence to support our hypothesis (H1).

Our second model was expected to be similar to the bottled water model. For instance, organoleptic perceptions were very important in predicting both behaviors: using bottled water or filters. This is in line with previous literature where bottled water and filtered water was perceived as having better organoleptic qualities (Anadu \& Harding 2000; Saylor et al. 2011; Zivin et al. 2011; Huerta-Saenz et al. 2012). In a 2007 survey in Canada, the main reason that households used filters was to improve organoleptic perceptions (Statistics Canada 2009). Turgeon et al. (2004) wrote that organoleptic perceptions may differ from the water treatment plant to the tap of the consumers. In this sense, the state of the distribution system may alter the quality of the tap water (Turgeon et al. 2004). Filters are used to neutralize taste, color and odor, indicating the same concern as bottled water users. Nonetheless, a major difference with the bottled water model is that income characterizes the most important variable predicting filter use, while income is not significant in predicting bottle use. Our findings suggest that the more income households have, the more likely they are to buy filters. This result is similar to Abrahams et al. (2000). In addition, age significantly explains the use of filters, replicating the findings of Abrahams et al. and $\mathrm{Hu}$ et al. Health risk perceptions are not significant in the second model, which indicates that bottle use and filter use are explained differently. While organoleptic perceptions both play a role in explaining these behaviors, education, environmental concern and risk perceptions only apply to bottle use. In the US, several studies explained that bottled water can pose some health-related issues among children who do not have a sufficient amount of fluoride in their household water, in contrast to tap water (Lalumandier \& Ayers 2000; HuertaSaenz et al. 2012). In that sense, filter use enables children to receive their fluoride intake. Even 
though the use of filters seems to offer a solution to organoleptic perceptions of the tap water, it seems to pose inequalities as more affluent households may be more likely to afford these filters. The fact that age is linked with filter use in the second model can indicate that certain audiences may be targeted. Here again, education might be helpful in determining the water quality to help the general public in understanding the quality of their tap water.

In West Virginia, a long history of extractive industries may possibly increase risk perceptions associated with drinking tap water. Notably, the 2014 Elk River spill in Charleston (WV) and the miscommunication that emerged during that crisis may have increased risk perceptions linked with tap water consumption (Zivin et al. 2011, Zivin \& Neidell 2013; Whelton et al. 2015). After two and a half years, the U.S. National Toxicology Program (2016, p.1) produced its final update about the risks involved with the raw content of this spill and found that "exposure at or below the screening level is considered not likely to be associated with any adverse health effects." This statement demonstrates that the tap water is safe to drink. However, Zivin et al. (2011) showed that catastrophes such as the Elk River spill or the lead contamination in Flint (MI) increase the number of bottled water sales in the US resulting from an avoidance behavior. In parallel, Dupont and Jahan (2012) found that these avoidance behaviors (purchasing bottled water or using filters) varied across regions in Canada, ranging from $\$ 34$ per household per year in Quebec versus $\$ 60$ in Ontario. These authors showed that memorability can affect behaviors since Ontario saw a water contamination of E. Coli in 2000 (Dupont \& Jahan 2012). In consequence, health risks and avoidance behaviors have ramifications on the economy and on the environment.

Our results are important because they showcase the dissimilarities between bottled water use and filter use. For instance, these results show evidence that organoleptic perceptions are their 
common predictor but that risk perceptions, environmental concern and education only affect bottle use. Income and age affect solely filter use. Our findings suggest that a substitution of bottle use by filter use is possible in the case of organoleptic perceptions but that communication and education efforts are needed to diminish bottle use. It is important to deliver messages that effectively communicate the factual quality differences between drinking tap water and bottled water. In addition, these results suggest that filter use can be an alternative to bottle use. A reduction in filter prices could enhance the shift toward filter use instead of bottled use. It could also be part of a campaign to advocate for the use of filters to increase the organoleptic qualities of the tap water.

Additionally, our results indicate that the importance of clean water for recreational activities does not predict bottle or filter uses, nor does perceptions of the water quality of streams, rivers or lakes in the local area. These are interesting results in terms of perceptions and how they affect the psychology of drinking water since the tap water from this municipality comes from a local river. Our results show that communication efforts regarding tap water quality might not need to include surface water quality to affect drinking behaviors. This may also indicate that most residents do not know where their water is coming from. This highlights the need to better inform Morgantown residents on the origin of their water. In the US, a 2001 national survey indicated that $86 \%$ of the respondents expressed some concern regarding their tap water quality, suggesting the need for more information given to the general public (Means 2002). Van der Linden (2015) found that specific normative-induced messages would have the greatest reduction in bottled water use. Means (2002) called for better marketing strategies from municipal water suppliers in order to re-assure the general public. In addition, Queiroz et al. (2012) added the role of media as an important tool for communicating water quality issues. As 
suggested by Dupont and Jahan (2012), infrastructure planning and investments should be made in accordance with the needs of the general public, together with delivering the right information. Nonetheless, our results must be interpreted with caution as the survey was conducted in an area that did not suffered from a large-scale chemical spill, as was seen in Charleston (WV). This indicates that further studies with larger geographic areas may find regional differences with the perceived water quality of the rivers, streams or lakes and its importance for recreation and whether they affect bottle and filter consumptions.

\section{Conclusion and implications}

In conclusion, our study aimed at understanding the differences between bottle use and filter use as well as the roles of perceptions of surface water quality and clean water for recreation to predict these uses. The examination of two logistic regression models to test the factors predicting bottle use and filter use as alternatives to tap water use showed that organoleptic perceptions are very important for the general public. Previous literature (Anadu \& Harding 2000; Raj 2005; Hu et al. 2011; Zivin et al. 2011) found that taste is especially responsible for bottled water use, which was verified in our study. Examined in parallel with the second model, it is possible to say that filters could be an alternative for the use of bottled water. If better information and education programs are displayed to the general public about the tap water quality, and efforts to promote filter use as alternatives to low organoleptic perceptions, the consumption of bottled water could decrease, reducing its environmental impacts (Saylor et al. 2011). Interestingly, perceptions of clean water for recreation and surface water quality were not found to be valid predictors for either of the two dependent variables, invalidating our hypothesis 
(H2). Our study as well demonstrated that income is a strong predictor of filter use: perhaps lower costs of filters could lead to a higher demand of filters. Further economic studies could estimate the willingness to pay for filter use.

Two main implications of our results are that (1) public institutions and leaders should work together to communicate effectively about the safety of the tap water quality, about the environmental costs of bottled water; and to promote the use of filters as a substitute for bottled water; and (2) the use of clean water for recreation to bolster communication strategies in drinking water might not be effective, as there is no link between clean water for recreation or perceptions of surface water quality and water drinking behavior.

\section{Limitations}

Limitations to this study (other than the ones addressed in the methods section) include factors that were not measured within the survey, such as trust in specific actors (e.g. media, local government, water provider) or past experiences with contamination. In addition, this study only represents residents of Morgantown. More studies should repeat this survey to other areas in order to compare and have a larger picture of drinking behaviors.

\section{Acknowledgments and Disclaimer}

Funding of this study was made possible thanks to US National Science FoundationExperimental Program to Stimulate Competitive Research (through WV-HEPC-Division of Science and Research) and the National Institute of Food and Agriculture (NIFA). The funding source had no involvement in study design; in the collection, analysis and interpretation of data; 
in the writing of the report; or in the decision to submit the article for publication. Free and informed consent was asked from participants or their legal representatives was obtained. Our study protocol was approved by the Committee for the Protection of Human Subjects (West Virginia University Institutional Review Board IRB), by West Virginia University, West Virginia, United States, protocol No.1510895135, November 2015.

\section{References}

Abrahams N. A., Hubbell B. J. \& Jordan J. L. 2000 Joint production and averting expenditure measures of willingness to pay: do water expenditures really measure avoidance costs?. American Journal of Agricultural Economics, 82(2), 427-437.

Anadu E. C. \& Harding A. K. 2000 Risk perception and bottled water use. American Water Works Association Journal, 92(11), 82.

Akpinar M. G. \& Gul M. 2014 An assessment of consumer preferences on the drinking water market: today to the future. Journal of Water Supply: Research and Technology-Aqua, 63(7), $525-531$.

Blair, E., \& Zinkhan, G. M. 2006 Nonresponse and generalizability in academic research. Journal of the Academy of Marketing Science, 34(1), 4-7.

De Giglio O., Quaranta A., Lovero G., Caggiano G. \& Montagna M. T. 2015 Mineral water or tap water? An endless debate. Annali di Igiene, 27, 58-65.

Dillman D. A., Smyth J. D. \& Christian L. M. 2014 Internet, phone, mail, and mixed-mode surveys: The tailored design method. John Wiley \& Sons. 
Doria M. F. 2006 Bottled water versus tap water: Understanding consumers' preferences. Journal of Water and Health, 4(2), 271-276.

Doria M. F. 2010 Factors influencing public perception of drinking water quality. Water Policy, 12(1), 1-19.

Doria M. F., Pidgeon N. \& Hunter P. R. 2009 Perceptions of drinking water quality and risk and its effect on behaviour: A Cross-National Study. Science of the Total Environment, 407(21), $5455-5464$.

Dupont D., Adamowicz W. L. \& Krupnick A. 2010 Differences in water consumption choices in Canada: the role of socio-demographics, experiences, and perceptions of health risks. Journal of Water and Health, 8(4), 671-686.

Dupont D. P. \& Jahan N. 2012 Defensive spending on tap water substitutes: the value of reducing perceived health risks. Journal of Water and Health, 10(1), 56-68.

Dutcher D. D., Finley J. C., Luloff A. E. \& Johnson, J. B. 2007 Connectivity with nature as a measure of environmental values. Environment and behavior, 39(4), 474-493.

Espinosa-García A. C., Díaz-Ávalos C., González-Villarreal F. J., Val-Segura R., MalvaezOrozco V. \& Mazari-Hiriart M. 2015 Drinking water quality in a Mexico City University community: Perception and preferences. EcoHealth, 12(1), 88-97.

Guadayol M., Cortina M., Guadayol J. M. \& Caixach J. 2016 Determination of dimethyl selenide and dimethyl sulphide compounds causing off-flavours in bottled mineral waters. Water Research, 92, 149-155. 
Higginbotham A., Pellillo A., Gurley-Calvez T. \& Witt T. S. 2010 The economic impact of the natural gas industry and the Marcellus shale development in West Virginia in 2009. Morgantown (WV): West Virginia University.

Hu Z., Morton L. W. \& Mahler R. L. 2011 Bottled water: United States consumers and their perceptions of water quality. International Journal of Environmental Research and Public Health, 8(2), 565-578.

Huerta-Saenz L., Irigoyen M., Benavides J. \& Mendoza M. 2012 Tap or bottled water: Drinking preferences among urban minority children and adolescents. Journal of Community Health, 37(1), 54-58.

International Bottle Water Association 2013 Water use benchmarking study. Antea Group, IBWA. Retrieved from http://www.bottledwater.org/files/IBWA\%20Water\%20Use\%20Benchmarking\%20Report\%20\%20Exec\%20Summary\%20FINAL\%20102113.pdf\#overlay-context=reports-studies. (Accessed 20 April 2016).

Israel G. D. 2011 Sampling issues: Nonresponse. PEOD9. Gainesville, FL: Agricultural Education and Communication Department, University of Florida. Retrieved from http://edis.ifas.ufl.edu/pd008. (Accessed 14 April 2016).

Lalumandier J. A. \& Ayers L. W. 2000 Fluoride and bacterial content of bottled water vs tap water. Archives of Family Medicine, 9(3), 246-250.

Levallois P., Grondin J. \& Gingras S. 1999 Evaluation of consumer attitudes on taste and tap water alternatives in Quebec. Water Science and Technology, 40(6), 135-139. 
Levêque, J. G., \& Burns, R. C. (2017). A Structural Equation Modeling approach to water quality perceptions. Journal of Environmental Management, 197, 440-447.

Means E. G. 2002 Drinking water quality in the new millennium: the risk of underestimating public perception. American Water Works Association Journal, 94(8), 28-34.

Merkel L., Bicking C. \& Sekhar D. 2012 Parents' perceptions of water safety and quality. Journal of Community Health, 37(1), 195-201.

O’Donnell C. \& Rice R. E. 2012 A communication approach to campus bottled water campaigns. Social Marketing Quarterly, 18(4), 255-273.

Proulx F., Rodriguez M. J., Sérodes J. B. \& Bouchard C. 2012 Spatio-temporal variability of tastes and odors of drinking water within a distribution system. Journal of Environmental Management, 105, 12-20.

Queiroz J. T. M., Rosenberg M. W., Heller L., Zhouri A. L. M. \& Silva S. R. 2012 News about tap and bottled water: Can this influence people's choices? Journal of Environmental Protection, 3, 324-333.

Raj S. D. 2005 Bottled water: How safe is it?. Water Environment Research, 77(7), 3013-3018.

Sagoff M. 2013 What does environmental protection protect?. Ethics, Policy \& Environment, 16(3), 239-257.

Sams III J. I. \& Beer K. M. 2000 Effects of coal-mine drainage on stream water quality in the Allegheny and Monongahela River basins - Sulfate transport and trends. (Water-Resources Investigations Report No. 99-4208). Lemoyne (PA): U.S. Geological Survey, National WaterQuality Assessment Program. 
Sax L. J., Gilmartin S. K. \& Bryant A. N. 2003 Assessing response rates and nonresponse bias in web and paper surveys. Research in Higher Education, 44(4), 409-432.

Saylor A., Prokopy L. S. \& Amberg S. 2011 What's wrong with the tap? Examining perceptions of tap water and bottled water at Purdue University. Environmental Management, 48(3), 588601.

Sjöberg, L. (2000). Factors in risk perception. Risk analysis, 20(1), 1-12.

Smith V. K. \& Desvousges W. H. 2012 Measuring water quality benefits (3rd ed.). Springer Science \& Business Media.

Statistics Canada 2009 Households and the environment survey (HES) (Report No. 11-526-X). Ottawa (ON): Statistics Canada. Retrieved from http://www.statcan.gc.ca/pub/11-526-x/11-526x2011001-eng.pdf. (Accessed 16 June 2016).

Syme G. J. \& Williams K. D. 1993 The psychology of drinking water quality: An exploratory study. Water Resources Research, 29(12), 4003-4010.

Turgeon S., Rodriguez M. J., Thériault M. \& Levallois P. 2004 Perception of drinking water in the Quebec City region (Canada): The influence of water quality and consumer location in the distribution system. Journal of Environmental Management, 70(4), 363-373.

Underwood B. E., Kruse N. A. \& Bowman J. R. 2014 Long-term chemical and biological improvement in an acid mine drainage-impacted watershed. Environmental Monitoring and Assessment, 186(11), 7539-7553. 
U.S. Census Bureau 2016 2010-2014 American community survey 5-Year Estimates. Retrieved from http://factfinder.census.gov/faces/nav/jsf/pages/community_facts.xhtml\#. (Accessed 22 May 2016).

U.S. National Toxicology Program 2016 NTP research program on chemicals spilled into the Elk River in West Virginia: Final update. Retrieved from

http://ntp.niehs.nih.gov/ntp/research/areas/wvspill/wv_finalupdate_july2016_508.pdf. (Accessed 10 July 2016).

Van Der Linden S. 2015 Exploring beliefs about bottled water and intentions to reduce consumption the dual-effect of social norm activation and persuasive information. Environment and Behavior, 47(5), 526-550.

Varga L. 2011 Bacteriological quality of bottled natural mineral waters commercialized in Hungary. Food Control, 22(3), 591-595.

Vaske J. J. 2008 Survey research and analysis: Applications in parks, recreation and human dimensions. State College, PA: Venture Publishing.

West Virginia Division of Tourism 2012 West Virginia ten-year tourism plan. AECOM and Mary Means + associates. Retrieved from https://gotowv.com/wpcontent/uploads/2015/09/AECOM-West-Virginia-Final-Report.pdf. (Accessed 30 September 2016).

Whelton A. J., McMillan L., Connell M., Kelley K. M., Gill J. P., White K. D., Gupta R., Dey R. \& Novy C. 2015 Residential tap water contamination following the Freedom Industries chemical spill: Perceptions, water quality, and health impacts. Environmental Science \& Technology, 49(2), 813-823. 
World Bank 2016 The critical face of climate change - Water. Washington D.C.: International Bank for Reconstruction and Development/the World Bank.

Zivin J. G. \& Neidell M. 2013 Environment, health, and human capital. Journal of Economic Literature, 51(3), 689-730.

Zivin, J. G., Neidell M. \& Schlenker W. 2011 Water quality violations and avoidance behavior: Evidence from bottled water consumption. American Economic Review, 101(3), 448-453. 


\title{
Chapter IV: Article 3
}

\section{A Structural Equation Modeling Approach to Water Quality Perceptions}

\author{
Jonas G. Levêque,
}

\author{
Robert C. Burns
}

(Article published in the Journal of Environmental Management, Elsevier, 2017, Volume 197, pp. 440-447)

\begin{abstract}
Researches on water quality perceptions have used various techniques and models to explain relationships between specific variables. Surprisingly, Structural Equation Modelling (SEM) has received little attention in water quality perceptions studies, and reporting has been inconsistent among existing studies. One objective of this article is to provide readers with a methodological example for conducting and reporting SEM. Another objective is to build a model that explains the different relationships among the diverse factors highlighted by previous studies on water quality perceptions. Our study focuses on the factors influencing people's perceptions of water quality in the Appalachian region. As such, researchers have conducted a survey in a mid-sized city in northcentral West Virginia to assess residents' perceptions of water quality for drinking and recreational purposes. Specifically, we aimed to understand the relationships between perceived water quality, health risk perceptions, organoleptic perceptions, environmental concern, area satisfaction and perceptions of surface water quality. Our model provided a good fit that explained about $50 \%$ of the variance in health risk perceptions and $43 \%$ of the variance in
\end{abstract}


organoleptic perceptions. Environmental concern, area satisfaction and perceived surface water quality are important factors in explaining these variances. Perceived water quality was dismissed in our analysis due to multicollinearity. Our study demonstrates that risk communication needs to be better addressed by local decision-makers and water managers.

Keywords: Water Quality Perceptions, Structural Equation Modeling, West Virginia.

\section{Introduction}

A large amount of public researches in developing countries have demonstrated evidence of a misconception regarding tap water quality. For instance, many studies reported that the general public believes bottled water to be of higher quality, to have lower health risks and to taste better than tap water (Anadu and Harding, 2000; Hu et al., 2011; Raj, 2005; Zivin et al., 2011).

Researchers identified several factors that explain the variation of public perceptions of tap water quality (Doria, 2010; Syme and Williams, 1993). More specifically, several studies showed that perceived tap water quality is positively influenced by organoleptic perceptions and negatively influenced by health risk perceptions, with health risk perceptions being negatively influenced by organoleptic perceptions (Doria et al., 2005; Proulx et al., 2012; Turgeon et al., 2004). Different methods of analysis have been used in the past to investigate water quality perceptions, but only a few studies proposed the use of a Structural Equation Modeling (SEM) approach: Doria et al. (2005, 2009). Notably, these two studies did not investigate the relationships between tap water quality perceptions and other factors such as environmental concern. In fact, several studies have linked environmental concern, perceptions of the water quality of streams, rivers and lakes or ground water quality in the area with tap water quality perceptions (Hu et al., 2011; Merkel et al., 2012; Syme and Williams, 1993). Including these variables in an SEM model increases current 
knowledge on water quality perceptions as SEM is a technique that can assess different relationships between variables at the same time (Hu and Bentler, 1999; Kline, 2015). Ultimately, SEM is used to analyze the discrepancy function between the covariance matrix of the sample under study and the fitted covariance matrix by a specified model that is based on these relationships (Hu and Bentler, 1999). This technique is a powerful statistical tool because it accounts for measurement error in the model, which is not possible in traditional regression approaches (Kline, 2015). Additionally, SEM allows researchers to investigate direct and indirect paths in their models (Kline, 2015).

In West Virginia, water management is critical, as many different human activities have the potential to affect the water quality. The Elk River pollution that occurred in Charleston (West Virginia) in early 2014 is an example of water contamination that directly impacted residents and their use of tap water (Whelton et al., 2015). In the context of global climate change and population growth, water management appears to be one of the most challenging issues for the $21^{\text {st }}$ century (World Bank, 2016). Yet, the impacts of water quality are many, not only for ecosystems but also for populations (World Bank, 2016). Merkel et al. (2012) demonstrated that environmental risks associated with human activities such as mining and gas drilling can increase risk perceptions linked with drinking tap water. In contrast to natural disaster risks, these risks are linked to technological risks (Flint and Luloff, 2005). Therefore, implementing preventive measures and risk management can reduce the likelihood of these risks. As a result, public risk perceptions may increase or decrease support for preventive measures and lead to behavioral changes. In comparison, Fessenden et al. (1987) explained the psychology of water consumption for US citizens: "if people have seen, tasted, or smelled something different about their water, whether or not the change is related to the contamination, they tend to exaggerate the 
risk. But if their own senses have given them no clue that a problem exists, people may feel that the risk they are being told about has been exaggerated" (p.97).

\section{Study purpose}

In summary, a first goal of our study is to help other researchers by designing an SEM model with an analyses report that follows SEM guidelines. Hurlimann et al. (2008) pointed to the existence of variability among the studies that report SEM results. A second goal of our study is to explain the water quality perceptions in a community of West Virginia. In order to proceed, we build on Doria et al.'s SEM model (2009) and propose to modify it by adding other factors such as environmental concern (Dutcher et al., 2006; Syme and Williams, 1993), area satisfaction (Syme and Williams,1993), and the perceived surface water quality (Hu et al., 2011). We created the item "the likelihood of a chemical spill" in order to better understand risk perceptions. Results of this study will help further research in the region and will enable targeting risk communication and general communication about water quality and environmental protection. These are important factors in a period of elections.

More specifically, we were interested in investigating the following relationships:

Hypothesis 1: Perceived water quality (PWQ) is negatively influenced by perceived health risks (PHR) (Doria et al., 2005), the likelihood of a chemical spill (CS) and environmental concern (EC) (Dutcher et al. 2007); positively influenced by organoleptic perceptions (OR) (Doria et al., 2005), the perceived surface water quality in the area (PSWQ), the satisfaction with living in the area (AS) (Syme and Williams, 1993) and the context (CTX) (Doria et al., 2005). 
Hypothesis 2: Perceived health risks are negatively influenced by organoleptic perceptions, the perceived surface water quality in the area, the satisfaction with living in the area and the context; positively influenced by environmental concern the likelihood of a chemical spill.

Hypothesis 3: Organoleptic perceptions are negatively influenced by the likelihood of a chemical spill and environmental concern; positively influenced by the perceived surface water quality in the area and the satisfaction with living in the area.

Hypothesis 4: Context is positively influenced by organoleptic perceptions (Doria et al., 2009) and we supposed it is also negatively influenced by environmental concern.

Hypothesis 5: The likelihood of a chemical spill is negatively influenced by the satisfaction with living in the area and the perceived surface water quality in the area; positively influenced by environmental concern.

Hypothesis 6: The perceived surface water quality in the area is positively influenced by the satisfaction with living in the area and negatively influenced by environmental concern.

The following conceptual model was proposed: 


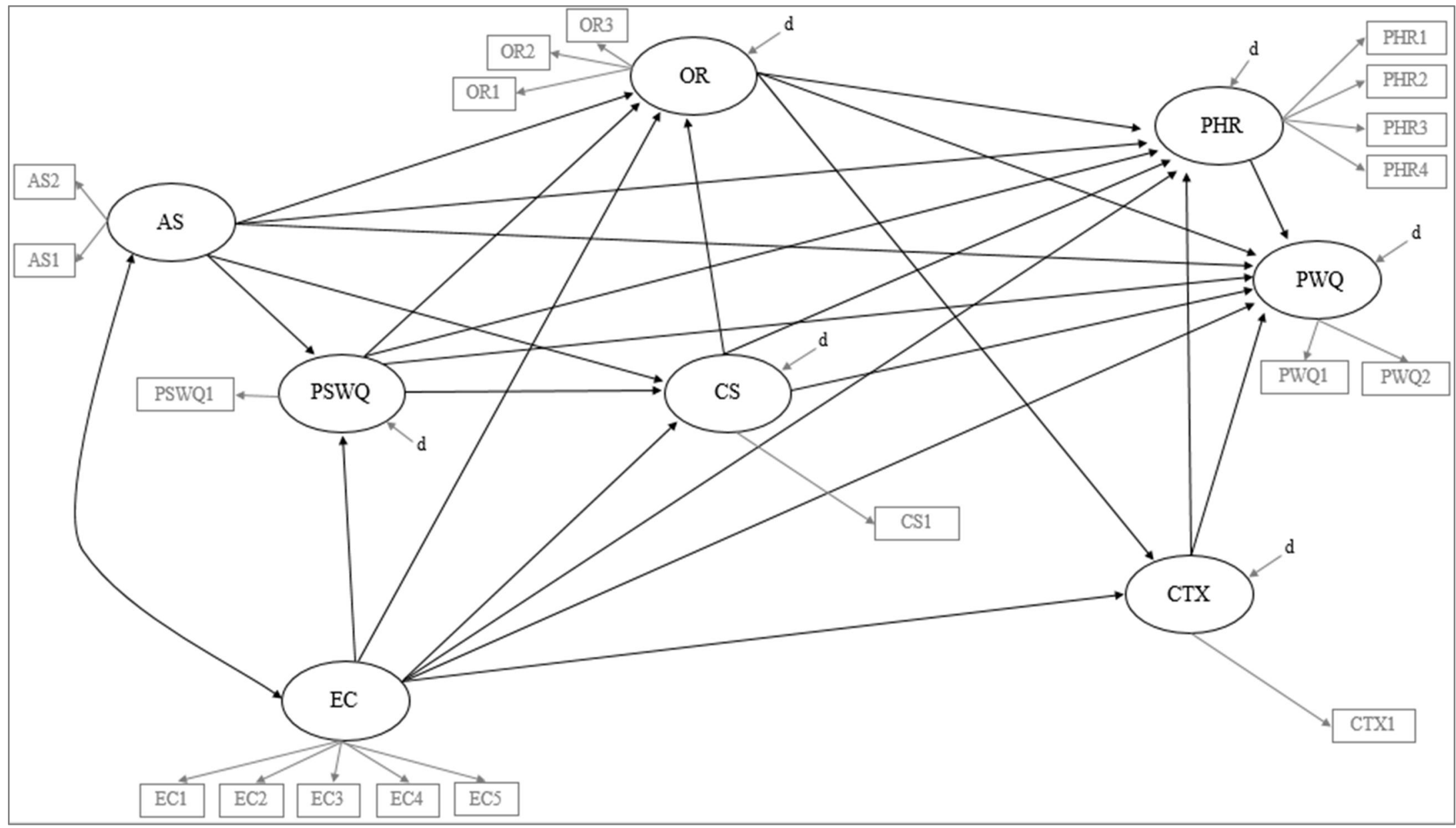

Figure 1: Full Structural Model. Latent constructs are shown in ellipses. Observed variables are shown in rectangles. $d$ represents the disturbances from the endogenous latent constructs. 
A description of the items used can be found in Appendix B (online supplementary content).

\section{Methods:}

\subsection{Data collection}

In order to test our model, we conducted a survey in northcentral West Virginia from November 2015 to January 2016. A sample of residents were randomly selected from a medium-sized city with an approximate population of 77,500 residents (see map in Appendix C, supplementary content). A mail-back survey was sent to 184 residents from a West Virginia University database, while an online survey was sent to another 5,492 residents from a third-party database. Later analyses of the results showed that there were no significant differences between the two survey methods for the variables of interest. A total of 603 residents completed the survey, achieving a $11.3 \%$ response rate. A non-response bias check was conducted comparing early respondents with late respondents, as suggested by Israel (1992). No significant differences were found. As the focus of the study is to build an SEM model, a non-response bias has less consequence than when analyzing univariate variables (Blair and Zinkhan, 2006). In addition, studies have shown that our non-response bias is reliable since we had a 45 -day delay between initial and final respondents (Blair and Zinkhan, 2006; Dillman et al. 2014).

\subsection{Results reporting}

As noted by Hurlimann et al. (2008), there exists an important variety of ways to report SEM results, depending on researchers and journals. We used several recommendations from different sources throughout the following sections, especially from McDonald and Ho (2002). 


\subsection{Data processing and analysis}

\subsubsection{Software used}

In order to investigate the nature of the different relationships developed through our hypotheses, we used the SEM software LInear Structural RELations (LISREL) 9.2, developed by Jöreskog and Sörbom. The SEM method was explicitly chosen because it allows the integration of error into the model, contrary to regression approaches that make the assumption of the perfect measurement of items (Kline, 2015). The Software Package for Social Sciences (SPSS) version 24 was utilized for the initial treatment of the data.

\subsubsection{Missing data and outliers' treatment}

As a result of missing values, the effective sample size achieved under listwise deletion was $\mathrm{n}=$ 567 , corresponding to $5.9 \%$ missing data. Since missing data can affect parameter estimates (Vaske, 2008), we decided to use an imputation method. Following warnings of Jöreskog and Sörbom (1996), we used the Expectation-Maximization (EM) method available in PRELIS (treatment software from LISREL) (Du Toit and Mels, 2002; Lin, 2010). After inspecting missing data, we detected a total of 22 multivariate outliers using the Mahalanobis distance with SPSS (IBM Corp., 2016). As different techniques in handling outlier detection exist, we chose to create one dataset with outliers $(n=603)$ and another dataset without outliers $(n=581)$ and to look at the models' chi-squares and fit indices in LISREL during the measurement testing (Aguinis et al., 2013). Our results indicated no significant difference in chi-square, with fit indices that were slightly better for the dataset containing the outliers. Individual parameter estimates did not change significantly. Therefore, we decided to keep the model with more data, $\mathrm{n}=603$. According to Schumacker and Lomax (2004), our sample size (in both cases) was large 
enough to develop a model using SEM following the recommendation of 20 responses per variable in the model; using 19 observed variables and 8 latent constructs in our model (see Appendix A), our sample size met this criterion. The different inter-correlations, means and standard deviations of the observed variables can be found online within the supplementary content (Appendix B).

\subsubsection{Normality}

An investigation of the descriptive statistics under PRELIS indicated the presence of univariate and multivariate non-normality. Because multivariate normality is an important assumption in

SEM, we chose to use an estimation method that would be robust to non-normality (Finney and Distefano, 2006; Kline, 2015; McDonald and Ho, 2002). As such, we used the Robust Maximum-Likelihood estimation method under LISREL, using the Satorra-Bentler corrected (SB) chi-square and fit indices. This estimation method has been found to correctly measure parameter estimates and to "outperform the ML-based chi-square" (Finney and Distefano, 2006, p.290).

\subsection{Model building}

This section describes the analyses and steps that were taken to assess and correct the performance of our model, especially in terms of reliability and validity.

\subsubsection{Model comparison / goodness of fit}

Since the chi-square test is sensitive to sample size, resulting in model rejection with $\mathrm{p}<0.05$, we added other fit indices to describe the model fit (Jöreskog and Sörbom, 1993). Precisely, the Comparative Fit Index (CFI), the Root Mean Square of Error of Approximation (RMSEA) and 
the Standardized Root Mean Square Residual (SRMR) were chosen, following recommendations from Kline (2015). As the CFI and the RMSEA are based on the S-B chi-square, the SRMR is based on the discrepancies between the observed correlations and the estimated correlations (Kline, 2015). Nonetheless, the chi-square difference test was used to compare nested models. Since we used a Satorra-Bentler chi-square, the estimation did not follow a normal chi-square distribution. Using Bryant and Satorra (2012), a re-scaling of the S-B chi-square was made possible for model comparison.

\subsubsection{Single-indicators}

For practical reasons and following items measured in previous researches (Doria et al., 2009; $\mathrm{Hu}$ et al., 2011), three of the latent constructs were measured using a single-item indicator. Sometimes seen as problematic in an SEM approach, an extensive review and discussion on the topic from Petrescu (2013) shows that single-item indicators can be used when precisely corrected. Since Doria et al. (2009) did not report the use of single-item indicators, and no other study used these items in an SEM approach, we followed the recommendations of Petrescu by setting the measurement error to [0.95* variance], based on SEM literatures (Kline, 2015; Thompson, 2000). Using Schumacker and Lomax's recommendations (2004) of a modification formula of [(1-reliability) * variance of the indicator], and using a conservative value of 0.85 for the reliability according to Jöreskog and Sörbom (1982), the single indicators were corrected as shown in Table 1 (when testing for influential outliers, these corrections were recalculated for each model). 
Table 1: Corrected measurement errors and error variances for single-item indicators (model with $n=603$ ).

\begin{tabular}{lcc} 
& Corrected measurement error & Corrected error variance \\
\hline CS1 & 0.93005 & 0.14685 \\
CTX1 & 0.76095 & 0.12015 \\
PSWQ1 & 0.67735 & 0.10695 \\
\hline
\end{tabular}

3.4.3. Construct validity: convergence and discriminant validity

In order to determine convergence validity, we tested whether the loadings of the observed variables on their latent constructs were above 0.70 within the measurement model (Farrell and Rudd, 2009). The standardized loading of the observed variable EC5 on the environmental concern construct was not reliable (loading $=0.60$ ), with a measurement error of 0.64 , indicating $64 \%$ of the variance was imputed to error (Fornell and Larcker, 1981). Since this item did not load correctly on its latent construct, we removed it from the analyses. The next step consisted in testing the reliability at the latent level. Using Fornell and Larcker (1981), we computed the construct reliability (CR) for the different latent constructs (see table 2). All of the constructs were found to be reliable (greater than 0.70). For single-indicator latent constructs, CR and AVE are equal, simply representing the squared standardized factor loading of the indicator on its latent construct. This is also the conservative value of 0.85 that Jöreskog and Sörbom (1982) recommended.

Regarding discriminant validity, or how a latent construct is significantly distinguishable from another latent construct, we used the method proposed by Fornell and Larcker (1981). The method consists in comparing the Average Variance Explained (AVE) with the squared 
correlations of the different latent constructs: the AVE of each construct should be larger than the squared correlation between two constructs (Fornell and Larcker, 1981).

Table 2: Construct Reliability (CR), Average Variance Extracted (AVE) and squared correlations for latent constructs.

\begin{tabular}{lcccccccc}
\hline & PHR & AS & CS & PWQ & CTX & OR & EC & PSWQ \\
\hline CR & 0.84 & 0.80 & 0.85 & 0.82 & 0.85 & 0.89 & 0.87 & 0.85 \\
PHR & $\mathbf{0 . 5 8}$ & & & & & & & \\
AS & 0.39 & $\mathbf{0 . 6 7}$ & & & & & & \\
CS & 0.20 & 0.15 & $\mathbf{0 . 8 5}$ & & & & & \\
PWQ & 0.83 & 0.44 & 0.17 & $\mathbf{0 . 6 9}$ & & & & \\
CTX & 0.15 & 0.08 & 0.05 & 0.12 & $\mathbf{0 . 8 5}$ & & & \\
OR & 0.55 & 0.38 & 0.10 & 0.79 & 0.12 & $\mathbf{0 . 7 4}$ & & \\
EC & 0.11 & 0.09 & 0.16 & 0.14 & 0.03 & 0.06 & $\mathbf{0 . 6 3}$ & \\
PSWQ & 0.29 & 0.26 & 0.15 & 0.35 & 0.03 & 0.28 & 0.14 & $\mathbf{0 . 8 5}$ \\
\hline
\end{tabular}

Note 1: AVE values are represented in bold for each latent construct, grayed cells indicate issues.

According to Table 2, it is possible to see that the latent construct Perceived Water Quality (PWQ) indicates issues of multicollinearity. This could be suspected from Appendix B when looking at the inter-item correlations, as PWQ1 and PWQ2 both have high correlations with other items. In order to solve the issue, we removed this latent construct from further analyses. Therefore, Hypothesis 1 was rejected. This has implications that are discussed later in this paper.

\subsubsection{Model re-specification}

Since PWQ was removed from the analyses, we re-specified the measurement model, and as such tested for convergence and discriminant validity in the new model. Analyses showed that 
two indicators within the Perceived Health Risk construct did not satisfy the condition of convergence validity with loadings less than 0.70: PHR1 and PHR4 were removed from this model. After deletion, the construct reliability was higher for PHR and the construct reliabilities for the other latent constructs were still satisfactory (see Table 3). These were deemed "very good", according to Kline (2015, p.92). No issues were encountered when testing for AVE, satisfying the validity of our model (see Table 3 ).

Table 3: Construct Reliability (CR), Average Variance Extracted (AVE) and squared correlations for latent constructs, for final model.

\begin{tabular}{lccccccc}
\hline & PHR & AS & CS & CTX & OR & EC & PSWQ \\
\hline CR & 0.87 & 0.80 & 0.85 & 0.85 & 0.89 & 0.87 & 0.85 \\
PHR & $\mathbf{0 . 7 7}$ & & & & & & \\
AS & 0.29 & $\mathbf{0 . 6 6}$ & & & & & \\
CS & 0.13 & 0.15 & $\mathbf{0 . 8 5}$ & & & & \\
CTX & 0.14 & 0.08 & 0.04 & $\mathbf{0 . 8 5}$ & & & \\
OR & 0.39 & 0.36 & 0.10 & 0.11 & $\mathbf{0 . 7 4}$ & & \\
EC & 0.08 & 0.10 & 0.16 & 0.03 & 0.06 & $\mathbf{0 . 6 3}$ & \\
PSWQ & 0.24 & 0.26 & 0.15 & 0.03 & 0.27 & 0.14 & $\mathbf{0 . 8 5}$ \\
\hline Note 2: AVE values are represented in bold for each latent construct. & & & & & \\
\hline
\end{tabular}

Note 2: AVE values are represented in bold for each latent construct.

\subsubsection{Two-indicator constructs}

After convergent and discriminant validities were assessed and validated, there were two latent constructs that had only two reflective indicators instead of the three recommended in SEM analyses (Kline, 2015). The solution to account for this issue in SEM is to fix the two factor loadings equal. Four different models were established with and without these restrictions (see 
Table 4). The examination of the chi-square difference tests proved that model $\mathrm{C}$ was not significantly different from model D, which was significantly better than model A, which was not significantly different from model B. Model C was favored, indicating that we needed to fix the loadings of PHR2 and PHR3 equally. The loadings of AS1 and AS2 did not need to be set equally.

Table 4: Model with and without restrictions on two-factor loadings.

$$
\text { PHR2 and PHR3 equal PRH2 and PHR3 not }
$$

equal

\begin{tabular}{lll}
\hline AS1 and AS2 equal & Model A: & Model B: \\
& S-B $\chi^{2}=133.61$ & S-B $\chi^{2}=131.43$ \\
& $\mathrm{df}=61$ & Mf $=60$ \\
AS1 and AS2 not equal & Model C: & Model D: \\
& S-B $\chi^{2}=124.85$ & Sf $\chi^{2}=122.68$ \\
& df $=60$ & df $=59$
\end{tabular}

Note 3: The chi-squares are Satorra-Bentler corrected $\left(S-B \chi^{2}\right)$.

\subsubsection{Model identification}

According to Hershberger and Marcoulides (2006), our measurement model was globally overidentified since there are more equations to explain the different latent constructs than the number of latent constructs. In terms of the path model identification, we did not omit nondirected arcs (McDonald and Ho, 2002). Also, our model was found to be recursive as we tested a causal approach between the latent constructs. As such we found that the path model was identified. 


\subsubsection{Equivalent models}

Hypotheses 1, 2, 3 and 4 for the elaboration of the path model were based on theory and previous researches. Hypothesis 5 was not based on previous researches as we introduced the likelihood of a chemical spill item, but we followed the logic from previous literatures (Hu et al. 2011; Syme and Williams 1993). Hypothesis 6 had not been seen in previous literatures, but we hypothesized that the effect of environmental concern and satisfaction of living in the area would have a significant effect on perceived surface water quality. As a result, an equivalent model to our final model is one that has correlations between CS, EC, AS and PSWQ instead of direct paths. Our model provides information about direct and indirect effects allowing us to answer hypotheses 5 and 6 , unlike the equivalent model. Consequently, our final model has been retained. In fact, there is a multitude of equivalent models that replicate the same covariance matrix estimated by our model (Lee and Hershberger, 1990). Yet, it is worth noting that some of these models are diverting from previous theories, and are not representing sound causation (Kline, 2015). Sjöberg (2000) affirms that attitudes generally precede beliefs in Structural Equation Modeling. Using the replacing rule described by Lee and Hershberger (1990), several equivalent models were especially of interest in our research: models that have a covariance error that explains the relationships between the endogenous latent constructs CTX, OR and PHR. This change expresses the fact of a non-directionality in the relationship: causality between these variables is no longer assumed. Choosing the model with OR causing PHR should be preferred due to previous literatures (Doria et al., 2005, 2009; Syme and Williams, 1993) that found taste, odor or color to influence risk perceptions. In that sense, there is a precedence in time: we could expect one to try the water before making a judgement about its risk. However, one could argue 
that at the time of the survey, the risk perceptions also influenced the satisfaction with the taste, odor and color of the tap water.

\section{Results}

\subsection{Measurement model}

The measurement model (CFA) had an adequate fit, with fit indices that were within

recommendations (see Table 6), especially in the case of the use of a S-B chi-square: CFI higher than 0.95, RMSEA and SRMR lower than 0.05 (Finney and Distefano, 2006; Yu and Muthén, 2002). Since we used the S-B chi-square, the $90 \%$ confidence interval of the RMSEA was not given by LISREL. We were able to recover this using O'Boyle and Williams (2011), and their Excel datasheet. Following their recommendation, we considered a lower bound lower than 0.05 and an upper bound lower than 0.10 as good fit. Table 5 represents the factor loadings of the CFA. 
Table 5: CFA parameter estimates, and latent standardized correlations.

\begin{tabular}{|c|c|c|c|c|c|c|c|}
\hline $\begin{array}{l}\text { Latent } \\
\text { constructs }\end{array}$ & $\begin{array}{l}\text { Observed } \\
\text { variables }\end{array}$ & $\begin{array}{l}\text { Unstandardized } \\
\text { Estimates }\end{array}$ & $\begin{array}{l}\text { Unstandardized } \\
\text { Standard errors }\end{array}$ & z-values & $\begin{array}{l}\text { Standardized } \\
\text { Estimates }\end{array}$ & & \\
\hline \multirow[t]{2}{*}{ PHR } & PHR2 & 0.99 & 0.03 & 35.67 & $0.93 * * *$ & & \\
\hline & PHR3 & 0.99 & 0.03 & 35.67 & $0.81 * * *$ & & \\
\hline \multirow[t]{2}{*}{ AS } & AS1 & 0.82 & 0.05 & 17.51 & $0.78 * * *$ & & \\
\hline & AS2 & 1.00 & 0.05 & 19.83 & $0.85 * * *$ & & \\
\hline $\mathrm{CS}$ & CS1 & $0.92^{\mathrm{a}}$ & & & $0.92^{\mathrm{a}}$ & & \\
\hline CTX & CTX1 & $0.75^{\mathrm{a}}$ & & & $0.92^{\mathrm{a}}$ & & \\
\hline \multirow[t]{3}{*}{ OR } & OR1 & 1.03 & 0.03 & 31.00 & $0.82 * * *$ & & \\
\hline & OR2 & 0.78 & 0.04 & 19.70 & $0.83 * * *$ & & \\
\hline & OR3 & 1.00 & 0.03 & 28.62 & $0.92 * * *$ & & \\
\hline \multirow[t]{4}{*}{$\mathrm{EC}$} & $\mathrm{EC} 1$ & 0.91 & 0.04 & 23.25 & $0.82 * * *$ & & \\
\hline & $\mathrm{EC} 2$ & 0.95 & 0.04 & 24.37 & $0.86 * * *$ & & \\
\hline & EC3 & 0.81 & 0.04 & 19.07 & $0.75 * * *$ & & \\
\hline & $\mathrm{EC} 4$ & 0.83 & 0.04 & 20.23 & $0.74 * * *$ & & \\
\hline \multirow[t]{2}{*}{ PSWQ } & PSWQ & $0.68^{\mathrm{a}}$ & & & $0.92^{\mathrm{a}}$ & & \\
\hline & PHR & $\mathrm{AS}$ & $\mathrm{CS}$ & CTX & OR & $\mathrm{EC}$ & PSWQ \\
\hline PHR & 1 & & & & & & \\
\hline AS & $-0.55 * * *$ & 1 & & & & & \\
\hline $\mathrm{CS}$ & $0.37 * * *$ & $-0.39 * * *$ & 1 & & & & \\
\hline CTX & $-0.39 * * *$ & $0.29 * * *$ & $-0.21 * * *$ & 1 & & & \\
\hline OR & $-0.63 * * *$ & $0.60 * * *$ & $-0.31 * * *$ & $0.33 * * *$ & 1 & & \\
\hline $\mathrm{EC}$ & $0.29 * * *$ & $-0.31 * * *$ & $0.40 * * *$ & $-0.17 * * *$ & $-0.24 * * *$ & 1 & \\
\hline PSWQ & $-0.49 * * *$ & $0.51 * * *$ & $-0.38 * * *$ & $0.17 * *$ & $0.52 * * *$ & $-0.38 * * *$ & 1 \\
\hline
\end{tabular}


Table 6: Fit indices for the final model.

\begin{tabular}{lllllll}
\hline Model & $d f$ & S-B $\chi^{2}(N=603)$ & CFI & SRMR & RMSEA & 90\% CI for RMSEA \\
\hline Measurement & 60 & 124.85 & 0.98 & 0.028 & 0.042 & {$[0.031,0.052]$} \\
Path & 3 & 5.59 & 1.00 & $/$ & 0.038 & {$[0.000,0.076]$} \\
Structural & 63 & 130.45 & 0.98 & 0.029 & 0.042 & {$[0.031,0.052]$} \\
\hline
\end{tabular}

Note 5: These fit indices are the same for all of the equivalent models. 


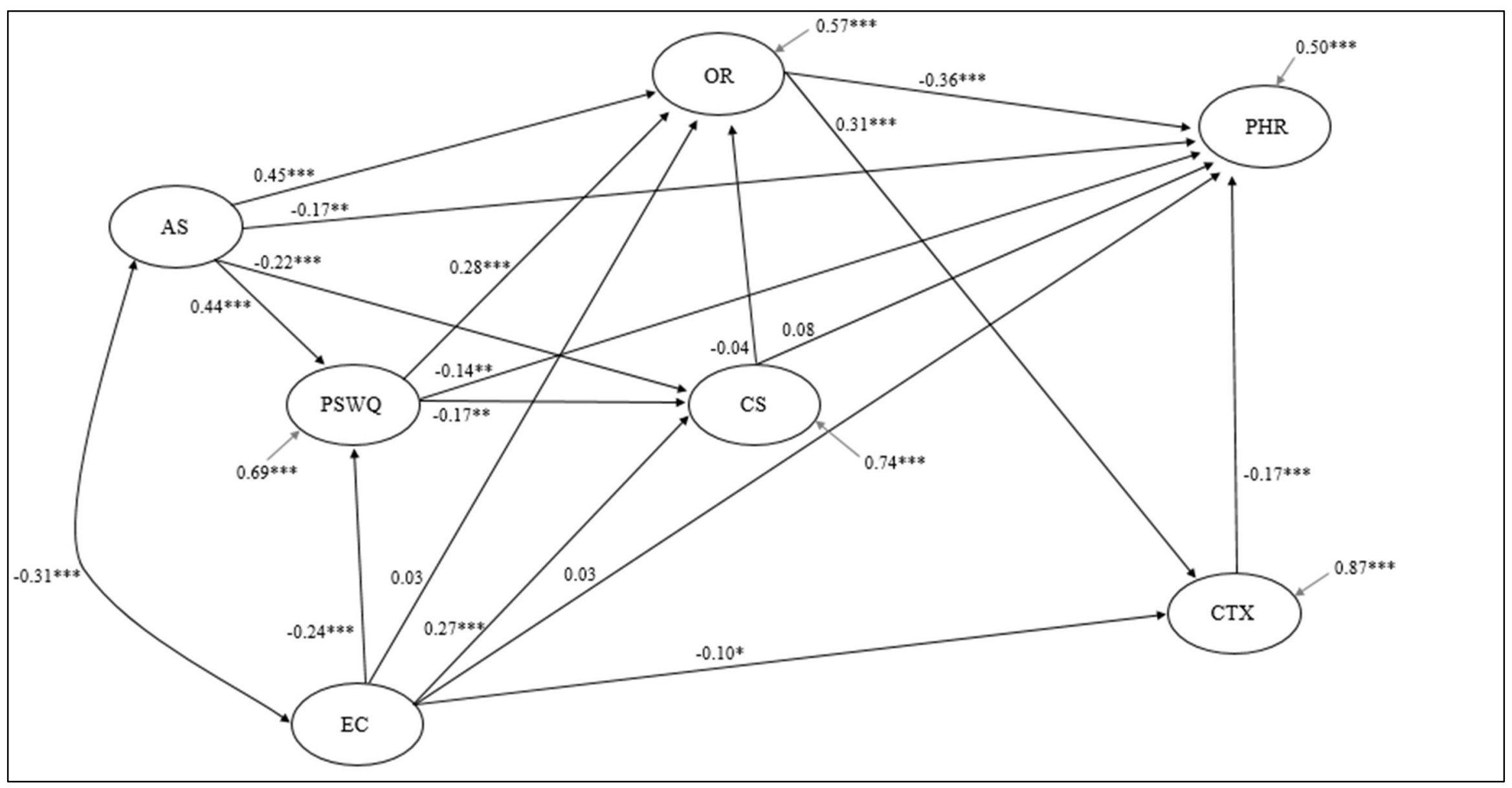

Figure 2: Path model and loadings. ${ }^{*} p<.05,{ }^{* *} p<.01,{ }^{* * *} p<.001$. Grey small arrows represent disturbances $\left(1-d=R^{2}\right)$. 


\subsection{Structural model}

The structural model had an adequate fit as well (see Table 6). Regarding the path model, we subtracted the structural model's S-B chi-square from the measurement model's S-B chi-square to find the S-B chi-square (McDonald and Ho, 2002). It is worth noting that the path model estimates fewer parameters than the measurement model, accordingly to McDonald and Ho (2002). The fit indices that are dependent on chi-square (RMSEA and CFI) were calculated and had a good fit (see Table 6). The confidence intervals of the RMSEA for the path and structural models were also recovered using O’Boyle and Williams (2011).

Figure 2 represents the path model and the different loadings among the different latent constructs. Disturbances represent the error terms, or variables that were not measured (Kline, 2015). Therefore, $1-d=R^{2}$ (Kline, 2015). According to figure 2, it is possible to say that half of the variance in perceived health risks was explained by the model $\left(\mathrm{R}^{2}=0.496\right)$. The model also explained $43 \%$ of the variance in organoleptic perceptions $\left(\mathrm{R}^{2}=0.430\right)$, a third of the variance in perceived surface water quality $\left(\mathrm{R}^{2}=0.314\right)$, a quarter of the variance in the likelihood of a chemical spill $\left(\mathrm{R}^{2}=0.258\right)$ and one-eighth of the variance of context $\left(\mathrm{R}^{2}=0.125\right)$. It is interesting to note that if most direct paths with either of the two major latent constructs (perceived health risks and organoleptic perceptions) were significant, the direct paths for likelihood of a chemical spill and the environmental concern were not significant.

\subsection{Total and indirect effects}


As noted earlier, SEM is a technique that allows the investigation of indirect paths. In this regard, LISREL prints the different effects between variables. It is worth noting, though, that the expression "indirect effects" here is the sum of the indirect effects of one variable onto another. The total effects are then the combination of indirect and direct effects. Table 7 summarizes the total and indirect effects between the different latent constructs. KSI represent exogenous latent constructs (AS and EC) while ETA represent endogenous constructs (PHR, CS, CTX, OR, PSWQ).

Table 7: Standardized total effects and (total) indirect effects of KSI and ETA on ETA.

\begin{tabular}{|c|c|c|c|c|c|c|}
\hline \multirow{2}{*}{$\begin{array}{l}\begin{array}{l}\text { Total } \\
\text { effects }\end{array} \\
\text { ETA }\end{array}$} & \multicolumn{2}{|c|}{$K S I$} & \multicolumn{4}{|c|}{$E T A$} \\
\hline & $\mathrm{AS}$ & $\mathrm{EC}$ & $\mathrm{CS}$ & CTX & OR & PSWQ \\
\hline PHR & $-0.50 * * *$ & $0.13 * * *$ & 0.10 & $-0.17 * * *$ & $-0.41 * * *$ & $-0.28 * * *$ \\
\hline CS & $-0.29 * * *$ & $0.31 * * *$ & & & & $-0.17 * *$ \\
\hline CTX & $0.18 * * *$ & $-0.12 *$ & -0.01 & & $0.31 * * *$ & $0.09 * * *$ \\
\hline OR & $0.59 * * *$ & -0.05 & -0.04 & & & $0.29 * * *$ \\
\hline PSWQ & $0.43 * * *$ & $-0.24 * * *$ & & & & \\
\hline $\begin{array}{l}\text { Indirect } \\
\text { effects }\end{array}$ & \multicolumn{2}{|c|}{$K S I$} & \multicolumn{4}{|c|}{ ETA } \\
\hline ETA & $\mathrm{AS}$ & $\mathrm{EC}$ & $\mathrm{CS}$ & CTX & OR & PSWQ \\
\hline PHR & $-0.33 * * *$ & $0.10 * * *$ & 0.02 & & $-0.05 * * *$ & $-0.13 * * *$ \\
\hline CS & $-0.07 * *$ & $0.04 *$ & & & & \\
\hline CTX & $0.18 * * *$ & -0.02 & -0.01 & & & $0.09 * * *$ \\
\hline $\begin{array}{l}\text { OR } \\
\text { PSWQ }\end{array}$ & $0.14 * * *$ & $-0.08 * * *$ & & & & 0.01 \\
\hline
\end{tabular}

\section{Discussion}

The fact that perceived water quality was removed from the model indicates a high degree of concern about the validity and reliability of the model identified by Doria et al. $(2005,2009)$. By 
using a multivariate regression analysis with multiple dependent variables, Syme and Williams (1993) indicated having high correlations between these variables and as such tested them separately. This result indicates that the items used by Doria et al. to describe water quality together with perceived health risks and organoleptic perceptions in the same model is not feasible. Our discriminant validity analysis demonstrated this issue. Solely using organoleptic perceptions and perceived health risks is encouraged for future research. Using other items to measure water quality perceptions would create a tautology effect in any sort of analyses, resulting in excessively large $\mathrm{R}^{2}$. This effect can be seen in Doria et al. (2009), with $\mathrm{R}^{2}$ of 0.86 and 0.98 for their U.K. and Portugal samples. The validity of their model appears suspect.

The fact that the item EC5 appeared to be inconsistent with the other items of the environmental concern construct is notably due to the fact that it assesses an economic question, that underlays the willingness to pay. Removing it from the analyses makes sense conceptually, as this is not a reliable item within the environmental concern construct. This result also indicates the need for research on economic valuation of water quality.

Executing adequate validity and reliability analyses enabled us to have an overall strong model after re-specification. The fit indices of the model confirmed that our model was performing well, allowing us to affirm that our results and inferences are reliable and valid.

Regarding the explained variance of the health risk perceptions, our results are similar to Doria et al. (2009). Since we added more variables to our model, our $\mathrm{R}^{2}$ is higher. The two items that were not loading correctly (PHR1 and PHR4) were not specific enough in terms of risks, demonstrating Ferrer and Klein's (2015, p.86) statement that items related to risk must be 
"threat-specific" and not generic. Concerning the explained variance of context, Doria et al. found a $\mathrm{R}^{2}$ of comparable magnitude with their U.K. sample $\left(\mathrm{R}^{2}=0.14\right)$. Context and organoleptic perceptions explained health risk perceptions in a similar fashion to Doria et al. In addition, our model explained the variance of organoleptic perceptions with a large $\mathrm{R}^{2}$, similar to health risk perceptions.

Even though the likelihood of a chemical spill was hypothesized to be significant with perceived health risks and organoleptic perceptions, these hypotheses were incorrect. This can be associated with the fact that the likelihood of a chemical spill was based on a single-item indicator, constructed by our team and not tested in previous researches. Further research that will better measure this risk could verify the relationship between this risk and water quality perceptions. Similarly, environmental concern was not significant with either perceived health risks or organoleptic perceptions when looking at the direct paths. In contrast, using a regression approach, Syme and Williams (1993) found that their environmental concern measures (slightly different from ours) significantly explained variance in health risk perceptions. Nonetheless, when looking at the indirect effects in our model, environmental concern was found to significantly explain variance in perceived health risks and in organoleptic perceptions. Besides, we found that environmental concern was significant with context. This is an interesting result because it shows that perceptions of tap water quality are not directly influenced by environmental concern in our study, but rather by indirect effects, and more precisely through the condition of the pipes and the state of the lakes, rivers and streams in the local area. Further analyses with replication of this result should be tested to enhance this theory. 
An important result from this study is the addition of the satisfaction with living in the area variable which explained a large portion of the variance in organoleptic perceptions, health risk perceptions and perceived water quality of lakes, rivers and streams in the area. This result was similar to Syme and Williams (1993). In parallel and comparable to Hu et al.'s study (2011), we found that perceived water quality of lakes, rivers and streams in the area significantly predicted the health risk perceptions and organoleptic perceptions. These relationships notably explain some of the significant indirect effects found earlier for environmental concern. Interestingly, environmental concern and satisfaction with living in the area were significantly negatively correlated. This indicates that the more respondents are satisfied with living in the area, the less they are concerned about the environment and the less they perceive health risks associated with the consumption of their tap water. This result has implications for risk communication, and for water managers.

Previous studies have suggested a gap between water quality perceptions and the actual water quality measured by instruments (Fessenden et al., 1987; Syme and Williams, 1993). Our results increase the evidence that communication is key in indicating the real risk that can affect populations. These results call for more and better targeted education on water quality in West Virginia.

\section{Conclusions}

Water quality is one of the world's most important challenges of the $21^{\text {st }}$ Century. Our study is an example that the public's perceptions of water quality are complex. Using more recent statistical methods, such as SEM, provide further insight into the factors affecting water quality 
perceptions. Our paper has been designed following SEM reporting guidelines, setting an example for other researchers.

Our model demonstrates that water quality perceptions and especially health risk perceptions associated with drinking tap water are based on various factors that need to be understood for risk communication to be efficient. Our results bring evidence to support that different populations/point of views may need different messages. In the current period of administration shifts, this is especially important for water management and local decision-makers. Further studies will be performed to replicate this model at a larger scale.

\section{Limitations}

Several limitations affect this study. The location of the study implies that it represents solely this place and as such, more work is needed to explore these results at a larger scale and to compare areas that are more rural within West Virginia, or outside West Virginia. Besides, other factors can explain variance in risk perceptions: the model leaves $50 \%$ of variance not explained. For example, trust in certain media, state or local agencies or government could be of interest in future studies.

\section{Acknowledgments}

We would like to thank the US National Science Foundation-Experimental Program to Stimulate Competitive Research (through WV-HEPC-Division of Science and Research) under the Award Number 145852 and the National Institute of Food and Agriculture (NIFA) for the funding of this study. 
We would also like to thank Dr. Gerhard Mels and Dr. Mark Gavin for their advice on technical issues in SEM, as well as two anonymous reviewers.

\section{Disclaimer}

The funding source had no involvement in study design; in the collection, analysis and interpretation of data; in the writing of the report; or in the decision to submit the article for publication. Free and informed consent was asked from participants or their legal representatives was obtained. Our study protocol was approved by West Virginia University Institutional Review Board IRB, by West Virginia University, West Virginia, United States, protocol No.1510895135, November 2015.

\section{References}

Aguinis, H., Gottfredson, R. K., Joo, H., 2013. Best-practice recommendations for defining, identifying, and handling outliers. Organizational Research Methods, 16(2), 270-301.

Anadu, E. C., Harding, A. K., 2000. Risk perception and bottled water use. American Water Works Association Journal, 92(11), 82.

Blair, E., Zinkhan, G. M., 2006. Nonresponse and generalizability in academic research. Journal of the Academy of Marketing Science, 34(1), 4-7.

Bryant, F. B., Satorra, A. 2012. Principles and practice of scaled difference chi-square testing. Structural Equation Modeling: A Multidisciplinary Journal, 19(3), 372-398. 
Dillman D. A., Smyth J. D., Christian L. M., 2014. Internet, phone, mail, and mixed-mode surveys: The tailored design method. John Wiley \& Sons.

Doria, M. F., 2010. Factors influencing public perception of drinking water quality. Water Policy, 12(1), 1-19.

Doria, M. F., Pidgeon, N., Hunter, P. R., 2009. Perceptions of drinking water quality and risk and its effect on behaviour: A Cross-National Study. Science of the Total Environment, 407(21), 5455-5464.

Doria, M. F., Pidgeon, N., Hunter, P. R., 2005. Perception of tap water risks and quality: a structural equation model approach. Water Science and Technology, 52(8), 143-149.

Du Toit, S. H. C., Mels, G., 2002. Supplementary Notes on Multiple Imputation. Scientific Software International, Inc. Chicago, Illinois.

Dutcher, D. D., Finley, J. C., Luloff, A. E., Johnson, J. B., 2007. Connectivity with nature as a measure of environmental values. Environment and behavior, 39(4), 474-493.

Farrell, A. M., Rudd, J. M., 2009. Factor analysis and discriminant validity: A brief review of some practical issues. Anzmac.

Ferrer, R. A., \& Klein, W. M. (2015). Risk perceptions and health behavior. Current opinion in psychology, 5, 85-89.

Fessenden-Raden, J., Fitchen, J. M., Heath, J. S., 1987. Providing risk information in communities: Factors influencing what is heard and accepted. Science, Technology, \& Human Values, 12(3/4), 94-101. 
Fornell, C., Larcker, D. F., 1981. Evaluating structural equation models with unobservable variables and measurement error. Journal of marketing research, 39-50.

Finney, S. J., DiStefano, C., 2006. Non-normal and categorical data in structural equation modeling, in Hancock, G. R., Mueller, R. O. (Eds.). Structural Equation Modeling: A Second Course. Information Age Publishing Inc., pp.269-314.

Flint, C. G., Luloff, A. E., 2005. Natural resource-based communities, risk, and disaster: An intersection of theories. Society and Natural Resources, 18(5), 399-412.

Hershberger, S. L., Marcoulides, G. A., 2006. The problem of equivalent structural models, in Hancock, G. R., Mueller, R. O. (Eds.). Structural Equation Modeling: A Second Course. Information Age Publishing Inc., pp.13-41.

Hu, L., Bentler, P. M., 1999. Cutoff Criteria for Fit Indexes in Covariance Structure Analysis: Conventional Criteria Versus New Alternatives. Structural Equation Modeling, 6(1), 1-55.

Hu, Z., Morton, L. W., Mahler, R. L., 2011. Bottled water: United States consumers and their perceptions of water quality. International Journal of Environmental Research and Public Health, 8(2), 565-578.

Hurlimann, A., Hemphill, E., McKay, J., Geursen, G., 2008. Establishing components of community satisfaction with recycled water use through a structural equation model. Journal of Environmental Management, 88(4), 1221-1232.

IBM Corp. Released 2016. IBM SPSS Statistics for Windows, Version 24.0. Armonk, NY: IBM Corp. 
Israel, G. D., 1992. Sampling Issues: Nonresponse. University of Florida Cooperative Extension Service, Institute of Food and Agriculture Sciences, EDIS.

Jöreskog, K. G., Sörbom, D., 1982. Recent developments in structural equation modeling. Journal of marketing research, 404-416.

Jöreskog, K., Sörbom, D., 1993. LISREL 8: Structural Equation Modeling with the SIMPLIS Command Language. Scientific Software International, Inc.

Jöreskog, K. G., Sörbom, D., 1996. PRELIS 2 User's Reference Guide: A Program for Multivariate Data Screening and Data Summarization: a Preprocessor for LISREL. Scientific Software International, Inc.

Kline, R. B., 2015. Principles and Practice of Structural Equation Modeling, fourth ed. Guilford Publications.

Lee, S., Hershberger, S., 1990. A simple rule for generating equivalent models in covariance structure modeling. Multivariate Behavioral Research, 25(3), 313-334.

Lin, T. H., 2010. A comparison of multiple imputation with EM algorithm and MCMC method for quality of life missing data. Quality \& quantity, 44(2), 277-287.

McDonald, R. P., Ho, M. H. R., 2002. Principles and practice in reporting structural equation analyses. Psychological methods, 7(1), 64.

Merkel, L., Bicking, C., Sekhar, D., 2012. Parents' perceptions of water safety and quality. Journal of Community Health, 37(1), 195-201. 
O'Boyle Jr, E. H., \& Williams, L. J., 2011. Decomposing model fit: Measurement vs. theory in organizational research using latent variables. Journal of Applied Psychology, 96(1), 1-12. Excel datasheet available at:

https://www.researchgate.net/publication/265167230_O'Boyle_Williams_RMSEA-

P_CI_calculator

Petrescu, M., 2013. Marketing research using single-item indicators in structural equation models. Journal of Marketing Analytics, 1(2), 99-117.

Proulx, F., Rodriguez, M. J., Sérodes, J. B., Bouchard, C., 2012. Spatio-temporal variability of tastes and odors of drinking water within a distribution system. Journal of Environmental Management, 105, 12-20.

Raj, S. D., 2005. Bottled water: How safe is it?. Water Environment Research, 77(7), 3013-3018.

Schumacker, R.E., Lomax, R.G., 2004. A Beginner's Guide to Structural Equation Modeling. Lawrence Erlbaum Associates. New Jersey.

Sjöberg, L. (2000). Factors in risk perception. Risk analysis, 20(1), 1-12.

Syme, G. J., Williams, K. D., 1993. The psychology of drinking water quality: An exploratory study. Water Resources Research, 29(12), 4003-4010.

Thompson, B., 2000. Ten commandments of structural equation modeling. In US Dept of Education, Office of Special Education Programs (OSEP) Project Directors' Conference, 1998, Washington, DC, US; A previous version of this chapter was presented at the aforementioned 
conference and at the same annual conference held in 1999. American Psychological Association.

Turgeon, S., Rodriguez, M. J., Thériault, M., Levallois, P., 2004. Perception of drinking water in the Quebec City region (Canada): The influence of water quality and consumer location in the distribution system. Journal of Environmental Management, 70(4), 363-373.

Vaske, J. J., 2008. Survey research and analysis: Applications in parks, recreation and human dimensions. State College, PA: Venture Publishing.

Whelton, A. J., McMillan, L., Connell, M., Kelley, K. M., Gill, J. P., White, K. D., Gupta, R., Dey, R., Novy, C., 2015. Residential tap water contamination following the Freedom Industries chemical spill: Perceptions, water quality, and health impacts. Environmental Science \& Technology, 49(2), 813-823.

World Bank, 2016. The critical face of climate change - Water. Washington D.C.: International Bank for Reconstruction and Development/the World Bank.

Yu, C. Y., Muthen, B., 2002, April. Evaluation of model fit indices for latent variable models with categorical and continuous outcomes. In annual meeting of the American Educational Research Association, New Orleans, LA.

Zivin, J. G., Neidell, M., Schlenker, W., 2011. Water quality violations and avoidance behavior: Evidence from bottled water consumption. American Economic Review, 101(3), 448-453.

\section{Appendix A: Observed and latent variables}

\begin{tabular}{|l|l|}
\hline Latent constructs & Observed variables \\
\hline
\end{tabular}




\begin{tabular}{|c|c|}
\hline PHR: Perceived Health Risks & $\begin{array}{l}\text { PHR1: There are health risks associated with drinking tap } \\
\text { water in my home } \\
\text { PHR2: My tap water will not harm anybody (reverse coded) } \\
\text { PHR3: I don't believe there is any possibility of becoming ill } \\
\text { from drinking water straight from the tap (reverse coded) } \\
\text { PHR4: There are so many chemicals and additives in my } \\
\text { home tap water that it must be unhealthy }\end{array}$ \\
\hline AS: Area Satisfaction & $\begin{array}{l}\text { AS1: In general, I would be happy living in this area for the } \\
\text { next } 15 \text { years } \\
\text { AS2: If I had the opportunity, I'd rather live in another area } \\
\text { (reverse coded) }\end{array}$ \\
\hline $\begin{array}{l}\text { CS: Perceived Chemical Spill } \\
\text { Likelihood }\end{array}$ & $\begin{array}{l}\text { CS1: I think that a chemical spill is highly likely in the near } \\
\text { future in Mon County }\end{array}$ \\
\hline PWQ: Perceived Water Quality & $\begin{array}{l}\text { PWQ1: I don't believe the quality of my home tap water is } \\
\text { that bad that it needs improvement } \\
\text { PWQ2: My tap water is usually of high quality }\end{array}$ \\
\hline CTX: Context & $\begin{array}{l}\text { CTX1: The water pipes and taps of my home are clean and } \\
\text { well maintained }\end{array}$ \\
\hline OR: Organoleptic Perceptions & $\begin{array}{l}\text { OR1: I am happy with the taste of my tap water } \\
\text { OR2: I am happy with the color of my tap water } \\
\text { OR3: I am happy with the odor of my tap water }\end{array}$ \\
\hline EC: Environmental Concern & $\begin{array}{l}\text { EC1: If things continue on their present course, we will soon } \\
\text { experience a major ecological catastrophe } \\
\text { EC2: The problems of the environment are not as bad as most } \\
\text { people think (reverse coded) } \\
\text { EC3: We are quickly using up the world's natural resources } \\
\text { EC4: People worry too much about human progress harming } \\
\text { the environment (reverse coded) } \\
\text { EC5: We are spending too little money on improving and } \\
\text { protecting the environment }\end{array}$ \\
\hline $\begin{array}{l}\text { PSWQ: Perceived Surface Water } \\
\text { Quality }\end{array}$ & $\begin{array}{l}\text { PSWQ1: Overall, what is the quality of surface water (rivers, } \\
\text { streams, lakes) at your home or vacation house in Mon } \\
\text { County? }\end{array}$ \\
\hline
\end{tabular}

Note 1: Observed variables were measured using 5-pt Likert scales: (1) strongly disagree, (5) strongly agree. PSWQ was measured using a 5-pt Likert scale: (1) very poor, (5) excellent. 
Appendix B: Correlations, means and standard deviations of observed variables $(n=603)$

\begin{tabular}{|c|c|c|c|c|c|c|c|c|c|c|c|c|c|c|c|c|c|c|c|}
\hline & PHR1 & PHR2 & PHR3 & PHR4 & AS1 & AS2 & CS1 & PWQ1 & PWQ2 & CTX1 & OR1 & OR2 & OR3 & EC1 & EC2 & EC3 & EC4 & EC5 & $\begin{array}{l}\text { PSWQ } \\
1\end{array}$ \\
\hline PHR1 & 1 & & & & & & & & & & & & & & & & & & \\
\hline PHR2 & 0.58 & 1 & & & & & & & & & & & & & & & & & \\
\hline PHR3 & 0.45 & 0.75 & 1 & & & & & & & & & & & & & & & & \\
\hline PHR4 & 0.61 & 0.57 & 0.44 & 1 & & & & & & & & & & & & & & & \\
\hline AS1 & -0.30 & -0.43 & -0.37 & -0.35 & 1 & & & & & & & & & & & & & & \\
\hline AS2 & -0.36 & -0.42 & -0.37 & -0.49 & 0.66 & 1 & & & & & & & & & & & & & \\
\hline CS1 & 0.35 & 0.32 & 0.27 & 0.33 & -0.28 & -0.30 & 1 & & & & & & & & & & & & \\
\hline PWQ1 & -0.53 & -0.66 & -0.51 & -0.58 & 0.41 & 0.40 & -0.31 & 1 & & & & & & & & & & & \\
\hline PWQ2 & -0.57 & -0.63 & -0.47 & -0.68 & 0.42 & 0.53 & -0.32 & 0.68 & 1 & & & & & & & & & & \\
\hline CTX1 & -0.23 & -0.32 & -0.33 & -0.17 & 0.21 & 0.22 & -0.18 & 0.28 & 0.27 & 1 & & & & & & & & & \\
\hline OR1 & -0.49 & -0.52 & -0.39 & -0.61 & 0.39 & 0.52 & -0.27 & 0.63 & 0.75 & 0.30 & 1 & & & & & & & & \\
\hline OR2 & -0.43 & -0.52 & -0.40 & -0.50 & 0.39 & 0.43 & -0.21 & 0.50 & 0.63 & 0.27 & 0.65 & 1 & & & & & & & \\
\hline OR3 & -0.45 & -0.54 & -0.42 & -0.56 & 0.40 & 0.46 & -0.27 & 0.56 & 0.68 & 0.26 & 0.77 & 0.78 & 1 & & & & & & \\
\hline EC1 & 0.30 & 0.24 & 0.17 & 0.30 & -0.23 & -0.23 & 0.38 & -0.27 & -0.28 & -0.14 & -0.21 & -0.15 & -0.21 & 1 & & & & & \\
\hline EC2 & 0.23 & 0.25 & 0.18 & 0.19 & -0.22 & -0.21 & 0.31 & -0.29 & -0.28 & -0.13 & -0.22 & -0.14 & -0.20 & 0.71 & 1 & & & & \\
\hline EC3 & 0.22 & 0.19 & 0.14 & 0.14 & -0.20 & -0.17 & 0.24 & -0.24 & -0.19 & -0.08 & -0.13 & -0.09 & -0.11 & 0.63 & 0.63 & 1 & & & \\
\hline EC4 & 0.17 & 0.19 & 0.11 & 0.14 & -0.21 & -0.18 & 0.19 & -0.21 & -0.22 & -0.17 & -0.16 & -0.12 & -0.13 & 0.58 & 0.65 & 0.58 & 1 & & \\
\hline EC5 & 0.18 & 0.17 & 0.07 & 0.17 & -0.14 & -0.16 & 0.20 & -0.18 & -0.22 & -0.12 & -0.14 & -0.06 & -0.11 & 0.51 & 0.47 & 0.53 & 0.42 & 1 & \\
\hline $\begin{array}{l}\text { PSWQ } \\
1\end{array}$ & -0.33 & -0.43 & -0.35 & -0.40 & 0.37 & 0.40 & -0.32 & 0.42 & 0.48 & 0.14 & 0.40 & 0.43 & 0.43 & -0.32 & -0.30 & -0.23 & -0.23 & -0.17 & 1 \\
\hline$M$ & 2.51 & 2.52 & 2.83 & 2.71 & 3.80 & 3.69 & 3.03 & 2.97 & 3.28 & 3.71 & 3.19 & 3.73 & 3.54 & 3.22 & 3.48 & 3.50 & 3.52 & 3.49 & 3.21 \\
\hline$S D$ & 1.03 & 1.07 & 1.20 & 1.11 & 1.05 & 1.18 & 0.98 & 1.19 & 1.12 & 0.89 & 1.24 & 0.95 & 1.08 & 1.10 & 1.10 & 1.08 & 1.13 & 1.14 & 0.84 \\
\hline
\end{tabular}

Note 1: Measures have been rounded. 
Appendix C: Map of the study location

\section{Appendix C: Study location}

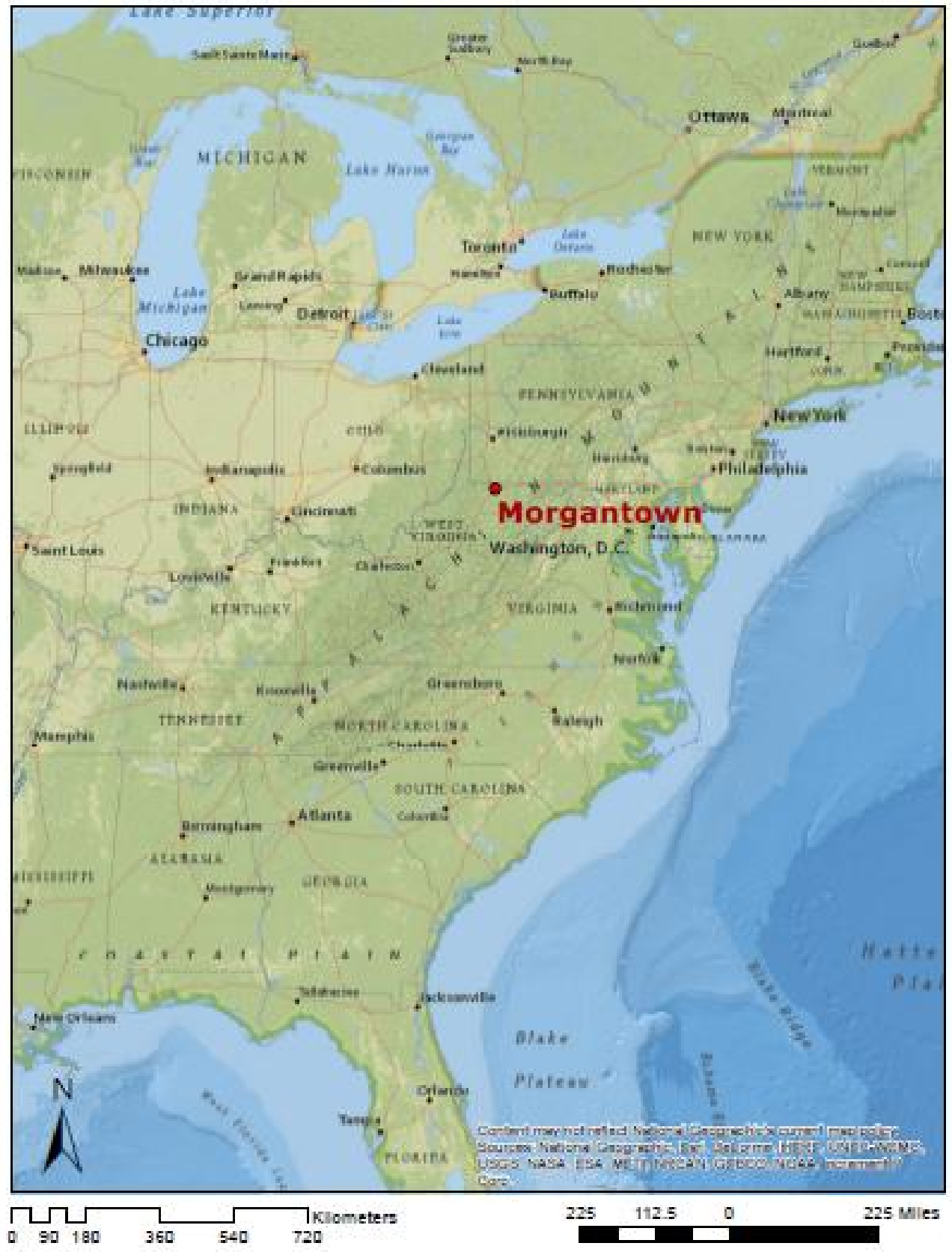




\title{
Chapter V: Article 4
}

Understanding Relationships between Water Quality Perceptions and Proximity in Northcentral West Virginia (US)

Jonas G. Levêque

Robert C. Burns

(Article submitted to the Journal of Society and Natural Resources, in review)

\begin{abstract}
In this paper, we aimed at understanding the factors explaining water quality perceptions in the northcentral West Virginia (US). Recent events in the United States show the vulnerability of the water quality in certain communities. As such, we conducted a survey in Monongalia County (WV) in order to investigate the factors that influence the perceptions of water quality. We sought to understand people's proximity to bodies of water by measuring the distance from their houses to lakes and rivers, and to understand whether geographical location is a predictor of water quality perceptions. In parallel, we sought to understand the link between these perceptions and proximity to oil and gas wells and mining activities. Results show significant differences between residents who live closer to or further away from these. However, when used as a predictor to water quality perceptions, proximity leads to significant results of small magnitude.
\end{abstract}

Keywords: Water Quality, Proximity, Perceptions, West Virginia.

\section{Introduction}


Considering the many recent water crises throughout the U.S., water quality has become a major issue in natural resource management affecting public perceptions of tap water quality and risk perceptions (Merkel et al. 2012). Conjointly, the Appalachia region has been known for coal mining and its impacts on water quality (Sams III and Beer 2000; Underwood et al. 2014). As recently as January 2014, a chemical spill resulting from a storage tank leaking a coal-related solvent contaminated the tap water of 300,000 persons in southern West Virginia (Whelton et al. 2015). Additionally, the Appalachia region is seeing an increase in development of natural gas extraction, notably with unconventional drilling (Higginbotham et al. 2010). In this respect, there has been uncertainty about the water quality and the potential risks this development creates. Several scientific articles have contradicting views on the likelihood of groundwater aquifer contamination, arguing that the risk is minimal in one case and high in another (Engelder et al. 2014; Harkness et al., 2017; Osborn et al. 2011). For instance, Osborn et al. (2011) found higher concentrations of methane in tap water within a 1 kilometer radius of gas wells, compared to areas without wells. In contrast, Harkness et al. (2017) found no evidence of water well contamination resulting from underground contamination in West Virginia. Notwithstanding, regarding surface contamination, there is a larger consensus on the existing risks of spills from waste disposal and water flowbacks during the extraction process (Engelder et al. 2014; Kharaka et al., 2013; Harkness et al., 2017; Osborn et al. 2011; Vengosh et al., 2013; Vidic et al. 2013). Harkness et al. (2017) found water well contaminations in West Virginia, directly linked to surface contamination. Several studies have looked at risk perceptions regarding communities located near natural resources extraction sites due to the fact that both coal mining and natural gas/oil drilling have potential risks of spills. For instance, when comparing two counties in 
Pennsylvania, Kriesky et al. (2013) found that residents who lived in the county with a higher density of wells perceived less environmental risks associated with non-conventional gas drilling and were more supportive of the practice in general. In an earlier study in four counties of Pennsylvania and New York, Brasier et al. (2011) conducted focus group research that highlighted the positive and negative impacts of non-conventional gas drilling. In this regard, they showed that some landowners feared water quality changes for drinking water as well as recreational water, impacting their environment and tourism (Brasier et al.). These authors also pointed out that some landowners were concerned about unconventional gas drilling based on their experiences with coal mining industries (Brasier et al.). Brasier et al. demonstrated that some landowners were attracted to the economic impacts of gas drilling development, regardless of these environmental issues. Similarly, Dogaru et al. (2009) described a certain acceptance of polluted water in coal-mining communities in Romania, favoring job security over health and environmental concerns.

Simultaneously, several studies have assessed proximity to bodies of water to understand environmental concern and water quality (Brody et al. 2004; Larson and Santelmann 2007; Sutherland and Walsh 1985). These studies demonstrated negative correlations between environmental protection and distance from the body of water under study. This suggests that respondents who lived closer to a lake or river under study were more sensitive to the protection of this resource. Differing from the two other studies, Larson and Santelmann (2007) determined that this relationship was non-linear in their model. These authors showed that proximity was important in decision-making for resource protection.

\section{Study purpose}


Much recent literature indicates a link between proximity, environmental concern and risk perceptions. Accordingly, the goal of our study was to understand how proximity to wells, mines and bodies of water influences water quality perceptions and environmental concern in West Virginia. Previous literature on water quality perceptions does not empirically evaluate proximity with water sources or natural resource extraction activities. In a period of environmental regulation changes in the US, investigating the existence of a link between distance to natural resource extraction sites and water quality perceptions is relevant. Four constructs were of particular interest when analyzing proximity: organoleptic perceptions (odor, color and taste) (based on Doria et al., 2009), perceived surface water quality (streams, rivers and lakes) (based on Hu et al., 2011), perceived health risks from drinking from the tap (based on Doria et al., 2009) and environmental concern (based on Dutcher et al., 2007). The following hypotheses were formulated:

Hypothesis 1: proximity to wells will decrease environmental concern and perceived health risks, but will increase the organoleptic perceptions and perceived surface water quality, based on Kriesky et al. (2013).

Hypothesis 2: proximity to mines will decrease environmental concern and perceived health risks, but will increase the organoleptic perceptions and decrease the perceived surface water quality, based on Dogaru et al. (2009) and expanding from Kriesky et al. (2013). Hypothesis 3: proximity to bodies of water (main rivers and lakes) will increase environmental concern and perceived health risks, but will decrease the organoleptic perceptions and the perceived surface water quality, based on Sutherland and Walsh (1985) and Brody et al. (2004). 
Hypothesis 4: proximity to the diverse features will significantly predict changes in water quality perceptions (i.e. the four dependent variables of interest).

\section{Methods}

Study area

The area that has been chosen for this study was in Monongalia County, West Virginia (US) (see Figure 1). Water is pumped from the County's major river, the Monongahela River, to be treated and distributed to the drinking water network by Morgantown Utility Board (MUB). MUB is responsible for distributing the water in the whole County and is the largest public water provider in West Virginia (MUB, 2015). 


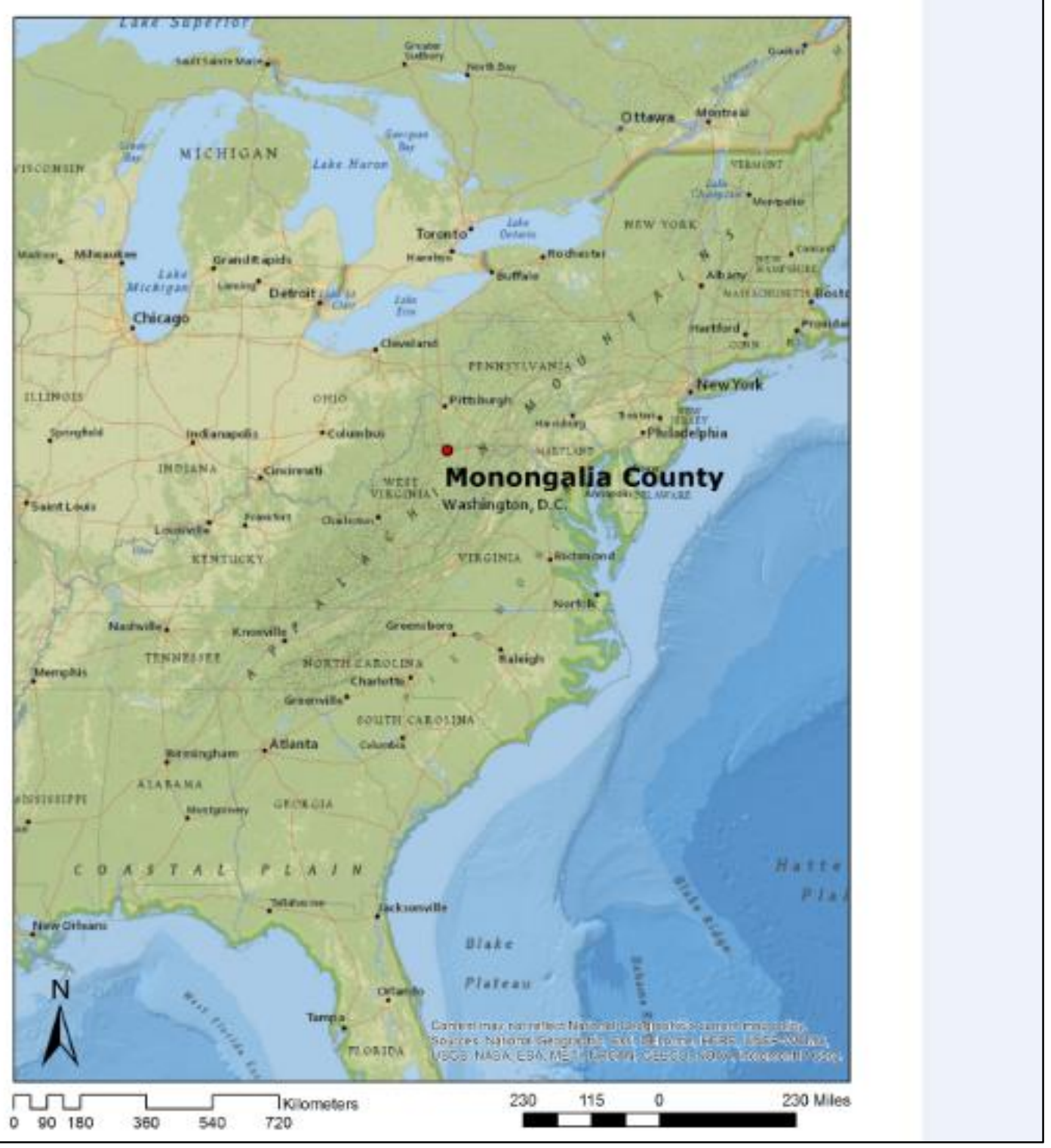

Figure 1: Map of the study location

\section{Data collection}

An online survey was conducted during the winter season of 2015-2016, targeting residents who lived in Morgantown and its surrounding areas within Monongalia County. Two different 
methods and samples were used to survey residents. The surveys were distributed online to 5492 residents and to 184 residents using a mail back survey. A total of 557 respondents answered the online questionnaire, while 46 residents answered the mail back survey. Due to anonymity, we could not match these 46 answers to their respective addresses and had to drop this data for proximity analyses. Similarly, 22 respondents from the online survey used P.O. boxes, which are not real residential addresses. As such, a total of 535 responses were used for the following analyses. The total effective response rate was $10.2 \%$.

\section{Variables}

Our questionnaire focused on four variables: environmental concern (EC, combining 5 items, $\alpha=.870$ ), perceived health risks (PHR, combining 4 items, $\alpha=.836$ ), organoleptic perceptions (OR, 3 items: odor, color and taste, $\alpha=.875$ ) and perceived surface water quality (PSWQ, streams, rivers and lakes as a single item). All of these items were measured using 5-pt Likert scales: 1 "strongly disagree," 5 "strongly agree" (for full description of the items and variable building, see Authors, 2017). With 535 useable responses, the demographics pattern is similar to that of the whole sample, which is typical of Monongalia County (see Table 1).

Table 5: Demographic Characteristics of Participants $(N=535)$

\begin{tabular}{lcccc}
\hline \multicolumn{1}{c}{ Characteristic } & $n$ & $\%$ & $M$ & $S D$ \\
\hline Gender & 519 & & \\
Male & 219 & 40.9 & \\
Female & 300 & 56.1 & \\
Highest Level of Education & 523 & &
\end{tabular}




\begin{tabular}{|c|c|c|c|c|}
\hline Some high school & 3 & 0.6 & & \\
\hline High school graduate & 40 & 7.6 & & \\
\hline Some college & 88 & 16.8 & & \\
\hline Two-year college & 48 & 9.2 & & \\
\hline Four-year college & 149 & 28.5 & & \\
\hline $\begin{array}{l}\text { Graduate or professional } \\
\text { degree }\end{array}$ & 195 & 37.3 & & \\
\hline Income $(\$)$ & 467 & & $\$ 87,580$ & / \\
\hline $0-24,999$ & 25 & 5.4 & & \\
\hline $25,000-49,999$ & 88 & 18.8 & & \\
\hline $50,000-74,999$ & 92 & 19.7 & & \\
\hline $75,000-99,999$ & 79 & 16.9 & & \\
\hline $100,000-149,999$ & 113 & 24.2 & & \\
\hline 150,000 or more & 70 & 15 & & \\
\hline Length of residency in & 525 & & 27.36 & 18.69 \\
\hline \multicolumn{5}{|l|}{ Monongalia County (years) } \\
\hline $0-5$ & 41 & 7.8 & & \\
\hline $6-10$ & 83 & 15.8 & & \\
\hline $11-20$ & 109 & 20.8 & & \\
\hline $21-30$ & 83 & 15.8 & & \\
\hline $31-40$ & 88 & 16.8 & & \\
\hline $41-50$ & 59 & 11.2 & & \\
\hline
\end{tabular}




\section{Geolocalization}

Online Geographic Information Systems (GIS) datasets were used to create the different maps. The software package ArcMap 10.4.1 was utilized to organize and map the different features of interest such as residents' addresses, oil and gas wells, mining activities, streams, rivers and lakes. Residents' addresses were converted into geo-spatial data points and added to the map. A buffer of five miles was drawn surrounding Monongalia County to include potential features of interest (wells, mines, rivers...) outside the County limits. As a result, GIS data from both the Department of Environmental Protection of West Virginia (2017) and Pennsylvania (2017) were downloaded and mapped. More specifically, the two different oil and gas well datasets were merged and refined to exclusively select wells that were active and abandoned during the data collection period. Plugged wells were not included within the dataset. A total of 2453 wells were mapped. Similarly, mining datasets were merged to include only active and abandoned mining sites, and sites that had not completed their reclamation by the time of the survey. A total of 641 mining sites were mapped. Streams, rivers and lakes were merged into a single dataset. Careful analysis of the map indicated that all of the respondents were located near a stream. Closer inspection of the type of streams resulted in the selection of major rivers, lakes and streams (creeks were included and smaller runs were deleted). Figure 2 represents all of these features in one map. In order to obtain a more precise picture of these features for analysis, we created six different categories of features: a) active mines, b) abandoned mines (including in reclamation), 
c) active conventional oil and gas wells, d) active unconventional oil and gas wells, e) abandoned oil and gas wells, and f) rivers.

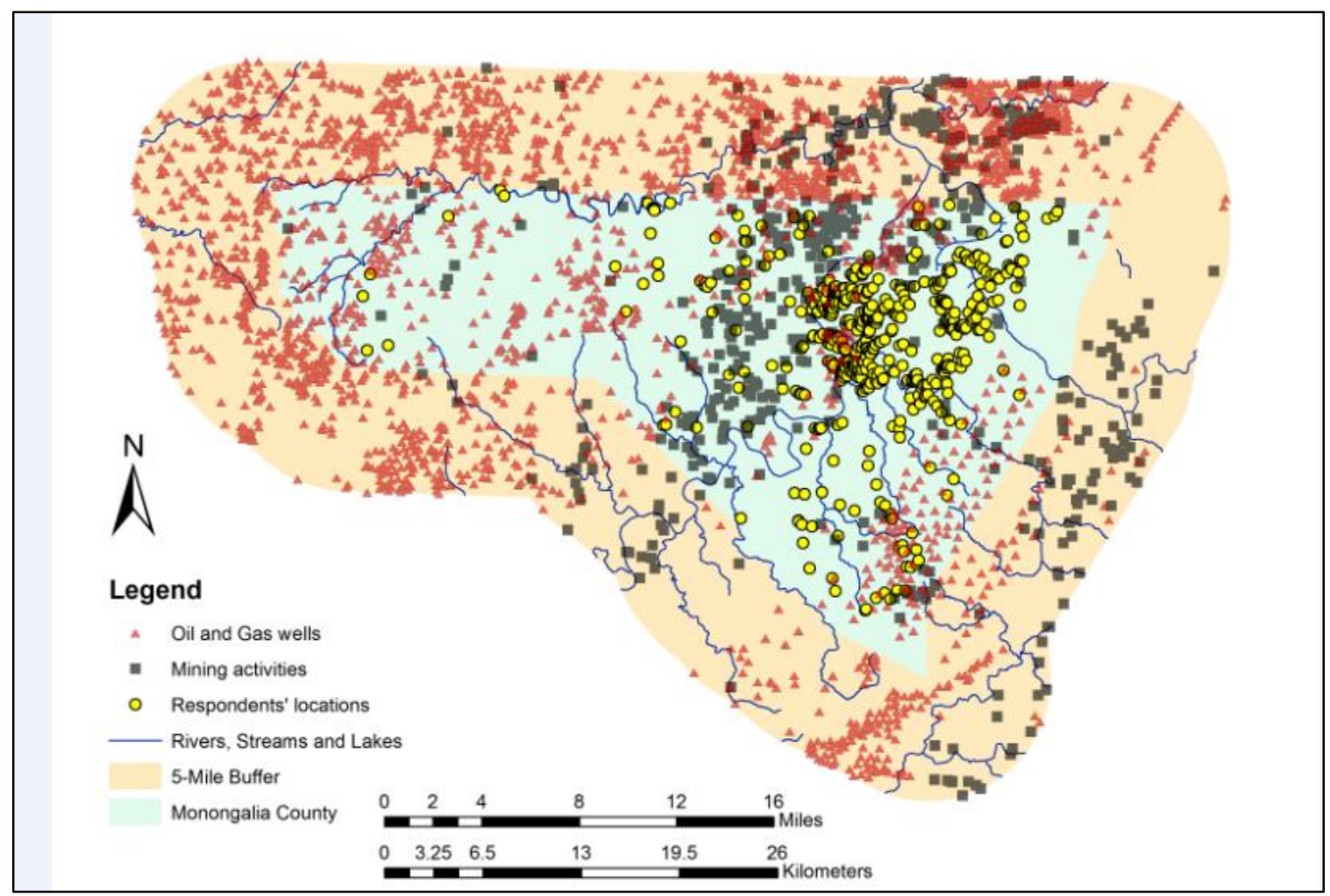

Figure 2: Locations of the different features and residents' locations

\section{Data analysis}

ArcMap was used to analyze distances between features and residents' locations by using the "generate near table" command providing various radius lengths from residents' addresses to the feature of interest. A pre-analysis consisted in identifying the nearest distances to wells, mines and rivers. Through defining the nearest distances (in meters), we initiated a better understanding of the distribution of the data for each category of features (see Table 2). 
Table 6: Descriptive statistics of the nearest distances per category of feature

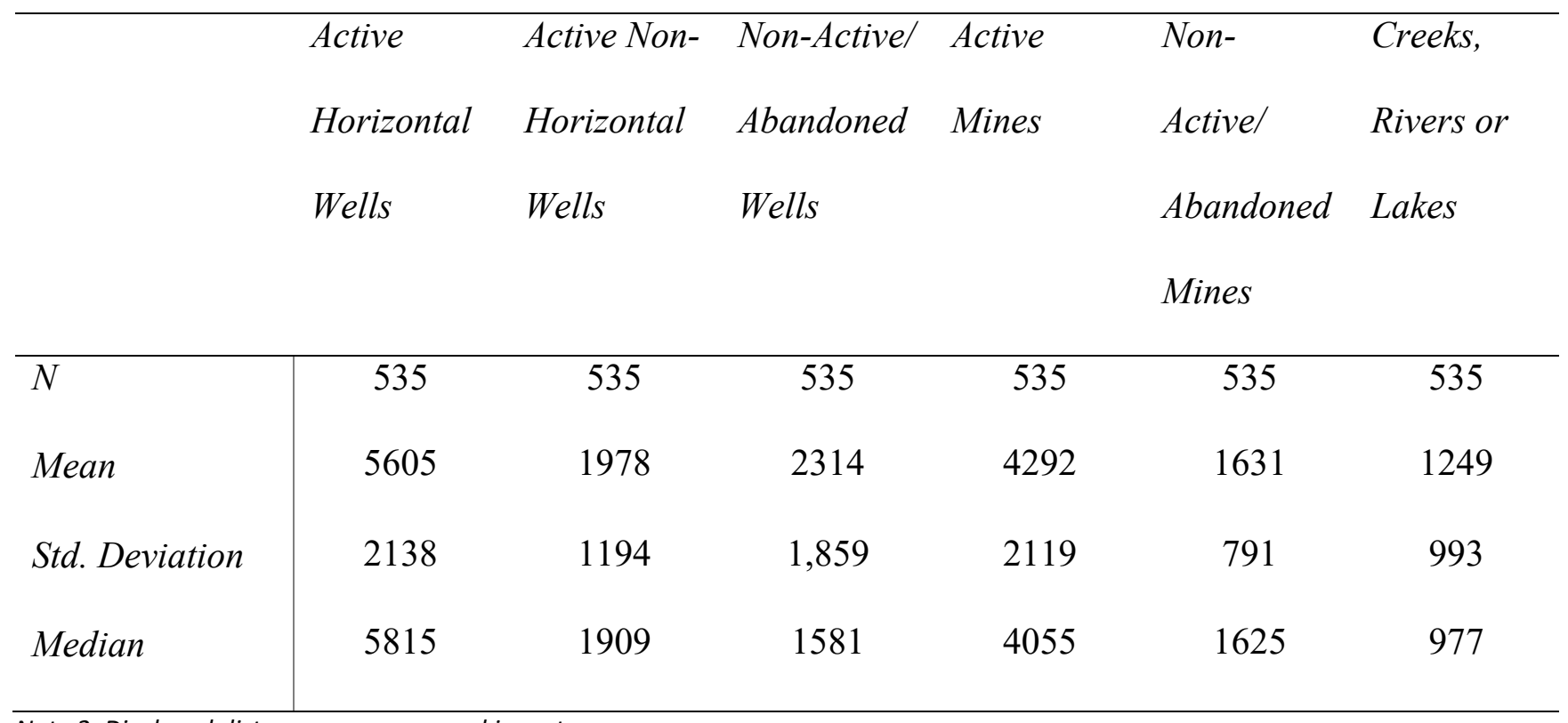

Note 2: Displayed distances are measured in meters.

All of the tables created in ArcMap were then transferred to Excel and pasted into IBM

Statistical Package for Social Sciences (SPSS) version 24 for analysis. Based on the analysis of the descriptive statistics, we were able to determine the radiuses that would be used in ArcMap for each one of the six categories of feature. The medians were of interest, and we also tested for other lengths. Using SPSS, t-tests and linear regressions were selected to test the different hypotheses. Table 2 explicitly demonstrated that the data are split in two categories: within a defined distance and away from a well, a mine or a body of water. The following results were coded as: 0 "within a certain distance to feature", 1 "away from feature." Using the different ttest analyses, we selected the distances were the data was closer to a $50 \%$ split and were the ttests were significant, in order to use in the regression analyses. As such, we did not use proximity to features that were not significant (in the t-test analyses) for the regression analyses. For the regression analyses, we controlled for gender, income, education and length of residency 
in the County. Effect sizes were calculated using Cohen's d or Hedges' g, depending on equal or different sample sizes for t-tests.

\section{Results}

T-tests

Using t-tests, we were able to assess the water quality perception differences between residents who lived closer to or further away from a well, mine or river.

Regarding active horizontal wells, our results indicate similar differences for 3 miles, 5000m, $5500 \mathrm{~m}, 3.5$ miles, up to the median ( $=5815$ meters). $6000 \mathrm{~m}$ did not show similar results for PSWQ. Table 3 represents results for the median:

Table 7: Water Quality Perceptions based on proximity to Active Horizontal Wells

\begin{tabular}{|c|c|c|c|c|c|c|c|c|}
\hline \multirow[b]{2}{*}{ Variable } & \multicolumn{2}{|c|}{ Close } & \multicolumn{2}{|l|}{ Far } & \multirow[b]{2}{*}{$d f$} & \multirow[b]{2}{*}{$t$} & \multirow[b]{2}{*}{$p$} & \multirow[b]{2}{*}{$\begin{array}{c}\text { Cohen's } \\
\quad d\end{array}$} \\
\hline & $M$ & $S D$ & $M$ & $S D$ & & & & \\
\hline OR & 3.36 & 1.03 & 3.59 & 0.88 & 517.06 & -2.85 & .005 & 0.25 \\
\hline $\mathrm{n}$ & 266 & & 265 & & & & & \\
\hline PSWQ & 3.08 & 0.84 & 3.30 & 0.82 & 533 & -3.06 & .002 & 0.26 \\
\hline $\mathrm{n}$ & 268 & & 267 & & & & & \\
\hline PHR & 2.78 & 0.92 & 2.54 & 0.84 & 532 & 3.12 & .002 & 0.27 \\
\hline $\mathrm{n}$ & 267 & & 267 & & & & & \\
\hline EC & 3.48 & 0.94 & 3.47 & 0.83 & 528 & 0.18 & .858 & 0.01 \\
\hline $\mathrm{n}$ & 263 & & 267 & & & & & \\
\hline
\end{tabular}


Note 3: Dependent variables are measured on 5-pt Likert scales.

From Table 3, it is possible to see that residents who have an unconventional well within 5815 meters of their house have: (1) significantly lower organoleptic perceptions of their tap water, (2) significantly lower perceptions of the water quality of the surface water as well as (3) significantly increased health risk perceptions regarding their tap water. However, there is no difference in environmental concern when comparing residents who have wells within 5815 meters of their home and residents who do not.

Concerning active conventional wells, using various radiuses $(1000 \mathrm{~m}, 1500 \mathrm{~m}, 1 \mathrm{mile}, 2000 \mathrm{~m}$, $2500 \mathrm{~m}$ ) resulted in no significant differences between residents living by wells within these radiuses and people living in areas including no wells. Regarding the median $(1,909 \mathrm{~m})$, there was a significant difference for environmental concern $(\mathrm{t}(528)=2.12, \mathrm{p}=.034)$. Residents closer to wells were more concerned $(n=266, M=3.56, \mathrm{sd}=0.89)$ than residents further away from wells $(\mathrm{n}=264, \mathrm{M}=3.39, \mathrm{sd}=0.88)$. However, the effect size was too small to be relevant $($ Cohen's d $=0.18)$.

Looking at abandoned/non-active wells, using $1000 \mathrm{~m}, 1500 \mathrm{~m}$, the median $(1581 \mathrm{~m})$, one mile, $2000 \mathrm{~m}$ and $2500 \mathrm{~m}$ to test proximity, there was one difference. Environmental concern was only significant for 1500 meters $(\mathrm{t}(526.94)=2.44, \mathrm{p}=.015)$. Residents close to wells were more concerned about the environment $(n=259, M=3.57, \mathrm{sd}=0.88)$ than residents further away from wells $(\mathrm{n}=271, \mathrm{M}=3.39, \mathrm{sd}=0.88)$. The effect size was small but sufficient (Cohen's $\mathrm{d}=$ $0.21)$.

In terms of active mines, using 3000m, 2 miles, $3500 \mathrm{~m}, 4000 \mathrm{~m}$, the median $(4055 \mathrm{~m})$ and $4500 \mathrm{~m}$, several differences were found. Past 2 miles, no differences were found to be statistically 
significant. However, for distances past 3000 meters and within 2 miles there were significant differences in organoleptic perceptions:

Table 8: Differences for organoleptic perceptions at 3000 meters and 2 miles

\begin{tabular}{|c|c|c|c|c|c|c|c|c|}
\hline \multirow[b]{2}{*}{ Variable } & \multicolumn{2}{|c|}{ Close } & \multicolumn{2}{|l|}{ Far } & \multirow[b]{2}{*}{$d f$} & \multirow[b]{2}{*}{$t$} & \multirow[b]{2}{*}{$p$} & \multirow[b]{2}{*}{$\begin{array}{c}\text { Hedge's } \\
g\end{array}$} \\
\hline & $M$ & $S D$ & $M$ & $S D$ & & & & \\
\hline $\begin{array}{l}\text { OR } \\
(3000 \mathrm{~m})\end{array}$ & 3.66 & 0.87 & 3.40 & 1.00 & 316.15 & 2.95 & .003 & 0.27 \\
\hline $\mathrm{n}$ & 153 & & 378 & & & & & \\
\hline $\begin{array}{l}\text { OR } \\
\text { (2 miles) }\end{array}$ & 3.65 & 0.92 & 3.40 & 0.97 & 324.93 & 2.89 & .004 & 0.27 \\
\hline $\mathrm{n}$ & 162 & & 369 & & & & & \\
\hline
\end{tabular}

Note 4: Hedge's $g$ is used due to different sample sizes.

According to Table 4, residents who live closer to active mines perceived their water quality to have better taste, odor and color than residents who live further away from mines.

Analyzing abandoned/non-active mines, using 1000m, 1500m, 1 mile, the median (1625m), $2000 \mathrm{~m}$ and $2500 \mathrm{~m}$ resulted in non-significant differences for any of these distances.

When looking at rivers, streams and lakes, using 500m, 750m, the median $(977 \mathrm{~m}), 1000 \mathrm{~m}$, $1250 \mathrm{~m}$ and $1500 \mathrm{~m}$, our results indicated significant differences for organoleptic perceptions for 3 distances (Table 5). 
Table 9: Differences in organoleptic perceptions for 750m, the median and $1000 \mathrm{~m}$

\begin{tabular}{|c|c|c|c|c|c|c|c|c|}
\hline \multirow[b]{2}{*}{ Variable } & \multicolumn{2}{|c|}{ Close } & \multicolumn{2}{|l|}{ Far } & \multirow[b]{2}{*}{$d f$} & \multirow[b]{2}{*}{$t$} & \multirow[b]{2}{*}{$p$} & \multirow[b]{2}{*}{$\begin{array}{c}\text { Hedge's } \\
g\end{array}$} \\
\hline & $M$ & $S D$ & $M$ & $S D$ & & & & \\
\hline $\begin{array}{l}\text { OR } \\
(750 \mathrm{~m})\end{array}$ & 3.35 & 1.04 & 3.56 & 0.90 & 418.04 & -2.42 & .016 & 0.22 \\
\hline $\mathrm{n}$ & 216 & & 315 & & & & & \\
\hline $\begin{array}{l}\text { OR } \\
(977 \mathrm{~m})\end{array}$ & 3.39 & 1.03 & 3.56 & 0.88 & 515.82 & -2.13 & .033 & 0.18 \\
\hline $\mathrm{n}$ & 265 & & 266 & & & & & \\
\hline $\begin{array}{l}\text { OR } \\
(1000 \mathrm{~m})\end{array}$ & 3.38 & 1.03 & 3.57 & 0.88 & 521.35 & -2.25 & .025 & 0.19 \\
\hline $\mathrm{n}$ & 269 & & 271 & & & & & \\
\hline
\end{tabular}

In regards to Table 5, we conclude that the median and 1000 meter distances have too small of effect sizes to be considered. As such, residents who lived within 750 meters of a river had significantly lower perceptions of their tap water quality: taste, odor and color.

Regressions

In order to conduct the regression analyses, we kept the dichotomous variables that were significant for the maximum distance. These were selected in order to show "to what extent" 
wells, mines or rivers could affect water quality perceptions. Additionally, we kept the distances for which effect sizes were sufficient (above .20).

Organoleptic perceptions

Table 10: Regression analysis summary for proximity variables predicting organoleptic perceptions, controlling for residents' demographics

\begin{tabular}{llclll}
\hline Variable & $B$ & $95 \% \mathrm{CI}$ & $\beta$ & $t$ & $p$ \\
\hline Active & 0.25 & {$[0.62,0.43]$} & 0.13 & 2.62 & .009 \\
horizontal wells & & & & \\
(median) & & & & \\
Abandoned or & 0.03 & {$[-0.16,0.22]$} & 0.02 & 0.34 & .736 \\
non-active wells & & & & & \\
(1500m) & & & & & \\
Active mines $(2$ & -0.28 & {$[-0.48,0.08]$} & -0.14 & -2.72 & .007 \\
miles) & & & & & .431 \\
Rivers (750m) & 0.07 & {$[-0.11,0.26]$} & 0.04 & 0.79 & .074 \\
Gender & -0.16 & {$[-0.33,0.15]$} & -0.08 & -1.79 & .001 \\
Length of & 0.01 & {$[0.00,0.01]$} & 0.16 & 3.37 & .052 \\
residency & & {$[-0.02,0.12]$} & 0.07 & 1.45 & \\
Education & 0.05 & {$[-0.00,0.12]$} & 0.09 & 1.95 & \\
Income & 0.06 & & & & \\
\hline
\end{tabular}

Note 5: Adjusted $R^{2}=.07(N=457, p<.001) . C l=$ confidence interval for $B$. 
According to Table 6, it is possible to see that proximity to active horizontal wells, length of residency and proximity to active mines are significant in predicting organoleptic perceptions ( $\mathrm{F}$ $(8,448)=5.02 ; \mathrm{p}<.001)$. Nonetheless, the multiple correlation coefficient is .29, which is a small effect size. The adjusted $\mathrm{R}^{2}$ informs us that less than $10 \%$ of the variance in organoleptic perceptions is explained by these variables.

Perceived surface water quality

Table 11: Regression analysis summary for proximity variables predicting perceived surface water quality, controlling for residents' demographics

\begin{tabular}{llllll}
\hline Variable & $B$ & $95 \%$ CI & $\beta$ & $t$ & $p$ \\
\hline Active & 0.18 & {$[0.02,0.35]$} & 0.11 & 2.20 & .028
\end{tabular}

horizontal wells

(median)

Abandoned or $\quad 0.05 \quad\left[\begin{array}{llll}-0.12,0.23 & 0.03 & 0.63 & .530\end{array}\right.$

non-active wells

$(1500 \mathrm{~m})$

Active mines $\left(\begin{array}{llllll}2 & -0.05 & {[-0.23,0.13}\end{array}\right] \quad-0.02 \quad 620$

miles)

$\begin{array}{llllll}\text { Rivers }(750 \mathrm{~m}) & -0.02 & {[-0.18,0.14]} & -0.01 & -0.23 & .815\end{array}$

$\begin{array}{llllll}\text { Gender } & -0.12 & {[-0.27,0.04]} & -0.07 & -1.50 & .134\end{array}$

$\begin{array}{llllll}\text { Length of } & 0.01 & {[0.00,0.01]} & 0.16 & 3.21\end{array}$

residency

$\left.\begin{array}{llllll}\text { Education } & 0.01 & {[-0.06,0.07}\end{array}\right] \quad 0.01 \quad 849$ 
$\begin{array}{llllll}\text { Income } & 0.05 & {[0.00,0.11]} & 0.10 & 1.98 & .048\end{array}$

Note 6: Adjusted $R^{2}=.03(N=458, p=.003) . C l=$ confidence interval for $B$.

According to Table 7, it is possible to see that proximity to active horizontal wells, length of residency and income are significant in predicting perceived surface water quality $(\mathrm{F}(8,449)=$ $3.00 ; \mathrm{p}=.003)$. Regardless, the multiple correlation coefficient is .22 , which is again a small effect size. The adjusted $\mathrm{R}^{2}$ informs us that less $3 \%$ of the variance in perceived surface water quality is explained by these variables. This significance is trivial.

Perceived health risks

Table 12: Regression analysis summary for proximity variables predicting perceived health risks, controlling for residents' demographics

\begin{tabular}{llllll}
\hline Variable & $B$ & $95 \%$ CI & $\beta$ & $t$ & $p$ \\
\hline Active & -0.22 & {$[-0.40,-0.05]$} & -0.12 & -2.48 & .013
\end{tabular}

horizontal wells

(median)

Abandoned or $\quad-0.06 \quad[-0.24,0.12] \quad-0.03 \quad-0.67 \quad .504$

non-active wells

$(1500 \mathrm{~m})$

Active mines $\left(\begin{array}{llllll}2 & 0.20 & {[0.00,0.40}\end{array}\right] \quad 0.10 \quad 045$

miles)

$\begin{array}{llllll}\text { Rivers }(750 \mathrm{~m}) & 0.06 & {[-0.11,0.24]} & 0.03 & 0.71 & .476\end{array}$

$\begin{array}{llllll}\text { Gender } & 0.14 & {[-0.02,0.31]} & 0.08 & 1.67 & .095\end{array}$ 


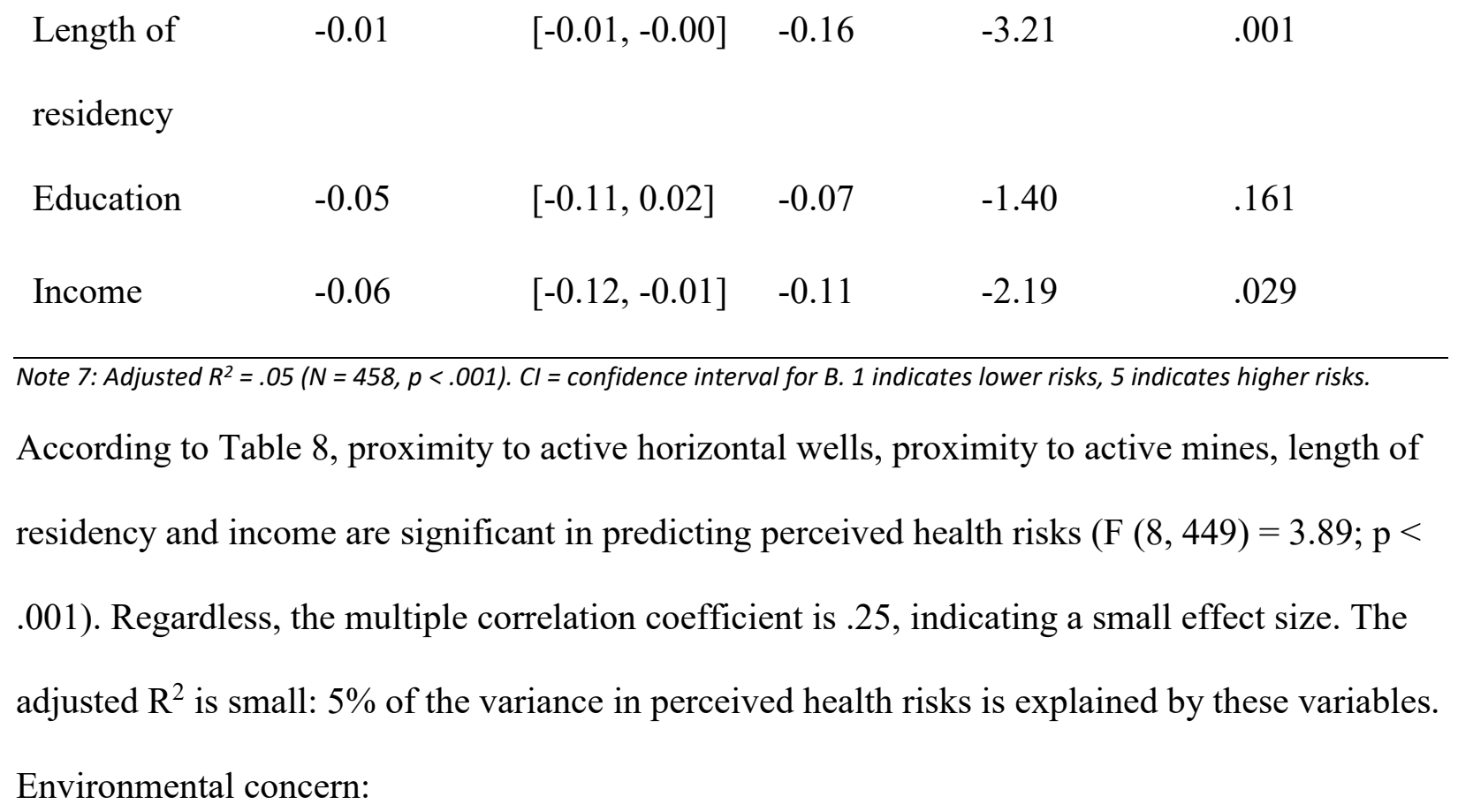

Table 13: Regression analysis summary for proximity variables predicting environmental concern, controlling for residents' demographics

\begin{tabular}{llllll}
\hline Variable & $B$ & $95 \%$ CI & $\beta$ & $t$ & $p$ \\
\hline Active & -0.02 & {$[-0.19,0.15]$} & -0.01 & -2.46 & .806 \\
horizontal wells & & & & \\
(median) & & & & & \\
Abandoned or & -0.14 & {$[-0.24,0.12]$} & -0.08 & -1.57 & .116 \\
non-active wells & & & & & \\
(1500m) & & & & & .410 \\
Active mines (2 & 0.08 & {$[-0.11,0.27]$} & 0.04 & 0.82 & .591 \\
miles) & & & & & \\
Rivers (750m) & 0.05 & {$[-0.12,0.22]$} & 0.03 & 0.54 &
\end{tabular}




$\begin{array}{lccccc}\text { Gender } & 0.41 & {[0.24,-0.57]} & 0.22 & 4.94 & <.001 \\ \text { Length of } & -0.01 & {[-0.01,-0.00]} & -0.15 & -3.24 & .001 \\ \text { residency } & & & & & \\ \text { Education } & 0.04 & {[-0.03,0.10]} & 0.05 & 1.11 & .266 \\ \text { Income } & -0.09 & {[-0.15,-0.04]} & -0.16 & -3.25 & .001\end{array}$

Note 8: Adjusted $R^{2}=.10(N=455, p<.001) . C l=$ confidence interval for $B$.

According to Table 9, only demographic variables (gender, length of residency and income) are significant predictors of environmental concern $(F(8,446)=7.30 ; p<.001)$. The multiple correlation coefficient is .34 , close to indicating a moderate effect size. The adjusted $\mathrm{R}^{2}$ indicates that $10 \%$ of the variance in perceived health risks is explained by these variables.

\section{Discussion}

In light of our results, it is possible to say that proximity has an impact on some water quality perceptions when segmenting the data into two groups of residents: close/far away. The t-tests especially highlighted the difference for active horizontal wells: residents who lived closer thought their water quality was diminished in contrast to residents who lived further away. These results are the opposite of our initial hypothesis (1). Since we used proximity for analysis and not density, comparing our results to Kriesky et al. (2013) is difficult. Nonetheless, one could expect that with a higher horizontal wells density, a resident would have higher "chances" to have a well located near his/her home. In that respect, our results contrast with Kriesky et al. in that we did not find differences for environmental concern. Our results indicate the need for more information regarding horizontal drilling and water quality monitoring, especially for residents 
who live closer to these wells (up to 5,815 meters). Consequences of this result have been seen through market research. For instance, Muehlenbachs et al. (2015) found that the risk of groundwater contamination by horizontal wells could have impacts on housing markets. This result is particularly interesting to compare with the most recent study of Harkness et al. (2017) who found no evidence of groundwater contamination within $1 \mathrm{~km}$ of horizontal wells, but evidence of contamination linked to surface spills. Our results show that horizontal wells affect public perceptions up to six times the distance used for contamination studies, highlighting the need for public communication.

Regarding other types of wells, the conventional wells did not show significant differences for any of the variables, except one trivial significant difference for environmental concern. This can be the result of many years of drilling activities in the region as well as considering the fact that conventional wells do not require the same type of infrastructure as horizontal wells.

Abandoned or non-active wells showed only a significant difference for environmental concern, with closer residents being more environmentally concerned. Surprisingly, proximity to these wells was not significant for perceived surface water quality, perceived health risks or organoleptic perceptions. These results imply that some residents might be concerned about the shape of abandoned or non-active wells.

Results about active mines were rather surprising as they showed the opposite of our hypothesis (2): closer residents thought the water properties (taste, odor and color) were better than residents who lived further away. In regards to the literature, this result is at the opposite of many studies (Morrice and Colaguiri, 2013; Shi and He, 2012). Interpretation of this result could be an effect of coping with coal mining in places where these activities have taken place for a long time 
(Dogaru et al., 2009). Shi and Fe (2012) indicated that age increased the perceptions of water quality: an interaction between age and proximity might be at play. Another explanation could be the fact that rivers that are impaired may receive treatment. The lack of differences for perceived health risks, environmental concern and perceived surface water quality can possibly be of the same order. Similarly, abandoned and non-active mines did not present significant differences with proximity. Therefore, our results illustrate differences for recent and active sites rather than abandoned/non-active sites.

Pertaining to proximity to bodies of water, residents who lived within 750 meters of a selected river thought their water had lower qualities than that of residents who lived further away. This result validated part of hypothesis (3) and adds evidence to the literature (Ryan, 1998). Nonetheless, the fact that proximity did not change environmental concern is different from past studies (Brody et al. 2004; Larson and Santelmann 2007; Ryan 1998; Sutherland and Walsh 1985). However, these studies asked specifically about the protection of certain rivers and named them in their survey. Our methods were different in this regard as we did not ask respondents about resource protection. Similar to our results, Brody et al. (2004) indicated small effect sizes and $\mathrm{R}^{2}$ in studying spatial locations of residents and rivers. Our results confirm these small effects.

Concerning the prediction of water quality variables from proximity, there were significant effects from active horizontal wells for organoleptic perceptions (lower), perceived health risks (higher) and perceived surface water quality (lower). Proximity to active mines significantly predicted organoleptic perceptions (higher) and perceived health risks (lower). However, the magnitude of these effects is rather small with effect sizes that are small. Proximity was not 
found to be significant in predicting environmental concern when controlled for demographic variables. As such, there is some evidence to support proximity as a predicting factor for these variables but of small magnitude. This partly invalidated hypothesis (4).

Our results indicate that the length of residency within the county strongly predicts the four variables of interest. This is a similar to Ryan (1998) who found that long-time residents had less concern for natural areas than new residents.

\section{Conclusions}

Changing environmental regulations in the context of a horizontal drilling boom and aging coal mines intensifies concern over water quality management. Understanding how proximity can affect residents is important as there is uncertainty regarding risks that can affect the general public. Our results indicate the need for future studies in risk assessment for horizontal wells at larger scales, and in other places in the U.S. There seems to be a gap in the literature for these types of studies. In addition to more general communication to the public about the factors which may pose risks to water quality. These are increasingly important as decisions on environmental protection can directly impact communities. As such, there needs to be more scientific communication between the public, scientists, regulators, and companies.

\section{Limitations and future studies}

Our study presented several limitations. First, we did not use driving distances or driving time to mines, wells or rivers which could affect the results. We solely used planar methods. In that same regard, we did not use the topography. Since Monongalia County is located within the 
Appalachian Region, topography could also make a difference. Further studies should integrate topography and driving distances to compare these results. Besides, we did not look at the perceived proximity from the river, coal mines or gas wells. This could be used for comparison. Additionally, we did not differentiate between the quality of the rivers utilized in our analyses. As such, further studies could segment between proximity to impaired or non-impaired streams. A final limitation is the fact that we did not ask whether residents received royalties from resource extraction activities or worked for drilling or mining companies. Future studies could pair water well contamination research together with residents' risk perceptions of water quality contamination.

\section{Acknowledgements}

We would like to thank the US National Science Foundation-Experimental Program to Stimulate Competitive Research (through WV-HEPC-Division of Science and Research) under the Award Number 145852 and the National Institute of Food and Agriculture (NIFA) for the funding of this study. We would also like to thank Dr. Jinyang Deng and Dr. Mike Strager for their help and advices for using ArcMap.

\section{References}

Authors (for review anonymity) (2017)

Brasier, Kathryn J., Matthew R. Filteau, Diane McLaughlin, Jeffrey Jacquet, Richard C.

Stedman, Timothy W. Kelsey and Stephan J. Goetz. 2011. “Residents' Perceptions of

Community and Environmental Impacts from Development of Natural Gas in the Marcellus

Shale: A Comparison of Pennsylvania and New York Cases." Journal of Rural Social Sciences 26(1):32-61. 
Brody, S. D., Highfield, W., \& Alston, L. (2004). Does location matter? Measuring environmental perceptions of creeks in two San Antonio watersheds. Environment and Behavior, 36(2), 229-250.

Dogaru, D., Zobrist, J., Balteanu, D., Popescu, C., Sima, M., Amini, M., \& Yang, H. (2009). Community perception of water quality in a mining-affected area: A case study for the Certej catchment in the Apuseni mountains in Romania. Environmental management, 43(6), 11311145.

Doria, Miguel de França, Nick Pidgeon and Paul R. Hunter. 2009. “Perceptions of drinking water quality and risk and its effect on behaviour: A cross-national study." Science of the Total Environment 407(21):5455-5464.

Dutcher D. D., Finley J. C., Luloff A. E. \& Johnson, J. B. 2007 Connectivity with nature as a measure of environmental values. Environment and behavior, 39(4), 474-493.

Engelder, T., Cathles, L. M., \& Bryndzia, L. T. (2014). The fate of residual treatment water in gas shale. Journal of Unconventional Oil and Gas Resources, 7, 33-48.

Harkness, J. S., Darrah, T. H., Warner, N. R., Whyte, C. J., Moore, M. T., Millot, R., Kloppmannd, W., Jacksone, R. B., \& Vengosh, A. (2017). The Geochemistry of Naturally Occurring Methane and Saline Groundwater in an Area of Unconventional Shale Gas Development. Geochimica et Cosmochimica Acta, 208, 302-334.

Higginbotham, Amy, Adam Pellillo, Tami Gurley-Calvez and Tom S. Witt. (2010). “The Economic Impact of the Natural Gas Industry and the Marcellus Shale Development in West Virginia in 2009." Bureau of Business and Economic Research West Virginia University. 
Hu Z., Morton L. W. \& Mahler R. L. 2011 Bottled water: United States consumers and their perceptions of water quality. International Journal of Environmental Research and Public Health, 8(2), 565-578.

IBM Corp. Released, 2016. IBM SPSS Statistics for Windows, Version 24.0. IBM Corp, Armonk, NY.

Kauko, T., Goetgeluk, R., \& Priemus, H. (2009). Water in residential environments. Built Environment, 35(4), 577-592.

Kharaka, Y. K., Thordsen, J. J., Conaway, C. H., \& Thomas, R. B. (2013). The energy-water nexus: Potential groundwater-quality degradation associated with production of shale gas. Procedia Earth and Planetary Science, 7, 417-422.

Kriesky, J., Goldstein, B. D., Zell, K., \& Beach, S. (2013). Differing opinions about natural gas drilling in two adjacent counties with different levels of drilling activity. Energy Policy, 58, 228236.

Larson, K. L., \& Santelmann, M. V. (2007). An analysis of the relationship between residents' proximity to water and attitudes about resource protection. The Professional Geographer, 59(3), 316-333.

Merkel, L., Bicking, C., \& Sekhar, D. (2012). Parents' perceptions of water safety and quality. Journal of Community Health, 37(1), 195-201.

Morgantown Utility Board (2015). Water Quality. Presentation at Green Team Community Forum, October $29^{\text {th }}, 2015$.

Morrice, E., \& Colagiuri, R. (2013). Coal mining, social injustice and health: A universal conflict of power and priorities. Health \& place, 19, 74-79. 
Muehlenbachs, L., Spiller, E., \& Timmins, C. (2015). The housing market impacts of shale gas development. The American Economic Review, 105(12), 3633-3659.

Osborn, S. G., Vengosh, A., Warner, N. R., \& Jackson, R. B. (2011). Methane contamination of drinking water accompanying gas-well drilling and hydraulic fracturing. Proceedings of the National Academy of Sciences, 108(20), 8172-8176.

Pennsylvania Department of Environmental Protection (2017) Geographic Information Systems (GIS) Mapping Tools. Retrieved January 10, 2017:

http://www.dep.pa.gov/DataandTools/Pages/GIS.aspx

Ryan, R. L. (1998). Local perceptions and values for a midwestern river corridor. Landscape and Urban Planning, 42(2), 225-237.

Sams III, James I. and Kevin M. Beer. 2000. Effects of coal-mine drainage on stream water quality in the Allegheny and Monongahela River basins - Sulfate transport and trends. WaterResources Investigations Report 99-4208. Lemoyne, PA: U.S. Department of the Interior, U.S. Geological Survey, National Water-Quality Assessment Program.

Shi, X., \& He, F. (2012). The environmental pollution perception of residents in coal mining areas: a case study in the Hancheng Mine Area, Shaanxi Province, China. Environmental management, 50(4), 505-513.

Sutherland, R. J., \& Walsh, R. G. (1985). Effect of distance on the preservation value of water quality. Land Economics, 61(3), 281-291.

Underwood, Bruce E., Natalie A. Kruse and Jennifer R. Bowman. (2014). Long-term chemical and biological improvement in an acid mine drainage-impacted watershed. Environmental Monitoring and Assessment 186(11):7539-7553. 
Vengosh, A., Warner, N., Jackson, R., \& Darrah, T. (2013). The effects of shale gas exploration and hydraulic fracturing on the quality of water resources in the United States. Procedia Earth and Planetary Science, 7, 863-866.

Vidic, R. D., S. L. Brantley, J. M. Vandenbossche, D. Yoxtheimer and J. D. Abad. 2013. "Impact of shale gas development on regional water quality." Science 340(6134):826-836.

West Virginia Department of Environmental Protection (2017) https://tagis.dep.wv.gov/home/Downloads

Whelton, Andrew J., Lakia McMillan, Matthew Connell, Keven M. Kelley, Jeffrey P. Gill, Kevin D. White, Rahul Gupta, Rajarshi Dey and Caroline Novy. (2015). "Residential tap water contamination following the Freedom Industries chemical spill: Perceptions, water quality, and health impacts." Environmental Science \& Technology 49(2):813-823.

\section{Chapter 6: Future research and next steps}

\section{Risk perceptions}

Future studies could look at communication/education studies. For example, a pre-test/post-test experiment could be potentially designed for the area of Morgantown in order to understand how people react to different targeted messages. The content of these messages could involve water consumption and existing risks associated with drinking from the tap, as well as information regarding the environmental impacts of bottled water.

In terms of theory development, the work of Fessenden-Raden et al. (1987) is significantly important in determining the role of trust in local government and state agencies, as well as the 
perceived potential local polluters, in defining risks perceptions. These authors also add a temporal component to the perceptions of risks and especially in terms of communications. Dosman et al. (2001) also explained that voting preferences were strong predictors of risk perceptions. This could be added in future studies.

Another step that could be taken is the use of focus groups. It could be interesting to use qualitative methods to understand water quality perceptions in West Virginia. This would perhaps enhance the perceptions of risks.

Overall, with the help of other papers, a risk perceptions theory should be developed as a holistic process. Since the current study lacks several factors, we need to include more items to expand the model and create a theory.

\section{Larger scale}

The study will be repeated at a larger scale and should be repeated in rural counties for comparison with the current results. We may see differences in risk perceptions and different factors explaining those risks.

\section{Knowledge}

Another step that could be realized is to assess objectively the level of knowledge from respondents in order to know how education might be necessary. Perceptions of risks do not precisely measure a lack of knowledge.

\section{Proximity}

Future studies should include topography and driving distances from a resident's house and the coal mine, river or gas well, as well as the perceived proximity to these. Stream quality should 
also be reported to differentiate between impaired and good quality streams. Regarding demographics, there might be interactions effects between residence location and specific streams, age and income categories. 